Portland State University

PDXScholar

Fall 12-19-2016

\title{
The Effects of Frequency of Social Interaction, Social Cohesion, Age, and the Built Environment on Walking
}

Gretchen Allison Luhr

Portland State University

Follow this and additional works at: https://pdxscholar.library.pdx.edu/open_access_etds

Part of the Public Health Commons, Transportation Commons, and the Urban Studies Commons Let us know how access to this document benefits you.

Recommended Citation

Luhr, Gretchen Allison, "The Effects of Frequency of Social Interaction, Social Cohesion, Age, and the Built Environment on Walking" (2016). Dissertations and Theses. Paper 3325.

https://doi.org/10.15760/etd.3306

This Dissertation is brought to you for free and open access. It has been accepted for inclusion in Dissertations and Theses by an authorized administrator of PDXScholar. Please contact us if we can make this document more accessible: pdxscholar@pdx.edu. 
The Effects of Frequency of Social Interaction, Social Cohesion, Age, and the Built

Environment on Walking

by

Gretchen Allison Luhr

A dissertation submitted in partial fulfillment of the requirements for the degree of

Doctor of Philosophy

in

Urban Studies

Dissertation Committee:

Jason Newsom, Chair

Jennifer Dill

Margaret Neal

Paula Carder

Alexis Dinno

Matthew Carlson

Portland State University

2016 
(C) 2016 Gretchen Allison Luhr 


\begin{abstract}
The purpose of this dissertation was to explore, through a social ecological framework, the multifaceted effects of the neighborhood environment by investigating how dimensions of both the built environment and the neighborhood social context may interact to influence walking. Aesthetics, land use mix, crime, and pedestrian infrastructure were considered with respect to built environment walkability, and the neighborhood social context was conceptualized using measures of both social cohesion and social interaction with neighbors. This research used data from an Environmental Protection Agency (EPA)funded study of 748 adults (18 years of age and older) residing in the Lents neighborhood in Portland, Oregon. Through a series of both multiple linear and logistic regression models, the analyses examined the specific pathways by which social interaction with neighbors, social cohesion, and age influenced the relationship between the built environment and walking behavior. Results suggest that both social interaction and social cohesion but not age moderate the effects of the built environment on walking. There was evidence of mediation, as well, for both social interaction and social cohesion. The implications of these findings for future research and policy are discussed.
\end{abstract}




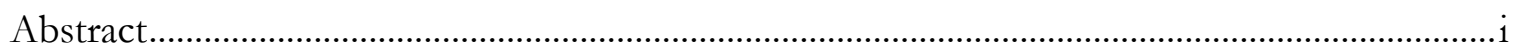

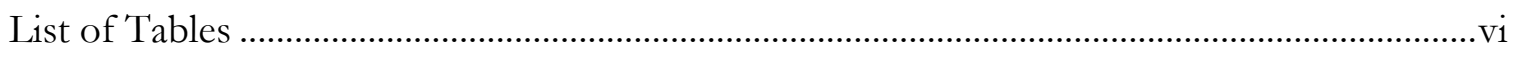

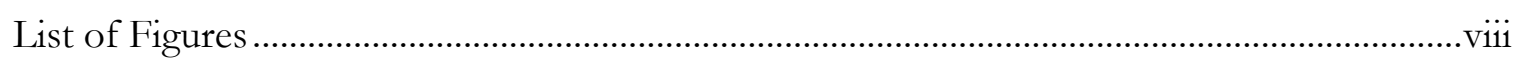

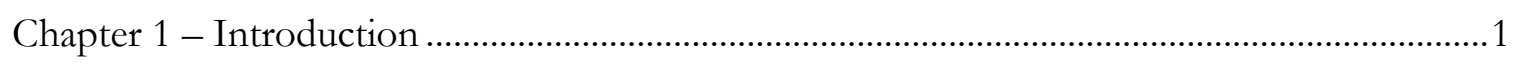

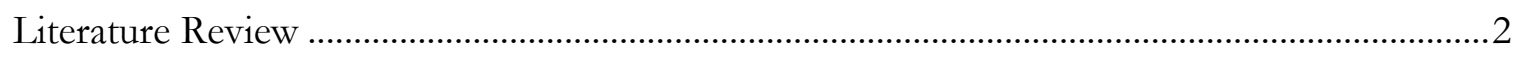

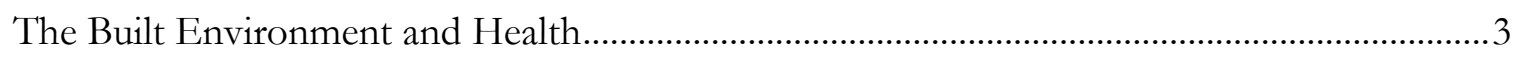

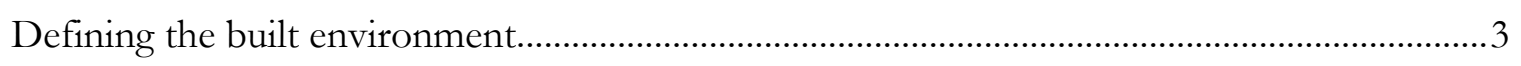

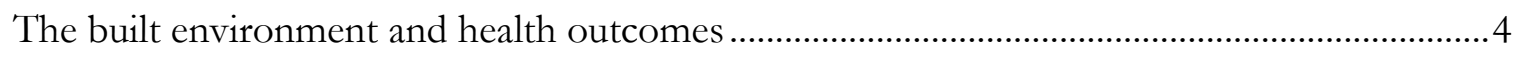

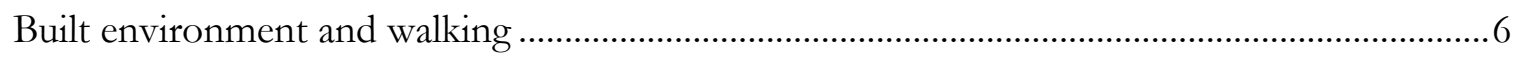

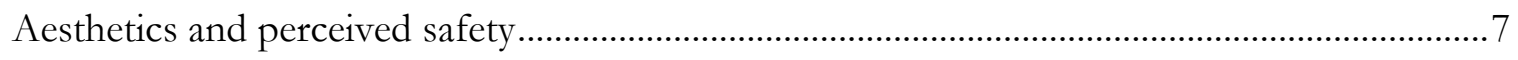

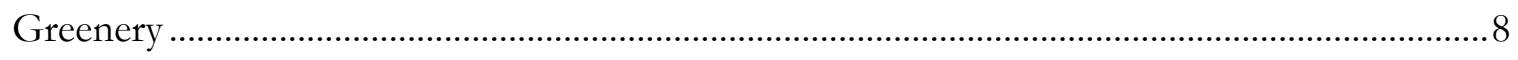

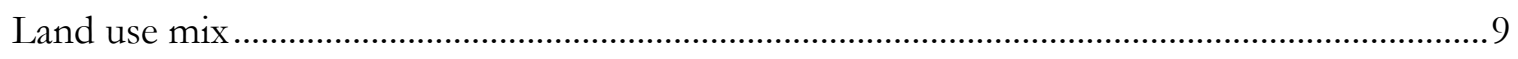

Quality and safety of pedestrian infrastructure .........................................................................

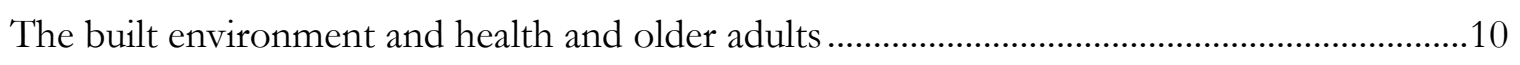

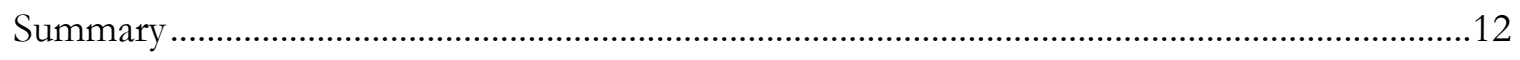

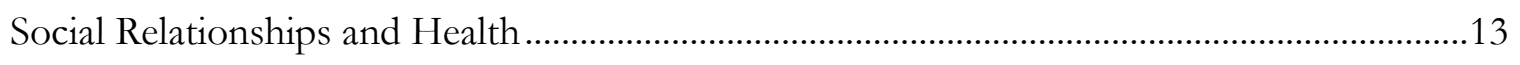

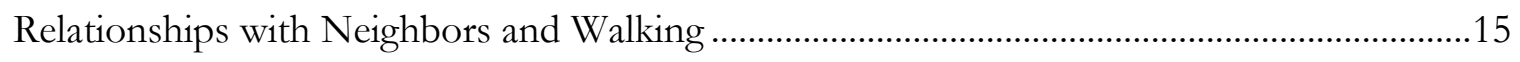

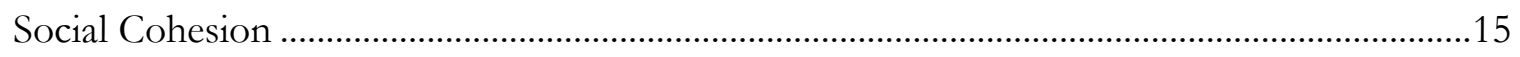


The Built Environment and Relationships with Neighbors

Chapter 2 - Theoretical Framework

Specific Aims .25

Chapter 3 - Methods .27

Original Project Design

Sample and Participant Selection

Case selection

Geographic area.

Measures

Independent variables - built environment and neighborhood social context measures .......28

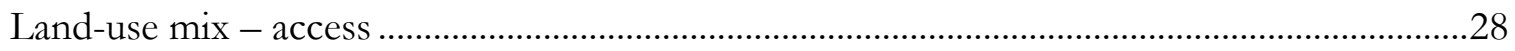

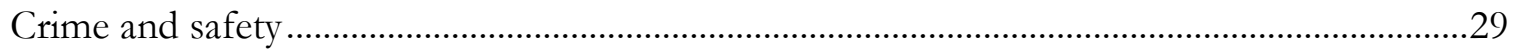

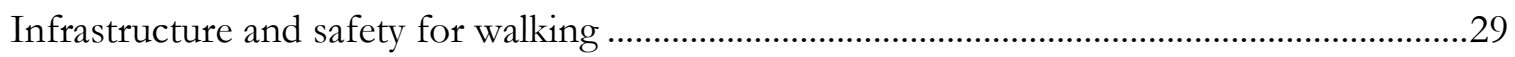

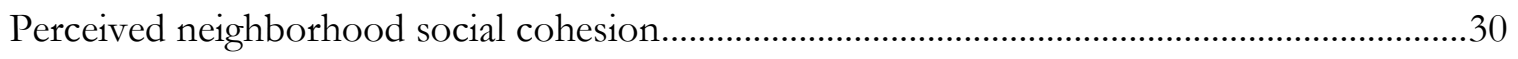

Frequency of social interaction with neighbors .....................................................................30

Dependent variables - walking measures. ..........................................................................31

Total monthly walking trips....................................................................................................

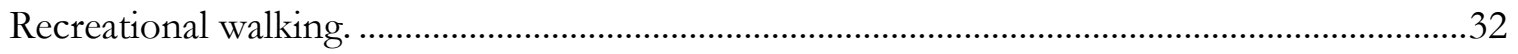

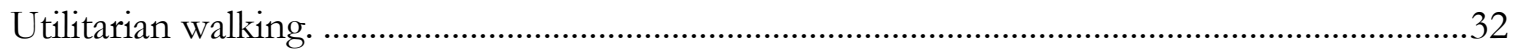


Covariates

Sociodemographic factors.

Physical functioning. .32

Analysis..... .33

Frequency of social interaction with neighbors and perceived neighborhood social cohesion as moderators

Frequency of social interaction and social cohesion as mediators. 34

Chapter 4 - Results 36

Description of the Sample .38

Correlation Analysis. .38

Correlation of age with study variables .38

Perceived neighborhood social cohesion correlation with study variables.

Frequency of social interaction correlation with study variables

Overview of Results .41

Chapter 5 - Discussion and Conclusion. .91

Recap of Dissertation Objectives

Key Findings in Relation to Theoretical Frameworks and Specific Research Aims .93

Neighborhood social context as moderator or mediator of the effect of built environment on walking......

Neighborhood social cohesion .95 
Land use mix.

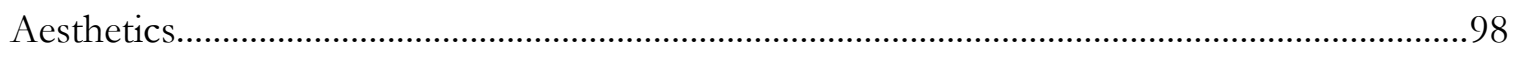

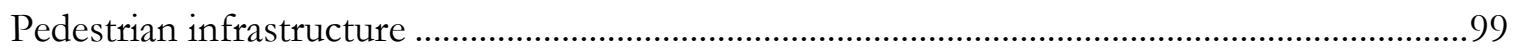

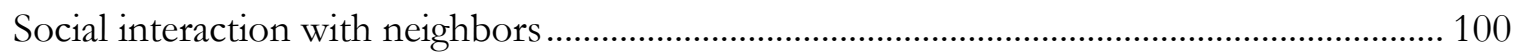

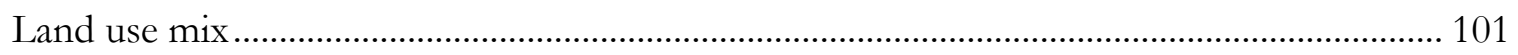

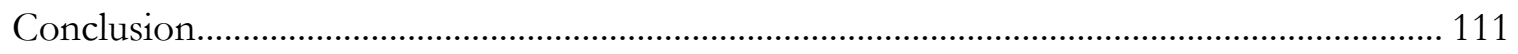

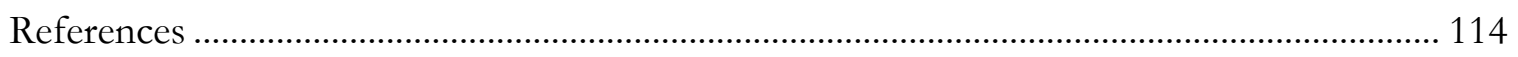

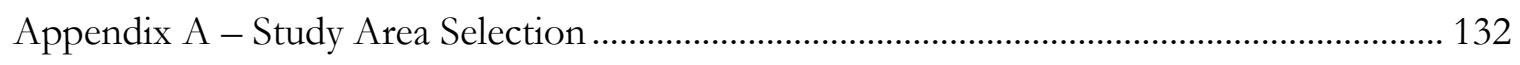

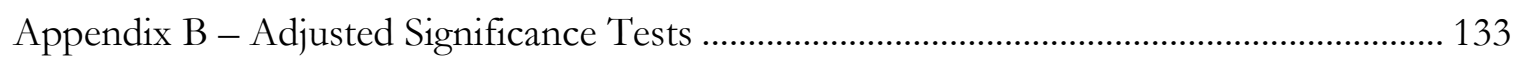




\section{List of Tables}

Table 1. Study Sample Sociodemographic Characteristics ...........................................................38

Table 2. Correlation Matrix of Key Study Variables ...................................................................41

Table 3. Correlation Matrix of Key Study Variables (continued) ...............................................41

Table 4. Correlation Matrix of Key Study Variables (continued)................................................41

Table 5. Overview of significant tests for mediation .................................................................42

Table 6. Overview of significant tests for moderation ................................................................44

Table 7. Moderating effects of perceptions of land use mix and perceived neighborhood social cohesion, frequency of social interaction with neighbors, and age on utilitarian walking and recreational walking.................................................................................5

Table 8. Moderating effects of perceptions of aesthetics and perceived neighborhood social cohesion, frequency of social interaction with neighbors, and age on utilitarian walking and recreational walking......

Table 9. Moderating effects of perceptions of crime and safety and perceived neighborhood social cohesion, frequency of social interaction with neighbors, and age on utilitarian walking and recreational walking......

Table 10. Moderating effects of perceptions of pedestrian infrastructure and safety and perceived neighborhood social cohesion, frequency of social interaction with neighbors, and age on utilitarian walking and recreational walking

Table 11. Moderating effects of perceptions of land use mix and perceived neighborhood social cohesion, frequency of social interaction with neighbors, and age on total monthly walking trips 
Table 12. Moderating effects of perceptions of aesthetics and perceived neighborhood social cohesion, frequency of social interaction with neighbors, and age on total monthly walking trips

Table 13. Moderating effects of perceptions of crime and safety and perceived neighborhood social cohesion, frequency of social interaction with neighbors, and age on total monthly walking trips.......

Table 14. Moderating effects of perceptions of pedestrian infrastructure and safety and perceived neighborhood social cohesion, frequency of social interaction with neighbors, and age on total monthly walking trip 


\section{List of Figures}

Figure 1. Lawton and Nahemow's (1973) environmental press-competence model as reprinted and adapted byin Tomey and Sowers (2009).

Figure 2. Causal model of neighborhood effects on aging (an extension of the ecological model on aging) .23

Figure 3. Hypothesized Mediating Effect of Neighborhood Social Context on Walking ......25

Figure 4. Hypothesized Moderating Effect of Neighborhood Social Context on Walking....26

Figure 5. Hypothesized Moderating Effect of Age on Walking................................................26

Figure 6. Simple slopes for recreational walking on perceptions of land use mix at values of

age

Figure 7. Simple slopes for utilitarian walking on perceptions of aesthetics at values of perceived neighborhood social cohesion

Figure 8. Simple slopes for utilitarian walking on perceptions of aesthetics at values of frequency of social interaction with neighbors .62

Figure 9. Simple slopes for utilitarian walking on perceptions of pedestrian infrastructure at values of perceived neighborhood social cohesion

Figure 10. Simple slopes for utilitarian walking on perceptions of pedestrian infrastructure and safety at values of frequency of social interaction with neighbors

Figure 11. Simple slopes for total monthly walking trips on perceptions of land use mix at values of frequency of social interaction with neighbors

Figure 12. Simple slopes for total monthly walking trips on perceptions of aesthetics at values of perceived neighborhood social cohesion 
Figure 13. Simple slopes for total monthly walking trips on perceptions of pedestrian infrastructure and safety at values of perceived neighborhood social cohesion ..........88

Figure 14. Simple slopes for total monthly walking trips on perceptions of pedestrian infrastructure and safety at values of perceived neighborhood social cohesion 


\section{Chapter 1 - Introduction}

This dissertation explored the effects of the built environment on health through an investigation of how features of the built environment influence dimensions of social relationships, specifically frequency of neighboring behaviors and perceived social cohesion among neighborhood residents, and in turn, how the relationship between the built environment and social relationships has the potential to influence walking behavior. Respondent self-report and investigator systematically-assessed measures of the built environment were integrated methodologically, as this multi-method measurement approach in combination with assessments of social relationships will further our understanding of the complex relationship between place and health (Cunningham \& Michael, 2004; Heath, et al., 2006; McCormack, et al., 2004; Saelens, Sallis, \& Frank, 2003). The analyses used data from an Environmental Protection Agency (EPA)-funded study of 748 adults (18 years of age and older) residing in the Lents neighborhood in Portland, Oregon (Dill, Neal, Shandas, Luhr, Adkins, Lund, 2010). The data were originally collected in an effort to demonstrate how changes to the physical infrastructure of the neighborhood (e.g., built environment) may be associated with changes in walking. The findings from this dissertation may advance knowledge in scientific study on the role of the physical and social environment on health by investigating how frequency of neighboring behaviors and perceived social cohesion may affect walking behavior and whether these processes differ by age.

The analytic goal was to advance understanding of the relationship between the built and social dimensions of the neighborhood environment and walking behavior among adults aged 18 years and older. Because the combined effects of the built and social dimensions of residential contexts have not been thoroughly explored (Diez Roux \& Mair, 2010), three 
general models were tested to examine the possible mediating and moderating roles that social relationship factors (e.g., perceived social cohesion and frequency of neighboring behaviors) may play in the relationship between the built environment and walking behavior. A social ecological framework (Glass \& Balfour, 2003) informed the research as it recognizes that a multitude of factors at varying levels of societal organization influence health and health behaviors. The specific research aims included investigating: (1) whether frequency of neighboring behaviors and perceived social cohesion moderate the relationship between built environment and walking behavior among adults; (2) whether frequency of neighboring behaviors and perceived social cohesion mediate the relationship between built environment and walking behavior among adults; and (3) whether resident age moderates the relationship between built environment and walking behavior and frequency of neighboring behaviors and perceived social cohesion among adults.

\section{Literature Review}

The following sections will review the literatures on seven conceptual areas pertinent to the aims: (1) the connections between the built environment and health and health behaviors; (2) connections between the built environment and walking; (3) the linkage between social relationship and health and health behaviors; (4) the ways in which social relationships with neighbors may influence health and health behaviors; (5) the ways in which the built environment and social relationships may interact in influencing walking; (6) how age might function in the linkage between the built environment and social relationships; and (7) the theoretical orientation guiding the analyses. 


\section{The Built Environment and Health}

Defining the built environment. There is a growing interest among researchers in the complex links between the built or physical environment of residential contexts and health behaviors (Cummins, Curtis, Diez-Roux, \& Macintyre, 2007; Dannenberg, Jackson, Frumkin, Schieber, Pratt, Kochtitzky, et al., 2003; Diez-Roux, 1998; Gordon-Larsen, Nelson, Page, \& Popkin, 2006). The links between place and health have been referred to as contextual effects (Chaix, et al., 2011; Feng, Glass, Curriero, Stewart, \& Schwartz, 2010; Godley, Haines, Hawe, \& Shiell, 2010; Omariba, 2010), place effects (Auchincloss \& Diez Roux, 2008; Jackson, Richardson, \& Best, 2008; Macintyre, Ellaway, \& Cummins, 2002), and neighborhood effects (Cagney, Browning, \& Wen, 2005; Wen \& Christakis, 2005). The built environment from a transportation and health perspective is thought to include the incorporation of land use patterns (i.e., spatial distribution of human activities), transportation system (i.e., physical infrastructure and services that provide the spatial links or connectivity of among activities), and design (i.e., the aesthetic, physical, and functional qualities of the built environment such as the design of buildings and streetscapes), which together may either provide barriers or opportunities for walking (Transportation Research Board \& Institute of Medicine, 2005). These three dimensions may be indicated through both a systematic audit or checklist and survey self-report. Actual and perceived aspects of the built environment are important in understanding the connections between the built environment and health. Both objectively or systematically assessed features (e.g., street connectivity, existence of greenery) of the built environment as well as perceived or experiential factors (e.g., sense of community, appraisals of place features) are thought to aid in explaining how the built environment may be considered a determinant of health (Chaix, 2009). The need to focus on the built 
environment as a determinant of health is underscored by Howard Frumkin (2002), who observed that opportunities for walking have been "engineered" out of communities and facilities for driving have been given precedence. Addressing the planning and design of walkable built environments may be important in promoting healthier communities.

Although the researchers use a variety of terms to describe effects of the built environment on health, many share a focus on local residential and occupational urban environments as determinants of health. Interest in this broad area of research has increased considerably over the past decade (Chaix, 2009; Diez Roux \& Mair, 2010). Illustrating growth of this topical area of research (using Web of Science and the following emphasized search terms), the number of studies assessing the built or physical environment (discussed below) and physical activity, has increased markedly from the year $2000(\mathrm{~N}=4)$ to $2010(\mathrm{~N}$ =163). The built environment factors found to have the greatest implications for physical activity such as walking and health are land use patterns, transportation system, and design. ${ }^{1}$

The built environment and health outcomes. It has been said that "your geography is your destiny" - in other words, where one lives matters for health by influencing health outcomes and opportunities for engaging in healthy behaviors. Different contextual and structural factors co-occurring at different systemic levels (see Theoretical Framework, p. 20)— that is micro-, meso-, and macro—-do not affect health in isolation, but rather interact to influence health. These factors comprising the economic (e.g., availability of services and amenities, jobs), social (e.g., relationships, social capital), and built environments (e.g., sidewalk infrastructure, land use zoning) of places have been linked to

\footnotetext{
${ }^{1}$ The review is not broken down by these three different dimensions of the built environment, but rather, they are integrated throughout the review. The delineation is merely to illustrate that the built environment consists of different dimensions.
} 
disparities in health (e.g., access to nutritious foods, premature and excess mortality). The following section will highlight how the built environment has been linked to health, in recognition that healthy communities stem from healthy environments and that they are part of the larger puzzle in understanding how place influences health (Jackson \& Sinclair, 2012).

Research on the built environment and health is multidisciplinary. Findings from environmental psychology, urban planning and active transportation, and public health indicate that the built environment have been linked to multiple health outcomes, including self-rated health and general well-being (Gidlof-Gunnarsson \& Ohrstrom, 2007; Matthews \& Yang, 2010), mental health, including depression (Kim, 2008; Kuo \& Sullivan, 2001; Mair, Diez Roux, \& Galea, 2008), BMI and obesity (Feng, et al., 2010; Frank, Saelens, Powell, \& Chapman, 2007a; Frank, Saelens, Powell, \& Chapman, 2007b), and cardiovascular disease (Leal \& Chaix, 2011; Li, Harmer, Cardinal, \& Vongjaturapat, 2009). Many active transportation and public health studies have emphasized the need to understand and adapt the built environment to promote bicycling and walking and reduce automobile use. The impetus for this targeted emphasis has been in part due to rising rates of preventable chronic diseases and their sequelae and modifiable health conditions. Some preliminary research suggests that the built environment influences health behaviors such as walking (Forsyth, Hearst, Oakes, \& Schmitz, 2008; Handy, Boarnet, Ewing, \& Killingsworth, 2002; Hooker, Cirill, \& Wicks, 2007; Rodriguez, Aytur, Forsyth, Oakes, \& Clifton, 2008; Saelens, et al., 2003; Strath, Isaacs, \& Greenwald, 2007).

Much of the literature on the built environment and health is comprised of studies that rely on study participant appraisals of the built environment and how these perceptions correlate with health outcomes. Comparatively, other studies have utilized systematically 
assessed measures of the built environment, and how these are associated with health outcomes. The following section highlights specific elements of the built environment that have been connected to walking, generally.

Built environment and walking. The built environment has important implications for health, one of which is the extent to which adults of different ages engage in walking. Walking, as purposeful physical activity, is among the most common forms of physical activity (Hu, Stampfer, Solomon, Liu, Colditz, Speizer, et al., 2001; Manson, Hu, RichEdwards, Colditz, \& Stampfer, 1999) that primarily occurs on neighborhood streets and in or around public facilities, such as parks (Lee \& Vernez Moudon, 2001).

The connection between the built environment and walking has been the focus of many active transportation studies at the nexus of public health and transportation and urban planning disciplines (Frank, Saelens, Powell, \& Chapman, 2007a; Sallis, et al., 2004). The built environment factors that facilitate walking among adults, in general, likely vary by individuals. Researchers have identified specific factors that enhance a sense of walkability and encourage walking as a preferential mode of transportation (Southworth, 2005), and one such factor is the walkable pedestrian environment. Southworth's (2005) review suggested that several factors might improve the walkability of the built environment. The first of these factors is connectivity through continuity of walkways and an absence of physical barriers to walking. Second is linkage with other modes of non-personal vehicle transportation such as mass transit buses and trains, whereby walking is augmented with other modes of transit. Mixed land-use areas with a variety of activities to meet daily needs, such as shops and schools that serve as destinations, may increase the perception of a built environment's walkability. Pedestrian environments that provide individuals a sense of safety from traffic, 
such as through the provision of buffers between the sidewalk and the road, are considered more walkable. Additionally, quality pedestrian pathways, such as sidewalks that are smooth and situated on non-auto-oriented roads, are considered more walkable. Lastly, interesting contexts for enhancing the enjoyment of walking, such as variation in building design and the presence of gardens and street trees, may also enhance walkability. Further, while there have been many studies and systematic reviews on the connections between walking and the built environment, few studies have included older adults as a population of interest (King, et al., 2011). Guided by the definition of the built environment specified earlier, the following facets of the built environment will be reviewed: aesthetics and safety, greenery, land use mix, and quality and safety of pedestrian infrastructure.

Aesthetics and perceived safety. Individuals' cognitive assessments of the built environment influence walking behavior. Areas perceived as either attractive or aesthetically pleasing may encourage walking as a means of recreational physical activity and active transportation (Foster, Giles-Corti, \& Knuiman, 2011; Kaczynski, 2010; Leslie, Cerin, \& Kremer, 2010; Saelens \& Handy, 2008; Strath, et al., 2007; Transportation Research Board \& Institute of Medicine, 2005; Wang \& Lee, 2010). Similarly, areas that are perceived as safe from crime or traffic may be associated with increased levels of outdoor physical activity (Gallagher, et al., 2010). Safe environments are often seen as aesthetically pleasing environments, so these two types of perceptions may be difficult to distinguish fully. A systematic review found that safe environments were correlated with walking across several studies (Saelens \& Handy, 2008). A review focusing on the built environment and physical activity among older adults in particular (Cunningham \& Michael, 2004) concluded that areas perceived as attractive and safe were more likely to result in increased levels of physical 
activity in the older adult population. The presence of graffiti and areas considered to be deterrents to walking and create a diminished sense of safety (Foster, et al., 2011).

Greenery. Perhaps related to the aesthetic appraisals of the built environment and safety is the amount of greenery in the pedestrian environment. Features such as street trees are thought to improve the attractiveness of the built environment and are often included as measure in systematic audits of pedestrian environments (Adams, et al., 2009). Additionally, greenery such as street trees not only may increase activity outdoors but also may increase social interaction in neighborhood environments, which suggests that greenery may promote health through different pathways (Sullivan, Kuo, \& DePooter, 2004) and may promote more outdoor physical activity for older adults (Takano, Nakamura, \& Watanabe, 2002) .

The presence and proximity of parks and other open space have also been demonstrated in prior cross-sectional studies to be correlates of walking (Saelens \& Handy, 2008). Across different disciplinary literatures (e.g., urban planning and transportation, public health) research has indicated that the availability of parks provides an incentive for walking or taking part in other physical recreational activities, and those areas with greenery are often perceived as more attractive and thus more desirable for walking. The existence of greenery (e.g., trees, parks, decorative shrubbery) has other health-related benefits as well, such as reducing stress and regulating negative emotional states such as anxiety (Thompson, et al., 2012).

While the presence of greenery may be beneficial for health, it is important to acknowledge that the presence of greenery can also be seen as a negative feature by individuals. How greenery is maintained in public places may be differentially associated at the individual-level and associated with one's willingness to walk. For example, parks that are 
poorly maintained or densely treed may inhibit walking in or around the park for fear of personal safety. In some studies, walking behavior has been considered a measure of perceptions of how well greenery is maintained is associated with reports of safety (Kuo, Bacaicoa, \& Sullivan, 1998; Talbot \& Kaplan, 1984). Although greenery, such as street trees, public parks and other open space, can lead to negative perceptions, it is, in general, considered a positive amenity that enhances walkability and that may be associated with an increase in walking. Exploratory analyses may either support or disconfirm the connection between the presence of parks and frequency of walking behavior, and there may be differences between younger and older adults.

Land use mix. Land use mix, defined as the mixture of residential, commercial, and industrial uses as opposed to a single-use (e.g., residential), also correlates with walking (Saelens \& Handy, 2008; Saelens, et al., 2003), and a recent qualitative assessment found that a mixture of land uses was connected to perceptions of an area's walkability (Kaczynski \& Sharratt, 2010). Relatedly, proximity to goods and services has been demonstrated to be a factor that increases walking (Lee \& Vernez Moudon, 2001; Lund, 2003; Moudon, et al., 2006; Patterson \& Chapman, 2004; Transportation Research Board \& Institute of Medicine, 2005). Commercial destinations often provide amenities that pedestrians might find useful (e.g., restaurants and cafes, retail, grocery and convenience stores) for meeting daily needs and that often serve as destinations for walking trips, whereas areas that are predominantly residential may be associated with less walking (Forsyth, et al., 2008; Kaczynski \& Sharratt, 2010; Saelens \& Handy, 2008). Additionally, these commercial amenities such as retail stores and cafes in and around residential environments may serve a social function, whereby communities gather, thus promoting a greater sense of community among area residents. 
Quality and safety of pedestrian infrastructure. Many studies have examined certain features of the built environment, such as the presence of sidewalks, which lead to increased perceptions of pedestrian safety and are an important facilitator of physical activity (Foster, et al., 2011; Saelens \& Handy, 2008; Stahl, Carlsson, Hovbrandt, \& Iwarsson, 2008; Strath, et al., 2007). Actual design of pedestrian infrastructure stems from a concern for safety, and some urban and transportation planners are concerned with incorporating pedestrian safety into master plans. A case study of active transportation (i.e., walking or biking) in Columbus, Ohio indicated that active transportation was increased with the widening and adding of sidewalks and increasing sidewalk connectivity (Green \& Klein, 2011), and a content analysis of pedestrian master plans in North Carolina found that incorporating safety through building new sidewalks and upgrading current infrastructure (Jones, Evenson, Rodriguez, \& Aytur, 2010). Conversely, the presence of roads with high traffic volumes are associated with a decreased sense of safety, and have been shown to be a barrier to physical activity (Owen, Humpel, Leslie, Bauman, \& Sallis, 2004).

The built environment and health and older adults. Adults 65 years of age and older comprise approximately $13 \%$ of the United States population, and this proportion is expected to increase considerably by the year 2030 to 20\% (Administration for Community Living, formerly known as Administration on Aging, 2011). Aging is associated with normative and pathological declines in both psychological and physical function. Sixty percent of older adults will be managing at least one chronic disease by 2030 (Healthy People 2020, 2012). Among the chronic disease burden in the older adult population, heart disease and diabetes have a high prevalence rate, and both are among the most common causes of mortality and are linked to obesity (Centers for Disease Control and Prevention, 2007). 
Additionally, physical inactivity is increasingly prevalent as adults age, with $28 \%$ to $36 \%$ adults $65-75$ years and older reporting no physical activity as compared to $25 \%$ among those 45-64 years and 22\% among adults 30-44 years (Centers for Disease Control and Prevention, 2007), and is also linked to obesity (Papas, et al., 2007). Research efforts to elucidate connections between the built environment and physical activity such as walking, and to ultimately develop interventions, programs, and policies to promote physical activity and active transportation, secondarily reducing rates of obesity, will benefit not only older adults but the population as a whole (Papas, et al., 2007). Evidence suggests that regular, moderate physical activity, such as brisk or vigorous walking, aids older adults in maintaining good health and functional ability (Paterson, Jones, \& Rice, 2007), and that interventions targeting individuals where they live, such as adapting physical architecture of the built environment, may be effective in promoting health through increases in physical activity and reducing rates of obesity (Michael \& Yen, 2009).

Attributes of the built environment conducive to optimal health and promotion of physical activity in general may be particularly important for older adults. Although there have been numerous studies on various built environment and health factors, such as the connection between physical activity and obesity, few studies have included older adult samples (King, et al., 2011). King and colleagues (2011) and others (Fried \& Barron, 2005; Michael, Green, \& Farquhar, 2006; Nagel, Carlson, Bosworth, \& Michael, 2008) have suggested that certain attributes of the built environment may be more important for older adults than younger adults. As an example, a recent Dutch study (Borst, et al., 2009) demonstrated that various features of the built environment—-front yard gardens, first floor dwellings, presence of sidewalks, retail shops-were valued by older adults with respect to 
walking behavior and route choice, and similar results were found in a Swedish study of community-dwelling older adults (Stahl, et al., 2008). Conversely, the following were considered deterrents to walking route choice: slopes, litter on the ground, and parks. What is important is determining what attributes should be targeted in residential environment (e.g., neighborhood) improvements. It is also important to note that it is possible that the extent to which the built environment is a determinant of physical activity may be in part a function of an older adult's functional ability. In other words, adults with functional impairments may be more impacted by built environments that are less conducive to engaging safely in physical activity, and areas that are more walkable may mitigate advancement of disability and decrements in physical function (Hirvensalo, Rantanen, \& Heikkinen, 2000; Langlois, et al., 1997). With urban planning and public health literatures increased emphasis on investing in and developing healthy communities for active living, efforts should be made to incorporate features that are meaningful to be individuals across the life course.

\section{Summary}

It is important to understand the linkages between the built environment and physical activity such as walking for both transportation and recreation, as rates of physical activity are reported to be on the decline while the rates of obesity continue to increase across age cohorts, and evidence from cross-national comparative studies has suggested that active transportation is associated with lower rates of obesity (Bassett, Pucher, Buehler, Thompson, \& Crouter, 2008). Health conditions such as obesity have implications for poorer long-term health outcomes and decrements in functional ability in later life. 
Furthermore, determining ways in which the built environment might be altered to encourage physical activity warrants further investigation. Extensive work in transportation and planning, environmental psychology, and public health has indicated a connection between aspects of the built environment (e.g., greenery, sidewalks), physical activity, and health outcomes. The results have been mixed, however, which may be because mediating or moderating factors need to be considered. The next section will explore how one such factor, social relationships, may elucidate the link between the built environment and health.

\section{Social Relationships and Health}

Many aspects of social relationships—-varying from social support to social integration-have been theorized and demonstrated empirically to have both positive and negative effects on health outcomes and behaviors (Berkman \& Glass, 2000; Berkman \& Syme, 1979; Cohen \& Wills, 1985; House, Landis, \& Umberson, 1988; Newsom, Mahan, Rook, \& Krause, 2008; Seeman, 2000; Seeman \& Crimmins, 2001; Uchino, 2004). The evidence is well-established across many disciplines that social relationships are critical for maintaining health and minimizing risk of premature mortality at both the population and individual level (Uchino, 2004). Generally, findings suggest that social relationships are: (1) protective against premature mortality and the onset of morbidity (Berkman \& Glass, 2000; Berkman \& Syme, 1979; Glass \& Balfour, 2003; House, et al., 1988; Uchino, 2004); (2) a source of social support in its various commonly recognized forms-informational, emotional, and instrumental — that may reduce rates of depression or buffer the emotional impact of stressful life events (Barrera, 1986; Berkman \& Glass, 2000; House, et al., 1988); and (3) contributors to a sense of community or belonging (Berkman \& Glass, 2000). Following the literature review, the above facts about social relationships will be the primary 
foci of my following review of the literature; specifically, how relationships with community members, specifically neighbors, may influence physical activity such as walking. While social relationships are important determinants of health, continued understanding of the mechanisms by which relationships might influence healthy behaviors still requires further investigation. Additionally, how different facets of social relationships could interact with various components of the built environment needs elucidation. Understanding the latter connections among social relationships and the built environment, it might be possible to develop interventions to promote health that capitalize upon social ties as opposed to relying solely on changes to physical or built infrastructure. In other words, social relationships may serve as a leveraging factor in the promotion of walking within the context of the built environment.

Several theoretical models of social support have been conceived that posit why social network ties may be either beneficial or harmful to health (Rook, 1984, 1992; Rook \& Pietromonaco, 1987). Social relationships act upon psychosocial mechanisms, which in turn, shape health through three basic pathways: psychological, such as well-being and depression, physiologic, such as the stress response and immune function, and health behaviors, such as diet and physical activity (for an overview see Berkman \& Glass, 2000). Different aspects of social relationships have been theorized to have both direct and buffering effects on physical health outcomes through mitigating the impacts of stress from both real and perceived stressors (Uchino, 2004). Social relationships have been linked to a variety of health behaviors and outcomes in studies of individuals across the life course (Seeman, 2000). Social support has a demonstrated association with more positive and fewer negative health behaviors such as lower smoking, less heavy alcohol consumption, better diet, and more 
physical activity (Fleming, White, \& Catalano, 2010; Krause, Shaw, \& Liang, 2011; Leonard \& Eiden, 2007).

\section{Relationships with Neighbors and Walking}

The social relationships literature has appeared more on proximal network members such as friends and family rather than immediate and extended social network members. Whereas the advantages and disadvantages of social relationships and the types of support that these friends and family members provide have been well documented, far less attention has been paid to the role that network members such as neighbors may play in influencing both health outcomes and health behaviors. Researchers have been exploring how less intimate ties, such as with neighbors, and the perception of an indeterminate number of individuals across different contexts as being trustworthy and socially connected might be associated with health outcomes (Beaudoin, 2009; du Toit, Cerin, Leslie, \& Owen, 2007;

Lund, 2003; Sampson, 2003), in accordance with a social ecological model of health, investigations into how relationships with others more macro to family and friends relate to health outcomes have not been as common.

Social Cohesion. Social cohesion is often discussed as the perception of connectedness among some aggregation of people. Kawachi \& Berkman (2000, p. 175) noted that social cohesion is characterized by two features: (1) the absence of latent social conflict, and (2) the presence of strong social bonds. For example, a community perceived as cohesive is theorized to be rich in social capital — that is, levels of interpersonal trust, norms of reciprocity, and mutual aid. It is important to note that there have been different theories of social capital posited by various scholars over the years, ranging from Bourdieu to Putnam (Bourdieu, 2001; Putnam, 2000). This dissertation does not discuss the merits of one 
theoretical orientation toward social capital over another but, instead, will focus on aspects of social capital that appear to be somewhat consistent across the different theoretical orientations. Specifically, this dissertation will focus on social cohesion. Researchers often will assess these social factors as characterizations of some abstraction of a social network such as society or the neighborhood, and they are often thought to be ecologic/population level measures of social structures (population-level) as opposed to social support provided by social networks (individual-level). While this distinction is important, there is reason to believe, as noted by Kawachi \& Berkman (2000), that social cohesion and social capital may operate through different pathways to influence individual health. This dissertation seeks to understand how perceptions of social cohesion by residents about their surrounding community (e.g., neighborhood) may be associated with walking as a means of physical activity (health-related behavioral pathway).

The extent to which an individual might perceive a neighborhood as socially cohesive may influence various health outcomes and behaviors. For example, a neighborhood perceived as high in social cohesion may increase the likelihood that an individual will walk in his/her neighborhood. A recent multilevel analysis of how social capital, may influence park use found that parks reported as being higher in social capital were associated with increased numbers of park users and increased energy expended through physical activity (Broyles, Mowen, Theall, Gustat, \& Rung, 2011).

The feeling that a neighborhood is cohesive may be linked to feelings of safety, which have also been linked to higher levels of engagement in physical activity and other health-related behaviors (Echeverria, Diez-Roux, Shea, Borrell, \& Jackson, 2008; Greiner, Li, Kawachi, Hunt, \& Ahluwalia, 2004). Relatedly, areas perceived as high in social cohesion 
were associated with increased neighborhood satisfaction (Dassopoulos \& Monnat, 2011). Other environmental psychology researchers have asked whether social capital or, by extension, social cohesion, is influenced by the built environment and how they may influence health (Wood \& Giles-Corti, 2008). Social cohesion is hypothesized to be an indicator of the well-being of communities, of individuals and of the civic health of society. The extent to which social cohesion may yield an effect on health behaviors is still inconclusive and warrants further investigation. Additionally, how perceptions of the cohesiveness of neighbors might interact with physical environment factors needs to be analyzed in order to further understand the complexities of place effects on health.

Many studies have discussed the extent to which a community characterized as being high in levels of collective efficacy, social capital, or social cohesion may be beneficial for both individuals and populations (Sampson, 2003). These social resources may offset the impacts of neighborhood disorganization-high levels of crime, abandoned buildings, vacant lots, graffiti (as examples)—and possibly indicate lower levels of social strain among neighbors (Browning \& Cagney, 2002; Morenoff, Sampson, \& Raudenbush, 2001; Sampson, Raudenbush, \& Earls, 1997).

A conceptual paper outlining the potential mechanisms by which various social factors in the neighborhood environment might influence activity suggested that social capital and social cohesion may influence engagement in physical activity through the reinforcement of positive social norms (Berkman \& Kawachi, 2000), and that a neighborhood perceived as socially cohesive may be associated with lower levels of crime (Ross \& Jang, 2000) which in turn may be associated with more physical activity. Further, one study found that walking in the neighborhood was associated with an increased sense of 
community among neighborhood residents (du Toit, et al., 2007). Additionally, collective

efficacy and social capital have been shown to exhibit an association with numerous health outcomes, including mortality (Wen, Cagney, \& Christakis, 2005), self-rated health, and depression (Kim, 2008; Kubzansky, et al., 2005). Despite these associations, some researchers believe that researchers linking social interaction factors to health has been lagging behind research on the physical and socioeconomic environmental aspects of places (Coutts \& Kawachi, 2006; Stafford \& McCarthy, 2006; Wood \& Giles-Corti, 2008), which suggests that social relationships with neighbors and perceptions about the social cohesiveness of communities may play a role in understanding how the built environment yields an effect on health behaviors and ultimately health outcomes.

\section{The Built Environment and Relationships with Neighbors}

Increasingly, researchers have been evaluating the complex connection between the social environment and other contextual factors such as the built environment on health (Augustin, Glass, James, \& Schwartz, 2008; Seeman \& Crimmins, 2001). Understanding various facets of social relationships and how they impact individual and population health is an important and growing area of research at the intersection of public health and urban planning. A comprehensive review indicates that studies of the environment and physical activity consider both social and physical environment factors and the use of multiple methods of data collection (e.g., surveys and systematic observation) for understanding contextual effects on health (McNeill, Kreuter, \& Subramanian, 2006), and that studies exploring the interrelationship of the physical and social dimension of residential environments are lagging behind other efforts at contextual effects research (Diez Roux \& Mair, 2010). This dissertation explored the relationship between different dimensions of the 
social and built contexts of the neighborhood environment and the relationship of these two dimensions as determinants of health, and adds to a growing literature in this area by investigating the interplay between the neighborhood social context and the built environment. The following two sections discuss the theoretical foundations and specific aims of the dissertation. 


\section{Chapter 2 - Theoretical Framework}

The literature cited above is informed by the theories described in this section. Granted, the theoretical link in this literature is not always made explicit (Yen, Michael, \& Perdue, 2009). The broad aim of this study, described in more detail in the following section, is the examination of the relationship between individuals and their environment. One objective underlying this person-environment research is the multi-directional relationship between individuals and their environment. As formalized in Lewin's often-cited ecological equation, behavior as a function of the person and its environment, is conceptually strong, but as Lawton and Nahemow argued, "overly broad" (Lawton, 1986, p. 11) in that it does not distinguish fully the person from the environment; nor was the role of social interaction specified, though it was presumably included in the concept of "environment," The ability to distinguish between the person and their environment has practical implications for policy and practice and determining where to target programs or interventions. For example, if the person and his or her behavior are the focal targets, then the intervention could be targeted toward behavior change; and conversely, if the environment is more deterministic of outcomes, policies could be targeted to alter the environment, which may or may not translate into individual behavior change. The reality of the person-environment dynamic is that the person and environment are inextricably linked, and that an effective health promotion intervention will most likely target both the person (e.g., walking behavior) and the environment (e.g., physical infrastructure and social networks). In 1973, Lawton and Nahemow expanded the model to recognize interactions between a person and their environment, and they defined the concepts of environmental press and personenvironment fit within what they called the ecological model of aging (see Figure 1). 
Environmental press refers to the extent to which environmental factors can both facilitate and limit behaviors in an environment. For example, incomplete sidewalks may present either positive or negative press depending on the individual's ability to negotiate such terrain. Person-environment fit refers to the degree of balance between environmental press and individual competence. Using the above example, a person with functional impairment may be limited by the absence of sidewalks, resulting in limited physical activity outdoors.

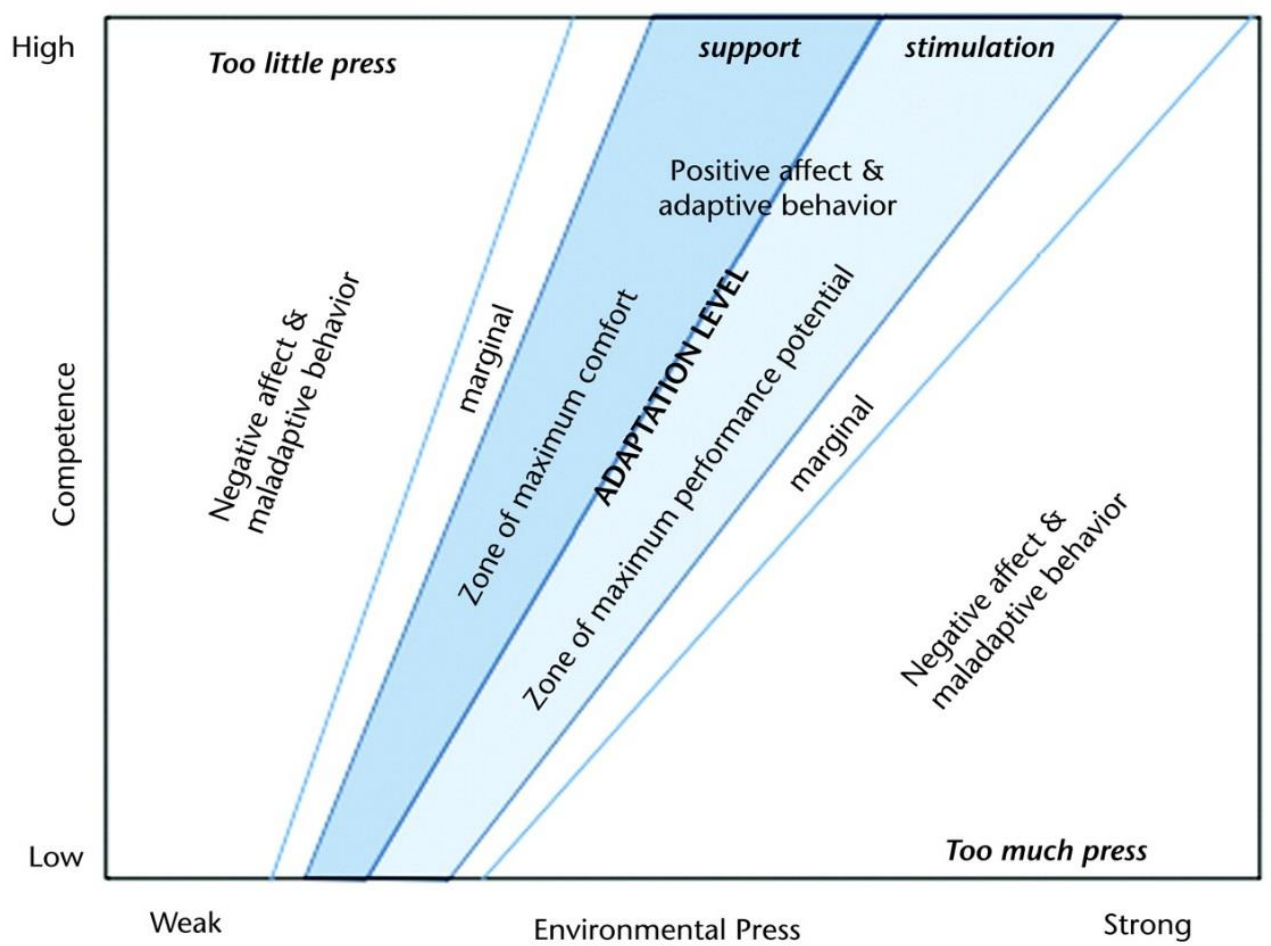

Figure 1. Lawton and Nahemow's (1973) environmental press-competence model as reprinted and adapted byin Tomey and Sowers (2009)

While Lawton and Nahemow (Lawton, 1986) focused specifically on older persons, social ecological models are applicable to individuals across the life span and have been used to examine connections between the built environment, social relationships, and health (Sallis, Owen, \& Fisher, 2008). Such models explain that health is influenced by multiple 
levels of social structures and processes, and that the environment in which individuals conduct day-to-day life has bearing on cognitions, behaviors, and psycho-social well-being (Stokols, 1996). Thus, the dynamic and interconnected levels of organization (ranging from micro to macro) that structure residential areas, such as neighborhoods and spaces for activity, serve as determinants of individual health outcomes. Stokol's description is especially pertinent here:

...physical, mental, and social well-being are influenced by a variety of environmental factors; personal characteristics and environmental conditions often have interactive as well as direct effects on well-being; and the degree of fit between people's biological, behavioral, and sociocultural needs and the environmental resources available to them is a key determinant of well-being (Stokols, 1996, p. 288).

These points are important because this dissertation examined not only the relationship between the built environment (e.g., sidewalks) and health behaviors (e.g., walking), but also the potential mediating and moderating effects of social relationships on health behaviors.

A more recent example of the ecological model of aging was developed by Glass and Balfour (Glass \& Balfour, 2003), who included potential distal and proximal determinants of the person-environment fit dynamic that lead to various behaviors which yield an effect on specific health outcomes (a representation of Glass and Balfour's model can be seen in Figure 2). Thus to summarize, the extent to which the built environment affects walking has implications for health outcomes such as heart disease and obesity (Chaix, 2009; Feng, et al., 2010). Their model explicitly lays out a causal framework for regression analysis in order to examine the relative effects of neighborhood factors on health outcomes. For example, an area, such as the street on which someone lives, not perceived as socially cohesive can 
function as a form of environment press, as indicated by the middle of the model. While the entirety of Glass and Balfour's model is too expansive to be tested in full in this dissertation, it is a useful framework for situating the causal models presented in the aims below.

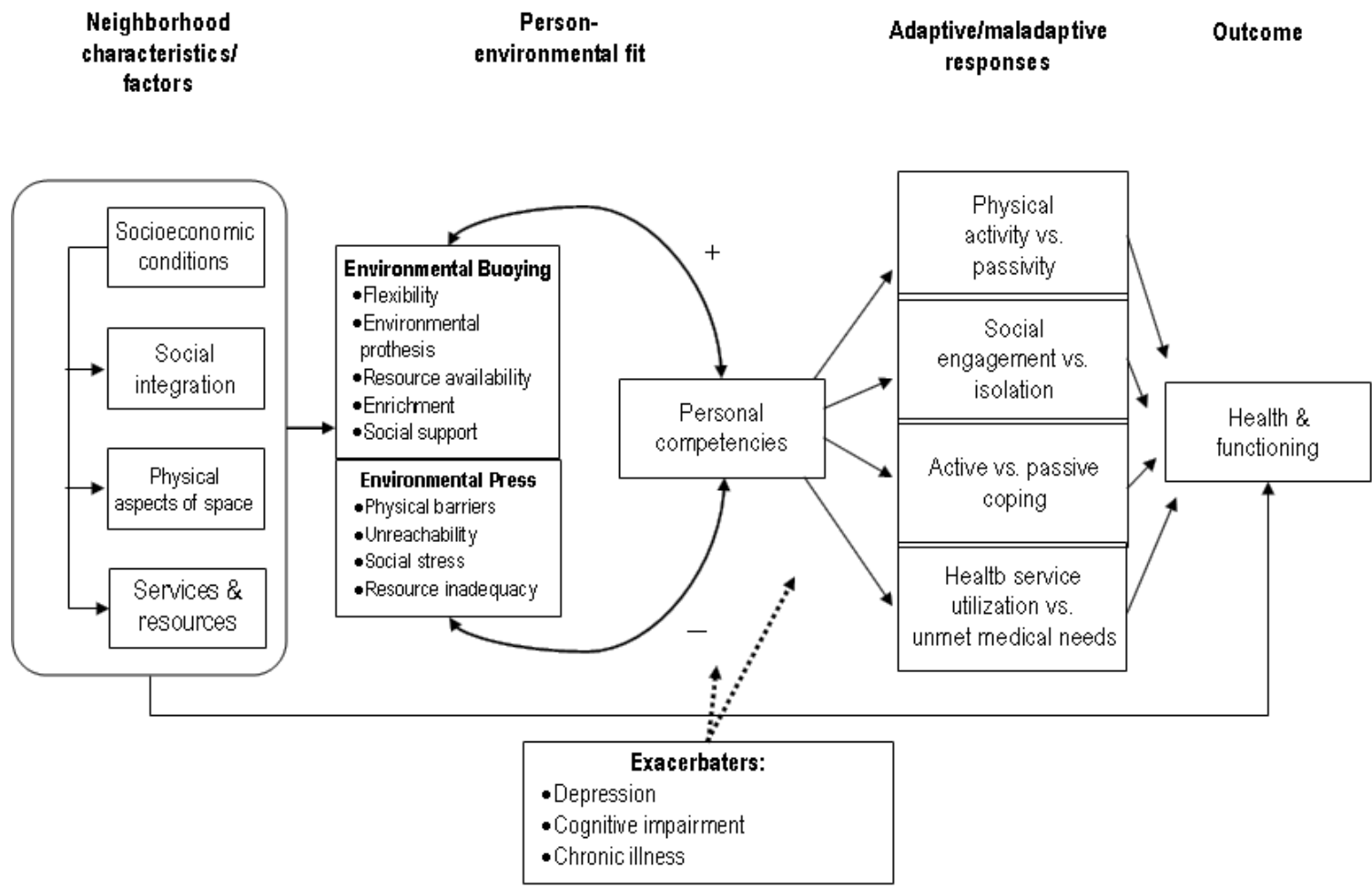

Figure 2. Causal model of neighborhood effects on aging (an extension of the ecological model on aging)

The theories selected to frame the following analyses as indicated in the aims, specifically outlined in the following section, are relevant for the reasons following each outlined aim:

1. Investigate whether social relationship factors moderate the relationship between built environment physical factors and physical activity among adults. The nature of social relationshipswhether they be perceptions of connectedness and similarity (i.e., social cohesion) or exposure to others (i.e., social interaction) may differentially affect behaviors such as walking through an environmental buoying mechanism given appraisals or perceptions of features or qualities about the built environment. 
2. Investigate whether social relationship factors mediate the relationship between built environment factors and physical activity among adults. Similar to the above explanation, perceptions of connectedness and similarity (i.e., social cohesion) or exposure to others (i.e., social interaction) may either reduce or eliminate the direct effect of appraisals or perceptions of features or qualities about the built environment on behaviors such as walking. In other words, social relationships have the potential to outweigh the press (e.g., missing or disconnected sidewalks, uniform land use) presented by the built environment.

3. Investigate whether the resident's age moderates the relationship between built environment factors and physical activity and social relationships among adults. How the appraisals of perceptions of features or qualities about the built environment yield an effect on behaviors such as walking, and how these effects of the built environment on walking may be differentially patterned or moderated by age.

As emphasized by Altman (Altman, 1975), this dissertation analysis considered that the built environment and other related environments (e.g., economic, social, home, family) are both determinants of behavior and an extension of behavior. The environmental psychological underpinnings of these multidirectional relationships suggest that individual perceptions are suitable manifestations of the physical environment. In other words, perceptions of the built environment are important determinants of individual behaviors in her or his environment. As an example, an older adult with physical limitations may identify barriers in the built environment (e.g., incomplete or uneven sidewalks) that constrain walking as compared to a younger or older adult with no physical limitations. Place, health and physical activity are critically important concepts in urban studies and public health. Addressing how the environment and persons' relationships with others influence walking behavior has implications for the development of interventions and policies that are inclusive of these different dimensions. 
The following section outlines the aims of this dissertation, including the ways in which the ecological model frames the selection of variables and analytic tests, and is followed by a description of the analytical methodology.

\section{Specific Aims}

The analyses sought to expand on the existing science explaining the relationships between built environments, social relationships, and walking among adults aged 18 years and older. The combined effects of the built environment and social relationships of residential environments have not been thoroughly explored (Diez Roux \& Mair, 2010). Because of this limitation, three general models were tested to examine the possible mediating and moderating roles that neighborhood social context (e.g., social cohesion and frequency of social interaction) play in the relationship between the built environment and walking. Specific research aims included:

1. Investigation of whether the neighborhood social context moderates the relationship between built environment factors and walking among adults (Error! Reference source not found.), by asking the following two questions: (1) Does greater perceived neighborhood social cohesion increase the likelihood that built environment factors (e.g., land-use mix, crime and safety, pedestrian infrastructure and safety, aesthetics) increase walking?; and (2) Does increased frequency of neighborhood social interaction increase the likelihood that built environment factors (e.g., land-use mix, crime and safety, pedestrian infrastructure and safety, aesthetics) increase walking?

Figure 3. Hypothesized Mediating Effect of Neighborhood Social Context on Walking

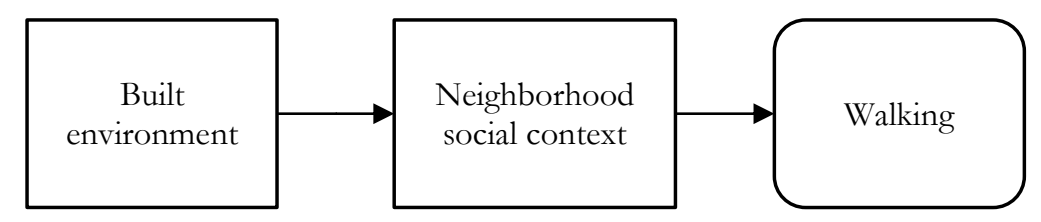


2. Investigation of whether social relationship factors mediate the relationship between built environment factors and physical activity among adults (see Error! Reference source not found.), by asking the following two questions: (1) Does greater perceived neighborhood social cohesion mediate the relationship between built environment factors (e.g., land-use mix, crime, pedestrian infrastructure and safety, aesthetics) and walking?; and (2) Does increased frequency of social interaction with neighbors mediate the relationship between built environment factors (e.g., land-use mix, crime, pedestrian infrastructure and safety, aesthetics) and walking?

Figure 4. Hypothesized Moderating Effect of Neighborhood Social Context on Walking

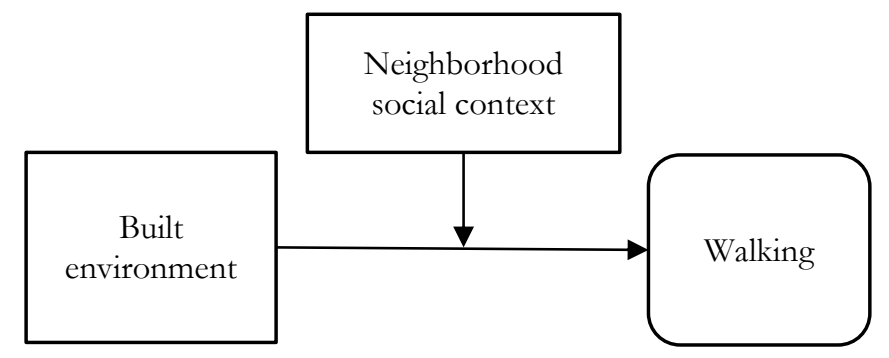

3. Investigation of whether the resident's age moderates the relationship between built environment factors and physical activity and social relationships among adults (see Error! Reference source not found.), by asking the following: Does the association between built environment factors (e.g., land-use mix, crime, pedestrian infrastructure and safety, aesthetics) and walking differ by age?

Figure 5. Hypothesized Moderating Effect of Age on Walking

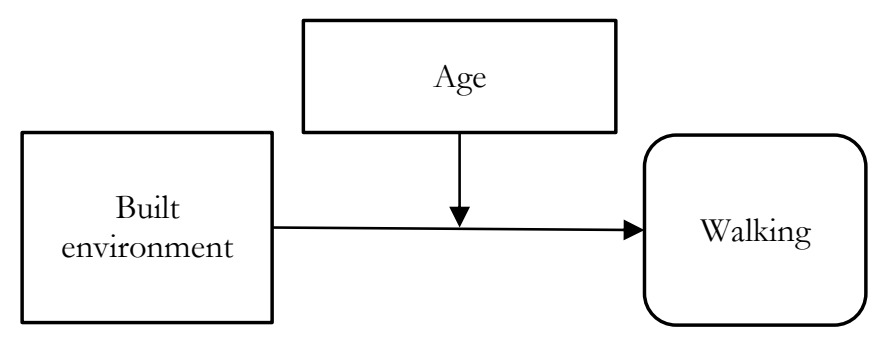




\section{Chapter 3 - Methods}

\section{Original Project Design}

The analyses sought to associate individual health measures of adults $(18+$ years of age) in Portland, Oregon, with different neighborhood social context factors - social cohesion and social interaction - and built environment aspects of a residential area using cross-sectional data collected from a recent Environmental Protection Agency-funded (EPA) study of neighborhood built environments and health, Demonstrating the Benefits of Green Streets for Active Aging [Green Streets Study] ( Dill, Neal, Shandas, Luhr, Adkins, \& Lund, 2010). The data were collected, in part, through mailed surveys to area residents within circumscribed boundaries defined by the study protocol (see Dill, et al., 2010 for the survey instrument). The Green Streets Study was designed to demonstrate the health benefits of "green streets" (e.g., rainwater catchment systems, bioswales), which the investigators believed might have implications for active aging. The Portland State University Institutional Review Board granted this dissertation research an exemption from review as a result of the low risk of utilizing secondary de-identified data.

\section{Sample and Participant Selection}

Case selection. Cases were selected from an anonymized dataset from Green Streets Study. In the original study, 2163 valid surveys were mailed to all households within the Green Streets Study study boundaries, of which 748 surveys were returned, yielding a household response rate of 26.4 percent, which is not an unusually low response rate for

mailed surveys. Cases were geographically situated within four sub-areas (two treatment and two control) of the Lents neighborhood in outer southeast Portland, Oregon (see Appendix 
I). Participants received a mailed 12-page (control) or 16-page (treatment) survey during May 2010 (see Appendix II for descriptive characteristics of sample; for more details on sampling see Dill, et al., 2010).

Geographic area. For the original study, the two treatment areas were determined based on the presence of concentrations of sustainable storm water management facilities (i.e., "green streets" or bioswales). One-quarter mile network buffers were drawn around each facility to determine each of the study treatment areas. Two additional nearby areas were selected to serve as controls. The control areas were matched based on area and 2000 Census sociodemographic characteristics (for more details regarding geographic sampling and population sampling see Dill, et al. (2010). To take into consideration edge effects, a 1/4mile buffer was created around each of the four areas selected by the original study using the mean center. For this dissertation, the four geographic areas were considered one contiguous area unless otherwise specified for the purpose of the specific analysis.

\section{Measures}

\section{Independent variables - built environment and neighborhood social context}

measures. Data for this current study were collected by use of a mailed survey to all households within the defined study area. Self-report data were gathered utilizing a survey assessing numerous topics ranging from perceptions of the neighborhood to self-rated health. The variables and derived measures used for the purpose of these analyses are as follows:

Land-use mix - access. Land-use mix refers to the variation in land-use types ranging from residential (e.g., single-family, multi-family) to commercial (e.g., retail, restaurants). To measure land-use mix, the Neighborhood Environment Walkability Scale - 
Abbreviated (NEWS-A) subscale was used (Cerin, Saelens, Sallis, \& Frank, 2006). The three items required respondents to indicate the extent to which they agreed with the following statements on a four-point scale ( $1=$ strongly disagree, $4=$ strongly agree): 1$)$ Stores are within easy walking distance of my home., 2) There are many places to go within easy walking distance of my home., 3) It is easy to walk to a transit stop (bus or $M A X$ ) from my home. Respondents were asked to consider the extent these amenities were within easy walking distance, which was defined as 'within a 10-15 minute walk from your home'. The third item was adapted such that the original item included '(bus, train)', and was changed to incorporate '(bus or MAX)' in order to refer to the mass transit options available in the study area.

Crime and safety. Fear of crime was a composite of three items from NEWS-A (Cerin, Saelens, Sallis, \& Frank, 2006), designed to capture perceptions of crime and safety at different times of day that might minimize the frequency with which individuals walk in their neighborhood. Respondents were asked to indicate the extent to which they agreed with the following statements on a four-point scale (1 = strongly disagree, $4=$ strongly agree): 1$)$ There is a high crime rate in my neighborhood., 2) The crime rate in my neighborhood makes it unsafe to go on walks during the day., 3) The crime rate in my neighborhood makes it unsafe to go on walks at night.

Infrastructure and safety for walking. This composite measure from NEWS-A (Cerin, Saelens, Sallis, \& Frank, 2006) captured the presence of sidewalks as an indicator of pedestrian safety. Respondents were asked to indicate the extent to which they agreed with the following statements on a four-point scale ( $1=$ strongly disagree, $4=$ strongly agree): 1$)$ There are sidewalks on most streets in my neighborhood., 2) Sidewalks are separated from 
the road/traffic in my neighborhood by parked cars., 3) There is a grass/dirt strip that separates the streets from the sidewalks in my neighborhood.

Aesthetics. This composite measure from NEWS-A captures the aesthetic appearance of the neighborhood, which is theorized to be associated with higher walkability (Cerin, Saelens, Sallis, \& Frank, 2006). Respondents were asked to indicate the extent to which they agreed with the following statements on a four-point scale $(1=$ strongly disagree, $4=$ strongly agree): 1) There are trees along the streets in my neighborhood., 2) There are many interesting things to look at while walking in my neighborhood., 3) There are many attractive natural sights in my neighborhood., and 4) There are attractive buildings/homes in my neighborhood.

Perceived neighborhood social cohesion. This is a four-item scale adapted from the original five-item measure developed by Sampson, Raudenbush, and Earls (1997). For each item respondents indicated their level of agreement on a five-point scale $(1=$ strongly disagree, $5=$ strongly agree) with each of the following: 1 ) This is a close knit neighborhood., 2) People around here are willing to help their neighbors., 3) People in this neighborhood do not share the same values., and 4) People in this neighborhood can be trusted. Item 3 was reverse coded. The combined responses of the four items had relatively high internal consistency, with an acceptable Cronbach's alpha $(r=.75)$.

Frequency of social interaction with neighbors. This measure was designed to assess the frequency with which respondents engaged in social interaction with their neighbors over the course of one month ("How many times in the past month have you..."), and was developed for the original study based on a measure adapted by du Toit, Cerin, Leslie, and Owen (2007; for original see: Parker, Lichtenstein, Schulz, et al., 2001). 
Respondents were asked to indicate on a six-point scale $(0=$ never, $1=$ less than 1 time per month, $2=1$ to 3 times per month, $3=1$ time per week, $4=2$ to 4 times per week, $5=5$ or more times per week) how often they had 1) Waved to a neighbor., 2) Said hello to a neighbor., 3) Stopped and talked with a neighbor., 4) Gone to a neighbor's house to socialize., 5) Had a neighbor at your house to socialize., 6) Gone somewhere (restaurant, shopping, football) with a neighbor., 7) Asked a neighbor for help., 8) Sought advice from a neighbor., and 9) Borrowed things or exchanged favors with a neighbor. Individual items were aggregated to create the final measure. The combined responses of the nine items had relatively high internal consistency, with an acceptable Cronbach's alpha $(r=.85)$ (du Toit, et al., 2007).

\section{Dependent variables - walking measures.}

Total monthly walking trips. Respondents were also asked to indicate the frequency $(0=$ never, $1=$ Less than 1 time per month, $2=1$ to 3 times per month, $3=1$ time per week, $4=2$ to 4 times per week, $5=5$ or more times per week) with which they walked to a series of destinations originating from their home: 1) Work or school, 2) A church or civic building, 3) A service provider, 4) A restaurant, bar or coffee place, 5) A store or place to shop, 6) A place to exercise, 7) The home of a friend or family member, 8) An entertainment spot, 9) Taking someone else to school or daycare, 10) To a bus stop, 11) To a MAX [train] stop, 12) No particular destination, but walking a dog, and 13) No particular destination, just out of the house. For the purposes of the proposed analyses, respondents' answers to each destination type will be summed to create a frequency with which walking trips were made from home to all destinations within the neighborhood over 
the span of a week. Internal consistency was not computed for this scale in the original study.

Recreational walking. This dichotomous measure was adapted from total monthly walking trips, whereby respondents engaged in recreational walking if they either walked to 'no particular destination, just out the house' or 'no particular destination, just walking the dog'.

Utilitarian walking. This dichotomous measure was adapted from total monthly walking trips, whereby respondents engaged in utilitarian walking if they specified walking to a particular destination as opposed to 'no particular destination'.

Covariates. The following measures were included in analyses as covariates:

Sociodemographic factors. As covariates in the proposed analyses, the following sociodemographic factors will be used: age (continuous), sex ( $1=$ female, $0=$ male), relationship status $(1=$ in a relationship, $0=$ not in a relationship), highest level of education completed $(1=$ high school or less, $0=$ more than high school $)$ and racial/ethnic minority (1 $=$ yes, $0=$ no) .

Physical functioning. The measure of functional limitations was based on the tenitem Medical Outcomes Study scale commonly used to assess the degree to which respondents are experiencing some level of functional disability. Respondents were asked to indicate how the following activities might have been limited by their current health status according to a three-point scale $(1=$ yes, limited a lot to $3=$ no, not limited at all): 1$)$ Vigorous activities, such as running, lifting heavy objects, participating in strenuous sports, 2) Moderate activities, such as moving a table, pushing a vacuum cleaner, bowling, or playing golf, 3) Lifting or carrying groceries, 4) Climbing several flights of stairs, 5) Climbing one 
flight of stairs, 6) Bending, kneeling, or stooping, 7) Walking more than one mile, 8) Walking several blocks, 9) Walking one block, and 10) Bathing or dressing yourself. The item scores will be summed and averaged to create an indicator of functional limitations.

\section{Analysis}

Prior to conducting regression analyses, descriptive statistics and correlations were conducted among all variables to assess potential multicollinearity and other potential violations of the assumption of independence.

Associations between the predictors (e.g., frequency of social interaction with neighbors and perceived neighborhood social cohesion) and the dependent outcomes (e.g., total monthly walking trips) were estimated using a series of different regression models (as described in the Study Aims). All analyses included and controlled for the following covariates: age, sex, physical functioning, education, racial/ethnic minority, and relationship status. The following questions were answered through the following analyses:

\section{Frequency of social interaction with neighbors and perceived neighborhood}

social cohesion as moderators. To investigate the interaction between the neighborhood social context and residential area built environment factors in predicting physical activity, regression analyses were conducted using two centered predictors to create an interaction term entered as a third predictor. Tests for simple slopes were used to explore the nature of any significant interactions (Aiken \& West, 1991).

(1) Does greater perceived neighborhood social cohesion increase the likelihood that residential area built environment factors (e.g., land-use mix, crime and safety, pedestrian infrastructure and safety, aesthetics) increase walking? 
To answer this question, perceived neighborhood social cohesion was specified as a

moderator of four dimensions of the built environment and their effects on walking. The

tests were as follows:

- whether perceived neighborhood social cohesion interacts with perceptions of crime and safety on walking;

- whether perceived neighborhood social cohesion interacts with perceptions of landuse mix walking;

- whether perceived neighborhood social cohesion interacts with perceptions of pedestrian infrastructure and safety on walking; and

- whether perceived neighborhood social cohesion interacts with perceptions of aesthetics on walking.

(2) Does increased frequency of social interaction with neighbors increase the likelihood that residential area built environment factors (e.g., land-use mix, crime and safety, pedestrian infrastructure and safety, aesthetics) increase walking?

To answer this question, frequency of social interaction with neighbors was specified as a moderator of four dimensions of the built environment and their effects on walking.

The tests were as follows:

- whether frequency of social interaction with neighbors interacts with crime and safety on walking;

- whether frequency of social interaction with neighbors interacts with land-use mix on walking;

- whether frequency of social interaction with neighbors interacts with pedestrian infrastructure and safety on walking; and

- whether frequency of social interaction with neighbors interacts with aesthetics on walking.

Frequency of social interaction and social cohesion as mediators. To test for

the possible mediating role of the neighborhood social context on the relationship between the built environment and walking, indirect effects coefficients were computed and tested following MacKinnon's recommended approach (MacKinnon, 2008). 
(3) Does greater social cohesion mediate the relationship between residential area built environment factors (e.g., land-use mix, crime and safety, pedestrian infrastructure and safety, aesthetics) and walking?

To answer this question, perceived neighborhood social cohesion was specified as a mediator of four dimensions of the built environment and their effects on walking. Tests for mediation were conducted as follows:

- whether perceived neighborhood social cohesion mediates the effect of crime and safety on walking;

- whether perceived neighborhood social cohesion mediates the effect of land-use mix on walking;

- whether perceived neighborhood social cohesion mediates the effect of pedestrian infrastructure and safety on walking; and

- whether perceived neighborhood social cohesion mediates the effect of aesthetics on walking.

(4) Does greater frequency of social interaction with neighbors mediate the relationship between residential area built environment factors (e.g., land-use mix, crime and safety, pedestrian infrastructure and safety, aesthetics) and walking?

To answer this question, frequency of social interaction with neighbors was specified as a mediator of four dimensions of the built environment and their effects on walking.

Tests for mediation were conducted as follows:

- whether frequency of social interaction with neighbors mediates the effect of crime and safety on walking;

- whether frequency of social interaction with neighbors mediates the effect of landuse mix on walking;

- whether frequency of social interaction with neighbors mediates the effect of pedestrian infrastructure and safety on walking; and

- whether frequency of social interaction mediates the effect of aesthetics on walking. 


\section{Chapter 4 - Results}

The purpose of this research was to analyze the mediating and moderating properties of social relationship factors - specifically, perceived neighborhood social cohesion and frequency of social interaction with neighbors. Mediation explains relationships in which the independent variable predicts the dependent variable through an intermediate factor; and moderation explains relationships in which the effect of the independent variable on the dependent variable varies at different levels of a moderating factor. With perceived neighborhood social cohesion and frequency of social interaction with neighbors, the objectives of this dissertation were to examine how each would either mediate or moderate the path between the built environment and walking. The results presented in this chapter focus on three walking outcomes as described in the prior chapter - utilitarian walking, recreational walking, and total monthly walking trips. The ensuing results focus on the paths between the built environment and total monthly walking trips and the odds of utilitarian and recreational walking at least once per month. To reiterate, the aims of this dissertation were to:

Investigate whether social relationship factors moderate the relationship between built environment physical factors and physical activity among adults. The nature of social relationships-whether they be perceptions of connectedness and similarity (i.e., social cohesion) or exposure to others (i.e., social interaction) -- may differentially affect behaviors such as walking through an environmental buoying mechanism given appraisals of or observable features of the built environment to clarify this person-environment fit dynamic). 
Investigate whether social relationship factors mediate the relationship between built environment factors and physical activity among adults. Similar to the above explanation, perceptions of connectedness and similarity (i.e., social cohesion) or exposure to others (i.e., social interaction) may either reduce or eliminate the direct effect of appraisals of or observable features of the built environment on behaviors such as walking. In other words, social relationships have the potential to outweigh the environmental press (e.g., missing or disconnected sidewalks, uniform land use) presented by the built environment.

Investigate whether the resident's age moderates the relationship between built environment factors and physical activity and social relationships among adults. How the built environment, either through appraisals of or observable features, yields an effect on behaviors such as walking may be differentially patterned or moderated by age. Age may also moderate how social relationships influence behavior such as walking. For example, older adults as compared to younger adults may be less influenced by connectedness with others than younger adults, such that older adults may walk more or less despite their frequency of social interaction with others, whereas younger adults may be more likely to walk if they are more socially connected to others.

Prior to testing for the moderating and mediating effects of both perceived neighborhood social cohesion and frequency of social interaction with neighbors, the associations among variables to be included in regression analyses were examine. This process provided information about the direction and strength of associations among variables. The correlation matrix (see Tables $2-4$ ) indicated moderately significantly positive or negative linear associations. Further, multicollinearity does not appear to be a problem, as the predictors and covariates were either slightly or moderately correlated with one another. 


\section{Description of the Sample}

Table 1 provides basic descriptive statistics for the study sample. Respondents were predominantly female (57\%), and were either married or living with a partner $(58 \%)$. The mean age for the sample was 49 years of age, and respondents ranged in age from 18 to 95 years of age. Approximately 77 percent of the identified as White as compared to other races $(23 \%)$. Approximately two-thirds of respondents reported having a high school education or less.

Table 1. Study Sample Sociodemographic Characteristics

\begin{tabular}{|l|l|c|}
\hline \multicolumn{1}{|c|}{ Variable } & \multicolumn{1}{c|}{$\%$} & $\mathrm{~N}$ \\
\hline Sex & & \\
\hline Male & 42.5 & 313 \\
\hline Female & 57.5 & 423 \\
\hline Relationship status & & \\
\hline In relationship & 57.9 & 424 \\
\hline Not in a relationship & 42.1 & 308 \\
\hline Race/ethnicity & & \\
\hline White & 76.7 & 574 \\
\hline Other race & 23.3 & 174 \\
\hline Education & & \\
\hline High school or less & 37.7 & 271 \\
\hline More than high school & 62.3 & 447 \\
\hline & M (SD) (Range) & $\mathrm{N}$ \\
\hline Age & $49.3(17.2)(18-95)$ & 719 \\
\hline Functional ability & $78.5(27.8)(0-100)$ & 732 \\
\hline
\end{tabular}

\section{Correlation Analysis}

Correlation of age with study variables. Age, a central variable in the analyses, had a significant relationship with only one of the four self-reported built environment measures. Specifically, age had a significant association with perceptions of land use mix $(r=-.20, p<$ .01). , but not the other self-reported built environment measures such perceptions of aesthetics, perceptions of crime and safety, and perceptions of pedestrian infrastructure. Age was associated with a few of the sociodemographic variables and functional ability $(r=-.45$, 
$\mathrm{p}<.01)$. Specifically, age was positively associated with being a racial/ethnic minority $(\mathrm{r}=$ $.16, \mathrm{p}<.01)$ and having a high school education or less $(\mathrm{r}=.13, \mathrm{p}<.01)$, and it was negatively associated with relationship status $(r=-.15, \mathrm{p}<.01)$. Age was significantly negatively associated with the different measures of walking, indicating less walking among older respondents.

\section{Perceived neighborhood social cohesion correlation with study variables.}

Perceived neighborhood social cohesion had several associations with the study measures. It was positively associated with perceptions of land use mix as measured by stores being within easy walking distance of home, many places to go within easy walking distance of home, and an easy walk to transit from home $(\mathrm{r}=.15, \mathrm{p}<.01)$, aesthetics as measured by trees along neighborhood streets, interesting things to look at while walking, attractive sights in neighborhood, and attractive architecture in neighborhood $(\mathrm{r}=.38, \mathrm{p}<.01)$, and pedestrian infrastructure as measured by sidewalks on most streets, sidewalks separated from streets by a buffer, well-lit streets, visibility of pedestrians, and crosswalks and pedestrian signals to aid in crossing $(\mathrm{r}=22, \mathrm{p}<.01)$. As might be expected, social cohesion was negatively associated with perceptions of crime and safety as measured by a high crime rate in the neighborhood, a sense that the crime makes walking unsafe during the day, and a sense that crime makes walking unsafe at night $(\mathrm{r}=-.35, \mathrm{p}<.01)$. Perceived neighborhood social cohesion was associated only with having a high school education or less $(\mathrm{r}=.08, \mathrm{p}<$ $.05)$, and this effect was small.

Frequency of social interaction correlation with study variables. Frequency of social interaction with neighbors had a significant positive association with perceptions of aesthetics $(\mathrm{r}=.08, \mathrm{p}<.05)$ but no other built environment measures. It was directly 
associated with being of racial/ethnic minority status $(\mathrm{r}=.12, \mathrm{p}<.01)$ and being in a relationship $(\mathrm{r}=.10, \mathrm{p}<.01)$. Also, those who interact with their neighbors more tended to have greater functional ability $(\mathrm{r}=.11, \mathrm{p}<.01)$. Respondents who reported more social interaction with neighbors also tended to walk more. The frequency of social interaction with neighbors was significantly positively associated with utilitarian walking $(r=.10, p<$ $.01)$, recreational walking $(\mathrm{r}=.18, \mathrm{p}<.01)$, and the total number of monthly walking trips $(\mathrm{r}$ $=.08, \mathrm{p}<.05)$

The different walking metrics varied in their associations with the sociodemographic variables. Minorities were less likely to engage in utilitarian walking as a compared to whites $(\mathrm{r}=-.12, \mathrm{p}<.01)$. Gender was negatively associated with utilitarian walking, such that women walked less for transportation than men $(\mathrm{r}=-.12, \mathrm{p}<.01)$. Education was negatively associated with recreational walking, such that those with a high school education or less walked less for recreation than respondents with more education $(r=-.08, \mathrm{p}<.05)$. Racial/ethnic minorities walked less overall as compared to whites when considering the total number monthly walking trips $(\mathrm{r}=-.12, \mathrm{p}<.01)$, and those who reported being in a relationship walked less in total than did those who were not in a relationship $(\mathrm{r}=-.08, \mathrm{p}<$ .05). All three walking measures were positively associated with physical functioning, which was expected, as those who are more functionally or physically able would typically walk more than those who have some physical or functional deficit. 
Table 2. Correlation Matrix of Key Study Variables

\begin{tabular}{|c|c|c|c|c|c|c|c|c|}
\hline & 2 & 3 & 4 & 5 & 6 & 7 & 8 & 9 \\
\hline Land use mix (1) & $.36^{* *}$ & $-.17 * *$ & $.21 * *$ & $.15^{* *}$ & .03 & $-.20 * *$ & $-.15^{* *}$ & .04 \\
\hline Aesthetics (2) & - & $-.30 * *$ & $.39 * *$ & $.38^{* *}$ & $.0 * 8$ & .03 & -.02 & .02 \\
\hline Crime (3) & & - & $-.12^{* *}$ & $-.35^{* *}$ & -.02 & .04 & .06 & $-.12^{*}$ \\
\hline Pedestrian infrastructure (4) & & & - & $.22 * *$ & .05 & .08 & -.01 & -.05 \\
\hline Social cohesion (5) & & & & - & $.20 * *$ & .07 & .04 & .05 \\
\hline Social interaction (6) & & & & & - & -.05 & $.12^{* *}$ & .01 \\
\hline Age (7) & & & & & & - & $.16^{* *}$ & .001 \\
\hline Minority (8) & & & & & & & - & $-.13^{* *}$ \\
\hline Female (9) & & & & & & & & - \\
\hline
\end{tabular}

Table 3. Correlation Matrix of Key Study Variables (continued)

\begin{tabular}{lllllll} 
& 10 & 11 & 12 & 13 & 14 & 15 \\
Land use mix (1) & $.09^{*}$ & .01 & $.19^{* *}$ & $.16^{* *}$ & $.11^{* *}$ & $.18^{* *}$ \\
Aesthetics (2) & $.08^{*}$ & -.05 & -.05 & .05 & $.08^{*}$ & $.18^{* *}$ \\
Crime (3) & .03 & -.06 & $-.10^{* *}$ & $-.14^{* *}$ & $-.08^{*}$ & -.07 \\
Pedestrian infrastructure (4) & $.10^{*}$ & $-.08^{*}$ & -.05 & $-.09^{*}$ & -.04 & .03 \\
Social cohesion (5) & $.08^{*}$ & -.02 & -.02 & .06 & $.08^{*}$ & $.09^{*}$ \\
Social interaction (6) & -.01 & $.10^{* *}$ & $.11^{* *}$ & $.10^{* *}$ & $.18^{* *}$ & $.08^{*}$ \\
Age (7) & $.13^{* *}$ & $-.15^{* *}$ & $-.45^{* *}$ & $-.26^{* *}$ & $-.17^{* *}$ & $-.21^{* *}$ \\
Minority (8) & $-.09^{*}$ & -.01 & .03 & $-.12^{* *}$ & .0004 & $-.12^{* *}$ \\
Female (9) & .03 & $.15^{* *}$ & .06 & .01 & -.02 & -.02 \\
\hline
\end{tabular}

${ }^{*} \mathrm{p}<.05 .{ }^{* *} \mathrm{p}<.01$. Variable key: $10=$ HS or less, $11=$ In a relationship, $12=$ Physical functioning, $13=$ Utilitarian walking, $14=$ Recreational walking, $15=$ Total monthly walking trips

Table 4. Correlation Matrix of Key Study Variables (continued)

\begin{tabular}{|l|l|l|l|l|l|}
\hline & 11 & 12 & 13 & 14 & 15 \\
\hline High school or less (10) & -.06 & $-.18^{* *}$ & -.06 & $-.08^{*}$ & .04 \\
\hline In a relationship (11) & - & $.12^{* *}$ & -.03 & .07 & $-.08^{*}$ \\
\hline Physical functioning (12) & & - & $.19^{* *}$ & $.21^{* *}$ & $.13^{* *}$ \\
\hline Utilitarian walking (13) & & & - & $.31^{* *}$ & $.46^{* *}$ \\
\hline Recreational walking (14) & & & & - & $.36^{* *}$ \\
\hline Total monthly walking trips (15) & & & & - \\
\hline
\end{tabular}

${ }^{*} \mathrm{p}<.05 .{ }^{* *} \mathrm{p}<.01$.

\section{Overview of Results}

The following two tables summarize the significant findings in this dissertation.

There was some evidence of results supporting either a partial or full mediation hypothesis that the built environment predicts walking through the neighborhood social context.

Specifically, evidence of full mediation was found in the relationships between perceptions of land use mix and perceived neighborhood social cohesion on recreational walking, 
perceptions of crime and safety and perceived neighborhood social cohesion on recreational walking, and perceptions of aesthetics and frequency of social interaction with neighbors on utilitarian walking. Evidence of partial mediation was found in the relationships between perceptions of land use mix and perceived neighborhood social cohesion on total monthly walking trips, perceptions of aesthetics and frequency of social interaction with neighbors on recreational walking, and perceptions of aesthetics and frequency of social interaction with neighbors on total monthly walking trips.

Table 5. Overview of significant tests for mediation

Utilitarian walking Recreational walking Total monthly trips

Mediation

Land use -- > Social cohesion

f $\quad p$

Aesthetics -- > Social cohesion

Crime -- > Social cohesion

f

Infrastructure -- > Social cohesion

Land use -- > Social interaction

Aesthetics -- $>$ Social interaction

f

$\mathrm{p}$

$\mathrm{p}$

Crime -- > Social interaction

Infrastructure -- > Social interaction

$\mathrm{p}=$ partial mediation, $\mathrm{f}=$ full mediation

Tests for mediation were conducted using a four-step process outlined by Baron and Kenny (1986). The first step involved conducting a simple regression analysis to examine the direct relationship between the independent variable and dependent variable. Second, a simple regression analysis was conducted to test the relationship between the independent variable and the hypothesized mediating variable; and the third step involved a simple regression analysis to test for the relationship between the mediator and dependent variable. 
If one or more of these three analyses was not significant, the decision was made to not conduct the fourth step as it was most likely that mediation was not possible. If the first three steps were significant, the fourth step was completed. This last step involved conducting a multiple regression analysis with both the independent variable and mediator predicting the dependent variable. At any step during the four-step process, all study covariates were included. Tests of indirect effects were conducted using bootstrapping with evidence to support the hypothesis of either partial or full mediation (Shrout and Bolger, 2002). Bootstrapping is a resampling of the sample that is a more conservative estimation of standard errors.

The table below summarizes the tests for which there was evidence to support the moderation hypothesis. Both the effects perceptions of aesthetics and perceptions of pedestrian infrastructure were moderated by the neighborhood social context on utilitarian walking and total monthly walking trips but not for recreational walking. The effect of perceptions of land use mix on recreational walking, that is walking for leisure, was modified by age only. 
Table 6. Overview of significant tests for moderation

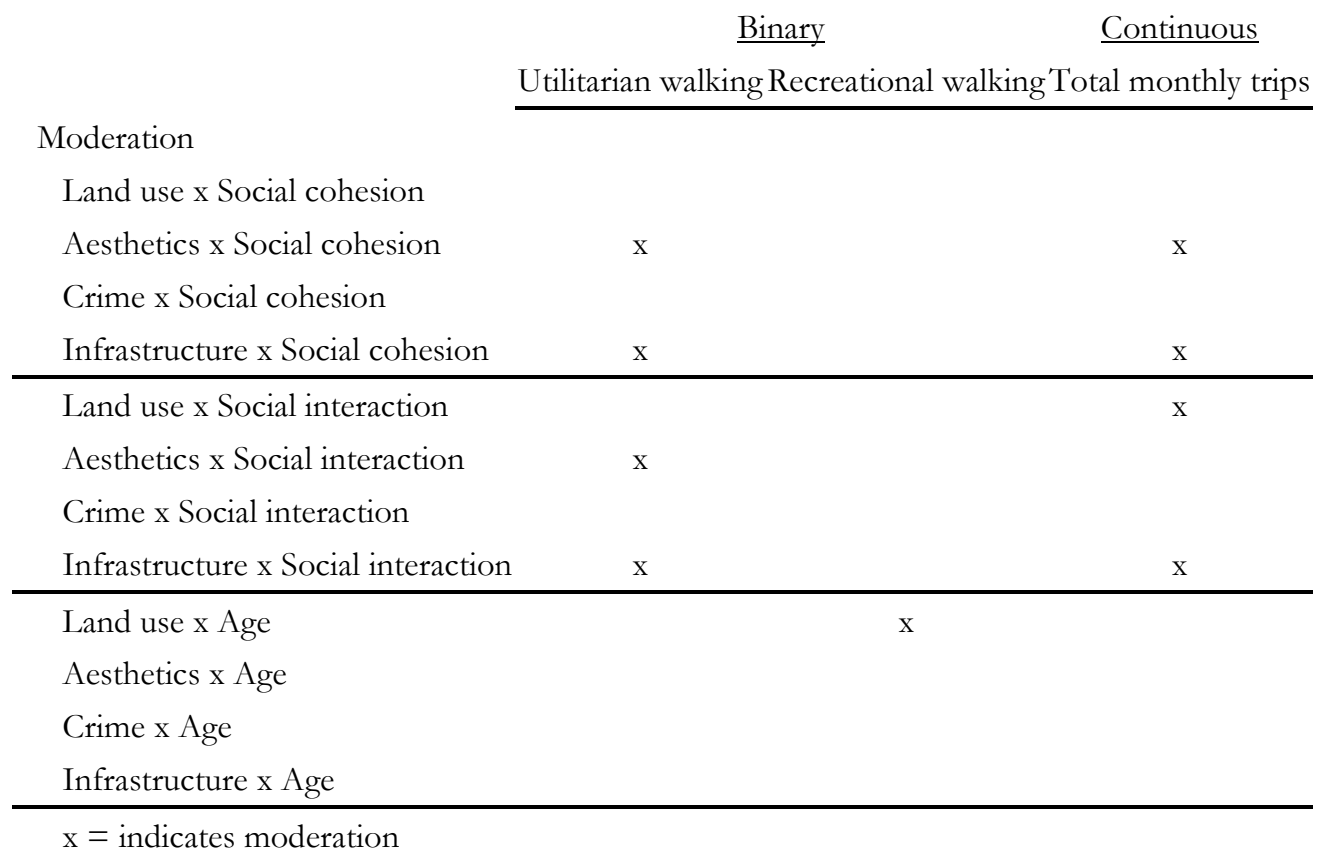

The Effects of the Built Environment on Utilitarian Walking and Recreational Walking as Mediated by Perceived Neighborhood Social Cohesion and Frequency of Social Interaction with Neighbors

The following sixteen tests for mediation, using multiple logistic linear regression, were conducted to test the hypotheses that perceived neighborhood social cohesion and frequency of social interaction with neighbors would mediate the effects of dimensions of the built environment - perceptions of land use mix, perceptions of aesthetics, perceptions of crime and safety, perceptions of pedestrian infrastructure and safety - on walking. The outcomes in these analyses were utilitarian walking and recreational walking. Covariates in all models included age, functional ability, race/ethnicity, gender, educational attainment, relationship status, and physical functioning. 


\section{Perceptions of Land Use Mix and Perceived Neighborhood Social Cohesion as Mediator}

Utilitarian walking. Perceptions of land use mix exhibited a significant positive association with utilitarian walking $(\mathrm{b}=.37, \mathrm{OR}=1.44, \mathrm{p}<.01)$. Each point increase on the perceptions of land use mix scale was associated with a .37 or approximately $44 \%$ increase in the odds of utilitarian walking. In the next step, perceptions of land use mix was significantly associated with perceived neighborhood social cohesion $(b=.19, \beta=.19, \mathrm{p}<.001)$.

Perceived neighborhood social cohesion approached statistical significance in its association with utilitarian walking $(\mathrm{b}=.20, \mathrm{OR}=1.23, \mathrm{p}=.09)$, such that for each point increase in perceived neighborhood social cohesion, there was a $23 \%$ increase in the odds of utilitarian walking. In the final step of the model, however, with both perceptions of land use mix and perceived neighborhood social cohesion in the model, only perceptions of land use mix was significantly associated with utilitarian walking $(\mathrm{b}=.35, \mathrm{OR}=1.42, \mathrm{p}<.01)$. Because perceived neighborhood social cohesion did not predict utilitarian walking $(\mathrm{b}=.18$, OR $=$ $1.19, \mathrm{~ns})$, there was insufficient evidence to support the mediation hypothesis, and a test of indirect effects was not conducted.

Recreational walking. The effect of perceptions of land use mix on recreational walking approached statistical significance in the first step of the mediation analysis model (b $=.20, \mathrm{OR}=1.22, \mathrm{p}=.10)$. For every point increase in perceptions of land use mix, there was an associated .20 or $22 \%$ increase in the odds of recreational walking. In the next step, perceptions of land use mix was significantly associated with perceived neighborhood social cohesion $(\mathrm{b}=.19, \beta=.19, \mathrm{p}<.001)$. In the third step, perceived neighborhood social cohesion significantly predicted recreational walking $(\mathrm{b}=.26, \mathrm{OR}=1.30, \mathrm{p}<.05)$. For each 
point increase in perceived neighborhood social cohesion, there was .26 or $30 \%$ increase in the odds of recreational walking. With both perceptions of land use mix and perceived neighborhood social cohesion in the model, perceived neighborhood social cohesion significantly predicted recreational walking $(\mathrm{b}=.26, \mathrm{OR}=1.30, \mathrm{p}<.05)$. Perceptions of land use mix no longer significantly predicted recreational walking when controlling for perceived neighborhood social cohesion $(\mathrm{b}=.14$, $\mathrm{OR}=1.15$, ns). These results were consistent with full mediation, and a further test for indirect effects was conducted.

A test of the indirect effect using bootstrap estimation indicated the coefficient was significant $(\mathrm{b}=.05, \mathrm{SE}=.03, \mathrm{CI}=.0066, .1174)$. There was a .05 change in recreational walking for each unit change in perceptions of land use mix as mediated by perceived neighborhood social cohesion.

\section{Perceptions of Land Use Mix and Frequency of Social Interaction with Neighbors as Mediator}

Utilitarian walking. Perceptions of land use mix exhibited a significant positive association with utilitarian walking $(\mathrm{b}=.37, \mathrm{OR}=1.44, \mathrm{p}<.01)$. For each point increase in perceptions of land use mix, there was a $44 \%$ increase in the odds of utilitarian walking. As perceptions of land use mix did not significantly predict frequency of social interaction with neighbors in the second stage of modeling $(b=.08, \beta=.06, \mathrm{~ns})$, there was insufficient evidence to support the mediation hypothesis, and a test of indirect effects was not conducted.

Recreational walking. Perceptions of land use mix predicted recreational walking with marginal significance in the first stage of modeling $(\mathrm{b}=.20, \mathrm{OR}=1.22, \mathrm{p}=.10)$. For each point increase in perceptions of land use mix, there was a .20 or $22 \%$ increase in the 
odds of recreational walking. However, in the second stage of modeling, perceptions of land use mix did not significantly predict frequency of social interaction with neighbors $(b=.08$, $\beta=.06, \mathrm{~ns})$, and as a result there was insufficient evidence to support the mediation hypothesis, and a test of indirect effects was not conducted.

\section{Perceptions of Aesthetics and Perceived Neighborhood Social Cohesion as Mediator}

Utilitarian walking. In the first stage of modeling, perceptions of aesthetics did exhibit a marginally significant positive association with utilitarian walking $(\mathrm{b}=.22$, $\mathrm{OR}=$ $1.25, \mathrm{p}=.08)$. For each point increase in perceptions of aesthetics, there was an associated .22 or $25 \%$ increase in the odds of utilitarian walking. In testing the direct effect between the independent variable and the hypothesized mediator, perceptions of aesthetics did significantly predict perceived neighborhood social cohesion $(b=.40, \beta=.38, \mathrm{p}<.001)$. There was a marginally significant direct effect of perceived neighborhood social cohesion on utilitarian walking $(\mathrm{b}=.20, \mathrm{OR}=1.23, \mathrm{p}=.09)$; such that for each point increase in perceived neighborhood social cohesion, there was a $23 \%$ increase in the odds of utilitarian walking. However, with both the independent variable and hypothesized mediator in the model, neither perceptions of aesthetics $(\mathrm{b}=.17, \mathrm{OR}=1.20$, ns) nor perceived neighborhood social cohesion $(\mathrm{b}=.12, \mathrm{OR}=1.13, \mathrm{~ns})$ significantly predicted utilitarian walking. These results provided insufficient evidence to support the mediation hypothesis, and a test of indirect effects was not conducted.

Recreational walking. In the first stage of modeling, perceptions of aesthetics did significantly predict recreational walking $(b=.34, \mathrm{OR}=1.40, \mathrm{p}<.01)$; such that for every point increase in perceptions of aesthetics, there was an associated $40 \%$ increase in the odds of recreational walking. In testing the direct effect between the independent variable and the 
hypothesized mediator, perceptions of aesthetics did significantly predict perceived neighborhood social cohesion $(\mathrm{b}=.40, \beta=.38, \mathrm{p}<.001)$. There was a significant direct effect of perceived neighborhood social cohesion on recreational walking $(b=.26, \mathrm{OR}=$ $1.30, \mathrm{p}<.05)$, such that for each point increase in perceived neighborhood social cohesion there was an associated 30\% increase in the odds of recreational walking. However, with both the independent variable and hypothesized mediator in the model, while perceptions of aesthetics was significantly associated with recreational walking $(\mathrm{b}=.30, \mathrm{OR}=1.35, \mathrm{p}<$ .05), perceived neighborhood social cohesion was not significantly associated with recreational walking $(\mathrm{b}=.16, \mathrm{OR}=1.13$, ns). These results provided insufficient evidence to support the mediation hypothesis, and a test of indirect effects was not conducted.

\section{Perceptions of Aesthetics and Frequency of Social Interaction with Neighbors as Mediator}

Utilitarian walking. Perceptions of aesthetics had a marginally significant direct effect on utilitarian walking $(\mathrm{b}=.22, \mathrm{OR}=1.25, \mathrm{p}=.08)$, such that for each point increase in perceptions of aesthetics, there was a $25 \%$ increase in the odds of utilitarian walking. In the second stage of modeling, perceptions of aesthetics was significantly associated with frequency of social interaction with neighbors $(b=.14, \beta=.09, \mathrm{p}<.05)$; and in the third stage, frequency of social interaction with neighbors was significantly associated with utilitarian walking $(\mathrm{b}=.26, \mathrm{OR}=1.30, \mathrm{p}<.01)$. For each point increase in frequency of social interaction with neighbors, there was an associated $30 \%$ increase in the odds of utilitarian walking. With both perceptions of aesthetics $(\mathrm{b}=.19, \mathrm{OR}=1.21$, ns) and frequency of social interaction with neighbors $(\mathrm{b}=.22$, OR $=1.25, \mathrm{p}<.01)$ in the model, the results were consistent with full mediation as perceptions of aesthetics no longer 
significantly was associated with utilitarian walking, and a further test for indirect effects was conducted.

A test of the indirect effect using bootstrap estimation indicated the coefficient was significant $(\mathrm{b}=.03, \mathrm{SE}=.02, \mathrm{CI}=.0024, .0751)$. There was a .03 change in utilitarian walking for each unit change in perceptions of aesthetics as mediated by frequency of social interaction with neighbors.

Recreational walking. Perceptions of aesthetics directly predicted recreational walking $(\mathrm{b}=.34, \mathrm{OR}=1.40, \mathrm{p}<.01)$, such that for every point increase in perceptions of aesthetics, there was an associated $40 \%$ increase in the odds of recreational walking. In the second stage of modeling, perceptions of aesthetics was significantly associated with frequency of social interaction with neighbors $(b=.14, \beta=.09, \mathrm{p}<.05)$; and in the third stage, frequency of social interaction with neighbors was significantly associated with recreational walking $(\mathrm{b}=.33, \mathrm{OR}=1.39, \mathrm{p}<.001)$. For each point increase in frequency of social interaction with neighbors, there was an associated $39 \%$ increase in the odds of recreational walking. With both the independent variable and hypothesized mediator in the model, the effect of perceptions of aesthetics on recreational walking, controlling for frequency of social interaction with neighbors, decreased in statistical significance $(b=.31$, $\mathrm{OR}=1.36, \mathrm{p}<.05)$, which was consistent with partial mediation, and a further test for indirect effects was conducted. Frequency of social interaction with neighbors, controlling for perception of aesthetics, was significantly associated with recreational walking $(b=.31$, $\mathrm{OR}=1.36, \mathrm{p}<.001)$

A test of the indirect effect indicated the coefficient was significant $(\mathrm{b}=.04, \mathrm{SE}=$ $.02, \mathrm{CI}=.0057, .0969)$, which suggests that, in part, perceptions of aesthetics influences 
walking through the extent to which individuals interact with their neighbors. There was a .04 change in recreational walking for each unit change in perceptions of aesthetics as mediated by frequency of social interaction with neighbors.

\section{Perceptions of Crime and Safety and Perceived Neighborhood Social Cohesion as Mediator}

Utilitarian walking. Perceptions of crime and safety directly predicted utilitarian walking $(\mathrm{b}=-.43, \mathrm{OR}=.65, \mathrm{p}<.001)$. Each point increase on the perceptions of crime and safety scale was associated with .65 , or approximately a $50 \%$ decrease in the odds of utilitarian walking. In the second stage of modeling, perceptions of crime and safety significantly predicted perceived neighborhood social cohesion $(b=-.35, \beta=-.36, \mathrm{p}<.001)$; and in the third stage, perceived neighborhood social cohesion was marginally significantly associated with utilitarian walking $(\mathrm{b}=.20, \mathrm{OR}=1.23, \mathrm{p}=.09)$. For every point increase in perceived neighborhood social cohesion, there was a $23 \%$ increase in the odds of utilitarian walking. However, when perceived neighborhood social cohesion $(\mathrm{b}=.08, \mathrm{OR}=1.08, \mathrm{~ns})$ was included in the model with perceptions of crime and safety, only perceptions of crime and safety significantly predicted utilitarian walking $(\mathrm{b}=-.37, \mathrm{OR}=.69, \mathrm{p}<.01)$. These results provided insufficient evidence to support the mediation hypothesis, and a test of indirect effects was not conducted.

Recreational walking. Higher levels of perceptions of crime and safety directly predicted less recreational walking $(\mathrm{b}=-.24, \mathrm{OR}=.79, \mathrm{p}<.05)$, such that every point increase in perceptions of crime and safety, there was approximately a $27 \%$ decrease in the odds of recreational walking. In the second stage of modeling, perceptions of crime and safety significantly predicted perceived neighborhood social cohesion $(b=-.35, \beta=-.36, p<$ 
$.001)$; and in the third stage, perceived neighborhood social cohesion was significantly associated with recreational walking $(\mathrm{b}=.26, \mathrm{OR}=1.30, \mathrm{p}<.05)$. For every point increase in perceived neighborhood social cohesion, there was an associated 30\% increase in the odds of recreational walking. With both the independent variable and hypothesized mediator in the model, perceptions of crime and safety no longer significantly predicted recreational walking $(\mathrm{b}=-.13, \mathrm{OR}=.88, \mathrm{~ns})$ while perceived neighborhood social cohesion significantly predicted recreational walking $(\mathrm{b}=.21, \mathrm{OR}=1.24, \mathrm{p}=.09)$. These results were consistent with full mediation, and an additional test of indirect effects was conducted.

A test of the indirect effect using bootstrap estimation indicated the coefficient was significant $(\mathrm{b}=-.08, \mathrm{SE}=.05, \mathrm{CI}=-.1728, .0108)$. There was a .03 change in recreational walking for each unit change in perceptions of crime and safety as mediated by perceived neighborhood social cohesion.

\section{Perceptions of Crime and Safety and Frequency of Social Interaction with Neighbors as Mediator}

Utilitarian walking. Perceptions of crime and safety had a significant direct effect on utilitarian walking $(\mathrm{b}=-.43, \mathrm{OR}=.65, \mathrm{p}<.001)$, such that for each point increase in perceptions of crime and safety, there was approximately a $54 \%$ decrease in the odds of utilitarian walking. Because perceptions of crime and safety did not significantly predict frequency of social interaction with neighbors $(b=-.04, \beta=-.03$, ns), there was insufficient evidence to support the mediation hypothesis, and a test of indirect effects was not conducted.

Recreational walking. Perceptions of crime and safety had a significant direct effect on recreational walking $(\mathrm{b}=-.24, \mathrm{OR}=.79, \mathrm{p}<.05)$, such that for each point increase 
in perceptions of crime and safety, there was approximately a $26 \%$ decrease in the odds of recreational walking. Because perceptions of crime and safety did not significantly predict frequency of social interaction with neighbors $(b=-.04, \beta=-.03$, ns), there was insufficient evidence to support the mediation hypothesis, and a test of indirect effects was not conducted.

\section{Perceptions of Pedestrian Infrastructure and Safety and Perceived Neighborhood Social Cohesion as Mediator}

Utilitarian walking. Perceptions of pedestrian infrastructure and safety had a marginally significant direct effect on utilitarian walking $(\mathrm{b}=-.30, \mathrm{OR}=.74, \mathrm{p}=.06)$, such that for each point increase in perceptions of pedestrian infrastructure and safety, there was approximately a $35 \%$ decrease in the odds of utilitarian walking. In the second stage of modeling, perceptions of pedestrian infrastructure and safety significantly predicted perceived neighborhood social cohesion $(b=.30, \beta=.29, \mathrm{p}<.001)$; and in the third stage of modeling perceived neighborhood social cohesion had a marginally significant effect on predicted utilitarian walking $(\mathrm{b}=.20, \mathrm{OR}=1.27, \mathrm{p}=.09)$. For each point increase in perceived neighborhood social cohesion, there was an associated $27 \%$ increase in the odds

of utilitarian walking. However, with both perceptions of pedestrian infrastructure $(b=-.34$, $\mathrm{OR}=.71, \mathrm{p}<.05)$ and perceived neighborhood social cohesion $(\mathrm{b}=.24, \mathrm{OR}=1.27, \mathrm{p}=$ .06) in the regression model, there was insufficient evidence to support the mediation hypothesis, and a test of indirect effects was not conducted.

Recreational walking. Perceptions of pedestrian infrastructure and safety did not directly predict recreational walking $(\mathrm{b}=-.08, \mathrm{OR}=.93, \mathrm{~ns})$, and as a result there was 
insufficient evidence to support the mediation hypothesis, and a test of indirect effects was not conducted.

\section{Perceptions of Pedestrian Infrastructure and Safety and Frequency of Social Interaction with Neighbors as Mediator}

Utilitarian walking. Perceptions of pedestrian infrastructure and safety had a marginally significant effect on utilitarian walking $(\mathrm{b}=-.30, \mathrm{OR}=.74, \mathrm{p}=.06)$, such that for every point increase in perceptions of pedestrian infrastructure and safety, there was an associated -.30 point or $35 \%$ decrease in the odds of utilitarian walking. In the second stage of modeling, perceptions of pedestrian infrastructure and safety had a significant effect on frequency of social interaction with neighbors $(\mathrm{b}=.14, \beta=.08, \mathrm{p}<.05)$; and in the third stage of modeling frequency of social interaction with neighbors significantly predicted utilitarian walking $(\mathrm{b}=.26, \mathrm{OR}=1.30, \mathrm{p}<.05)$. For each point increase in frequency of social interaction with neighbors, there was an associated 30\% increase in the odds of utilitarian walking. When both perceptions of pedestrian infrastructure and safety and frequency of social interaction with neighbors were simultaneously included in the regression model, both perceptions of pedestrian infrastructure and safety $(b=-.34, \mathrm{OR}=.71, \mathrm{p}<$ .050 and frequency of social interaction with neighbors had a significant effects on utilitarian walking $(\mathrm{b}=.23, \mathrm{OR}=1.26, \mathrm{p}<.05)$. These results provided insufficient evidence to support the mediation hypothesis, and a test of indirect effects was not conducted.

Recreational walking. Perceptions of pedestrian infrastructure and safety did not significantly predict recreational walking $(\mathrm{b}=-.08, \mathrm{OR}=.93, \mathrm{~ns})$. These results provided insufficient evidence to support the mediation hypothesis, and a test of indirect effects was not conducted. 


\section{The Effects of the Built Environment on Utilitarian Walking and Recreational Walking as Moderated by Perceived Neighborhood Social Cohesion, Frequency of Social Interaction with Neighbors, and Age}

It was hypothesized that perceived neighborhood social cohesion might ameliorate deficits in the built environment. Specifically, it was hypothesized that if an individual perceives some dimension of the built environment to be lacking (e.g., not enough sidewalks, few amenities within close walking distance, not aesthetically appealing or attractive surroundings), those who perceive their area of residence to be socially cohesive will walk more than those who perceive their area of residence to be less socially cohesive. Both main effects and interactions were considered statistically significant and worthy of reporting if the p-value was .10 or less, as p-values greater than .05 and less than .10 are sometimes reported as 'approaching significance'. Covariates in all of the models included age, functional ability, race/ethnicity, gender, educational attainment, relationship status, and physical functioning.

\section{Perceptions of Land Use Mix}

The following six multiple logistic regression analyses were conducted to test hypotheses that perceived neighborhood social cohesion, frequency of social with neighbors, and age would moderate the effects of perceptions of land use mix walking. The outcomes in these multiple logistic regression analyses were utilitarian and recreational walking (see Figure 6. Simple slopes for recreational walking on perceptions of land use mix at values of age

Note: Low = minus $1 \mathrm{SD}$, High = plus $1 \mathrm{SD} ; \mathrm{y}$-axis truncated to provide clear indication of relationship 
Table 7).

\section{Perceptions of land use mix and utilitarian walking - perceived neighborhood}

social cohesion. There was a significant positive effect for perceptions of land use mix on utilitarian walking $(\mathrm{b}=.35, \mathrm{OR}=1.42, \mathrm{p}<.01)$, but an absence of a main effect for perceived neighborhood social cohesion on utilitarian walking ( $\mathrm{b}=.19$, OR $=1.20$, ns).

Further, there was not a significant statistical interaction between perceived neighborhood social cohesion and perceptions of land use mix on utilitarian walking $(b=.11$, $\mathrm{OR}=1.12$, ns). More positive perceptions of land use mix were associated with an increased likelihood of utilitarian walking, meaning that if respondents agreed that there were amenities within walking distance of home, that they were more likely to walk as a means of transportation. Age was a significant predictor of utilitarian walking $(\mathrm{b}=-.03, \mathrm{OR}=.98, \mathrm{p}<.001)$, whereby older respondents were less likely to walk as a means of transportation as compared to younger adults.

\section{Perceptions of land use mix and utilitarian walking - frequency of social} interaction with neighbors. Whereas perceived neighborhood social cohesion did not independently predict utilitarian walking, there was a significant main effect of frequency of social interaction with neighbors $(\mathrm{b}=.26, \mathrm{OR}=1.30, \mathrm{p}<.01)$ on utilitarian walking. Additionally, perceptions of land use mix had a significant main effect on utilitarian walking $(\mathrm{b}=.36, \mathrm{OR}=1.43, \mathrm{p}<.01)$, however, there was not a significant interaction perceptions of land use mix and frequency of social interaction with neighbors on utilitarian walking $(\mathrm{b}=$ $.07, \mathrm{OR}=1.08, \mathrm{~ns})$. Age significantly predicted utilitarian walking $(\mathrm{b}=-.03, \mathrm{OR}=.98, \mathrm{p}<$ .001), such that with increasing age, there was less walking for transportation. 
Perceptions of land use mix and utilitarian walking - age. In examining the possible moderating role of age in the relationship between the built environment and walking, there were main effects for both perceptions of land use mix $(b=.35, \mathrm{OR}=1.41, \mathrm{p}$ $<.01)$ and age $(\mathrm{b}=-.03, \mathrm{OR}=.97, \mathrm{p}<.001)$ on utilitarian walking. There was not a significant interaction perceptions of land use mix and age on utilitarian walking $(b=.01$, $\mathrm{OR}=1.01, \mathrm{~ns})$. These results suggest that both land use mix and age are independent predictors of walking for transportation, but the effect of land use mix on walking for transportation is not different across age. Respondents walk less for transportation with increasing age, and those who are more aware of amenities, different land uses, and mass transit, are more likely to walk for transportation as compared to those who are less aware.

\section{Perceptions of land use mix and recreational walking - perceived}

neighborhood social cohesion. Perceived neighborhood social cohesion had a significant direct effect on recreational walking $(\mathrm{b}=.26, \mathrm{OR}=1.30, \mathrm{p}<.05)$, but there was not a main effect for perceptions of land use mix on recreational walking $(\mathrm{b}=.14, \mathrm{OR}=1.15$, ns). These findings suggest that the more a neighborhood is considered socially cohesive, the more that individuals will be likely to walk for recreation. Age also had a significant effect on recreational walking, such that with increased age, there was less walking as a means of recreation $(\mathrm{b}=-.01, \mathrm{OR}=.99, \mathrm{p}<.05)$. There was no interaction between perceptions of land use mix and perceived neighborhood social cohesion on recreational walking $(\mathrm{b}=.03$, $\mathrm{OR}=1.03, \mathrm{~ns})$

\section{Perceptions of land use mix and recreational walking - frequency of social} interaction with neighbors. Frequency of social interaction with neighbors independently predicted recreational walking $(\mathrm{b}=.32, \mathrm{OR}=1.37, \mathrm{p}<.001)$, suggesting that more 
engagement with neighbors was associated with more walking as an activity; but perceptions of land use mix did not predict recreational walking $(\mathrm{b}=.16, \mathrm{OR}=1.18$, ns). Age significantly predicted recreational walking $(\mathrm{b}=-.01, \mathrm{OR}=.99, \mathrm{p}<.05)$, which indicated that with increasing age, there is less walking as a recreational activity. The interaction between perceptions of land use mix and frequency of social interaction on recreational walking was not significant $(\mathrm{b}=.04, \mathrm{OR}=1.05, \mathrm{~ns})$, so the moderation hypothesis that the effect of perceptions of land use mix on recreational walking would be moderated by frequency of social interaction with neighbors was not supported by the results.

Perceptions of land use mix and recreational walking - age. There was a significant main effect for age on recreational walking $(\mathrm{b}=-.01$, OR $=.99, \mathrm{p}<.05)$, such that there was less walking with age. Perceptions of land use mix did not have a significant main effect on recreational walking $(\mathrm{b}=.17, \mathrm{OR}=1.19$, ns). There was a significant interaction of the independent variable and hypothesized moderator, such that perceptions of land use mix and age had a multiplicative effect on recreational walking $(\mathrm{b}=.01$, OR $=$ $1.01, \mathrm{p}<.05)$. This interaction suggests that the effect of land use mix on recreational walking varies by age.

The interaction for the association between perceptions of land use mix and recreational walking were plotted for low (one standard deviation below the mean) and high (one standard deviation above the mean) age. These plots depicted a difference in perceptions of land use mix at different values of age. At one standard deviation above the mean for frequency of age, there was a statistically significant difference in recreational walking $(\mathrm{b}=.41, \mathrm{OR}=1.51, \mathrm{p}<.01)$. However, at one standard deviation below the mean 
of age, there was not a significant difference in recreational walking $(\mathrm{b}=-.06$, OR $=.94$, ns) (see Figure 6). 
Figure 6. Simple slopes for recreational walking on perceptions of land use mix at values of age

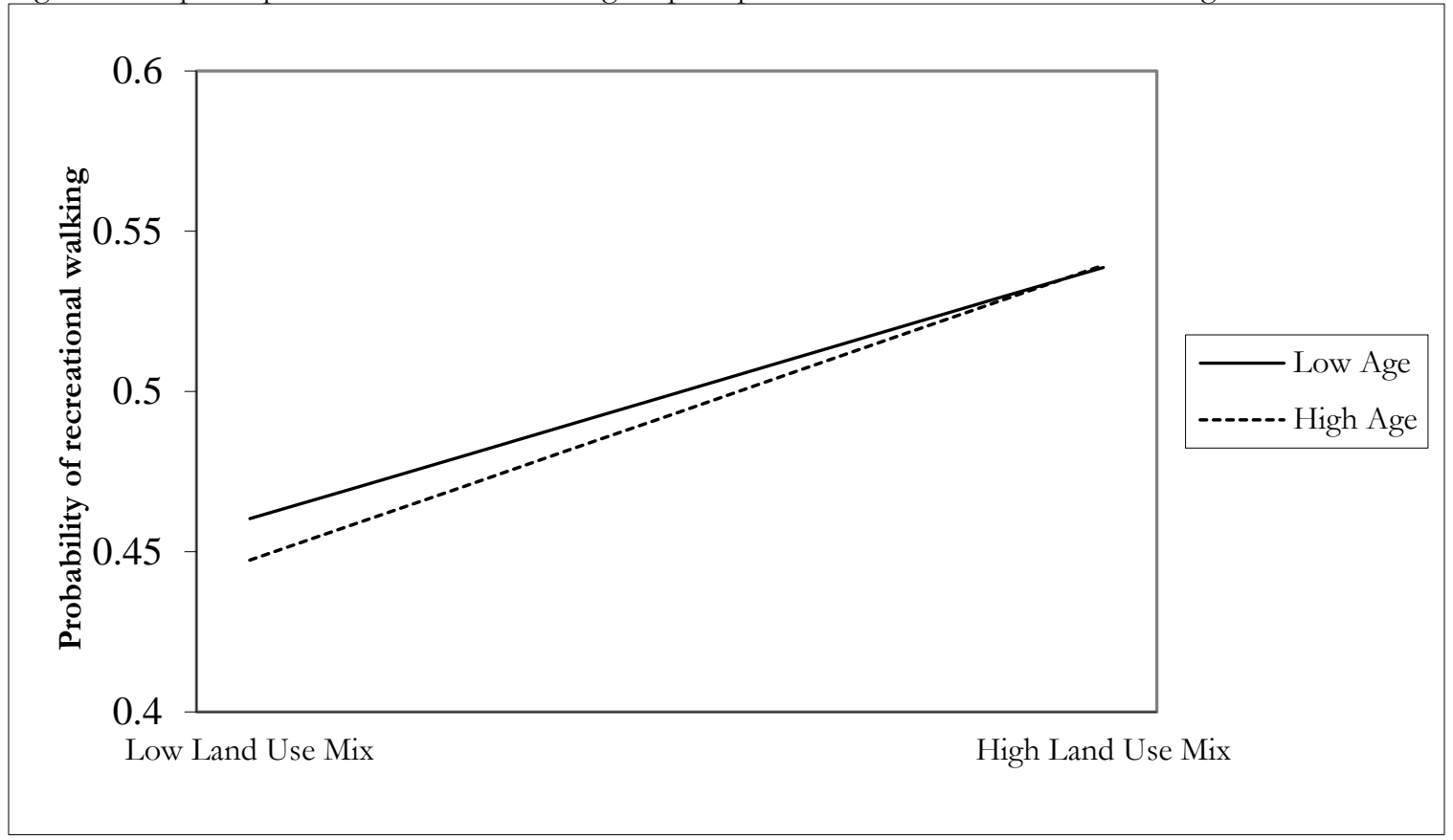

Note: Low $=$ minus $1 \mathrm{SD}$, High $=$ plus $1 \mathrm{SD}$; $\mathrm{y}$-axis truncated to provide clear indication of relationship 
Table 7. Moderating effects of perceptions of land use mix and perceived neighborhood social cohesion, frequency of social interaction with neighbors, and age on utilitarian walking and recreational walking

\begin{tabular}{c|ccc}
\hline Utilitarian Walking & \multicolumn{3}{|c}{ Recreational Walking } \\
\hline Perceived Neighborhood Social Cohesion & \\
\hline $95 \% \quad 95 \%$ & $95 \%$ & $95 \%$
\end{tabular}

$\begin{array}{lllllllllllll}\mathrm{b} & \mathrm{SE} & \mathrm{p} & \mathrm{OR} & \mathrm{CI} & \mathrm{CI} & \mathrm{b} & \mathrm{SE} & \mathrm{p} & \mathrm{OR} & \mathrm{CI} & \mathrm{CI}\end{array}$

\begin{tabular}{cc|cccccc} 
LCL & UCL & & & & & LCL & UCL \\
\hline 1.11 & 1.83 & .14 & .13 & .26 & 1.15 & .90 & 1.47
\end{tabular}

\begin{tabular}{|c|c|c|c|c|c|c|c|c|c|c|c|c|}
\hline Land use mix & .35 & .13 & .01 & 1.42 & 1.11 & 1.83 & .14 & .13 & .26 & 1.15 & .90 & 1.47 \\
\hline Social cohesion & .19 & .12 & .13 & 1.20 & .94 & 1.53 & .26 & .12 & .03 & 1.30 & 1.03 & 1.65 \\
\hline $\begin{array}{l}\text { Land use mix x } \\
\text { Social cohesion }\end{array}$ & 11 & .16 & .49 & 1.12 & .82 & 1.52 & .03 & .15 & .83 & 1.03 & .77 & 1.39 \\
\hline Age & -.03 & .01 & .001 & .98 & .96 & .99 & -.01 & .01 & .03 & .99 & .98 & 1.00 \\
\hline Minority & -.58 & .23 & .01 & .56 & .36 & .88 & -.04 & .21 & .85 & .96 & .63 & 1.46 \\
\hline Female & .07 & .18 & .70 & 1.07 & .75 & 1.53 & -.13 & .18 & .47 & .88 & .63 & 1.24 \\
\hline$\leq$ High school & -.27 & .18 & .15 & .77 & .53 & 1.10 & -.19 & .18 & .30 & .83 & .58 & 1.18 \\
\hline $\begin{array}{l}\text { In a } \\
\text { relationship }\end{array}$ & -.29 & .18 & .11 & .75 & .52 & 1.07 & .24 & .17 & .16 & 1.28 & .91 & 1.79 \\
\hline \multirow[t]{3}{*}{$\begin{array}{l}\text { Physical } \\
\text { functioning }\end{array}$} & .005 & .003 & .18 & 1.00 & 1.00 & 1.01 & .01 & .003 & .01 & 1.01 & 1.00 & 1.02 \\
\hline & \multicolumn{12}{|c|}{ Frequency of Social Interaction with Neighbors } \\
\hline & $\mathrm{b}$ & SE & $\mathrm{p}$ & OR & $\begin{array}{c}95 \% \\
\text { CI } \\
\text { LCL } \\
\end{array}$ & $\begin{array}{c}95 \% \\
\text { CI } \\
\text { UCL } \\
\end{array}$ & $\mathrm{b}$ & SE & $\mathrm{p}$ & OR & $\begin{array}{l}95 \% \\
\text { CI } \\
\text { LCL } \\
\end{array}$ & $\begin{array}{l}95 \% \\
\text { CI } \\
\text { UCL }\end{array}$ \\
\hline Land use mix & .36 & .12 & .01 & 1.43 & 1.12 & 1.82 & .16 & .12 & .17 & 1.18 & .93 & 1.49 \\
\hline $\begin{array}{l}\text { Social } \\
\text { interaction } \\
\text { Land use mix x }\end{array}$ & .26 & .08 & .01 & 1.30 & 1.10 & 1.53 & .32 & .08 & .001 & 1.37 & 1.17 & 1.61 \\
\hline $\begin{array}{l}\text { Social } \\
\text { interaction }\end{array}$ & .07 & .12 & .53 & 1.08 & .86 & 1.35 & .04 & .11 & .69 & 1.05 & .84 & 1.30 \\
\hline Age & -.02 & .01 & .001 & .98 & .96 & .99 & -.01 & .01 & .03 & .99 & .98 & 1.00 \\
\hline Minority & -.63 & .23 & .01 & .53 & .34 & .83 & -.14 & .21 & .50 & .87 & .57 & 1.31 \\
\hline Female & .03 & .18 & .87 & 1.03 & .73 & 1.45 & -.07 & .17 & .68 & .93 & .66 & 1.31 \\
\hline$\leq$ High school & -.24 & .18 & .18 & .78 & .55 & 1.12 & -.21 & .18 & .22 & .81 & .57 & 1.14 \\
\hline $\begin{array}{l}\text { In a } \\
\text { relationship }\end{array}$ & -.37 & .18 & .04 & .69 & .48 & .98 & .12 & .17 & .48 & 1.13 & .81 & 1.59 \\
\hline \multirow[t]{3}{*}{$\begin{array}{l}\text { Physical } \\
\text { functioning }\end{array}$} & .004 & .003 & .21 & 1.00 & 1.00 & 1.01 & .01 & .003 & .01 & 1.01 & 1.00 & 1.02 \\
\hline & \multicolumn{12}{|c|}{ Age } \\
\hline & $\mathrm{b}$ & SE & $\mathrm{p}$ & OR & $\begin{array}{c}95 \% \\
\text { CI } \\
\text { LCL } \\
\end{array}$ & $\begin{array}{c}95 \% \\
\text { CI } \\
\text { UCL } \\
\end{array}$ & $\mathrm{b}$ & SE & $\mathrm{p}$ & OR & $\begin{array}{l}95 \% \\
\mathrm{CI} \\
\mathrm{LCL} \\
\end{array}$ & $\begin{array}{c}95 \% \\
\text { CI } \\
\text { UCL } \\
\end{array}$ \\
\hline Land use mix & .35 & .13 & .01 & 1.41 & 1.11 & 1.80 & .17 & .12 & .16 & 1.19 & .94 & 1.51 \\
\hline Age & -.03 & .01 & .001 & .97 & .96 & .99 & -.01 & .01 & .03 & .99 & .98 & 1.00 \\
\hline $\begin{array}{l}\text { Land use mix x } \\
\text { Age }\end{array}$ & .01 & .01 & .19 & 1.01 & 1.00 & 1.02 & .01 & .01 & .04 & 1.01 & 1.00 & 1.03 \\
\hline Minority & -.50 & .22 & .02 & .60 & .39 & .93 & -.02 & .21 & .91 & .98 & .65 & 1.46 \\
\hline Female & .03 & .18 & .88 & 1.03 & .73 & 1.45 & -.10 & .17 & .56 & .91 & .65 & 1.26 \\
\hline$\leq$ High school & -.21 & .18 & .24 & .81 & .57 & 1.15 & -.17 & .17 & .34 & .85 & .60 & 1.19 \\
\hline $\begin{array}{l}\text { In a } \\
\text { relationship }\end{array}$ & -.36 & .18 & .04 & .70 & .49 & .99 & .16 & .17 & .36 & 1.17 & .84 & 1.63 \\
\hline $\begin{array}{l}\text { Physical } \\
\text { functioning }\end{array}$ & .004 & .003 & .26 & 1.00 & 1.00 & 1.01 & .01 & .003 & .01 & 1.01 & 1.00 & 1.02 \\
\hline
\end{tabular}




\section{Perceptions of Aesthetics}

The following six multiple logistic regression analyses were conducted to test the hypotheses that perceived neighborhood social cohesion, frequency of social interaction with neighbors, and age would moderate the effects of perceptions of aesthetics on walking. The outcomes in these analyses included utilitarian walking and recreational walking (see Table 8).

\section{Perceptions of aesthetics and utilitarian walking - perceived neighborhood}

social cohesion. There was an absence of a significant main effect for perceptions of aesthetics on utilitarian walking $(\mathrm{b}=.18, \mathrm{OR}=1.26$, ns), and no significant main effect for perceived neighborhood social cohesion on utilitarian walking $(\mathrm{b}=.16, \mathrm{OR}=1.27, \mathrm{~ns})$. Age, however, significantly predicted utilitarian walking $(\mathrm{b}=-.03$, OR $=.97, \mathrm{p}<.001)$, such that there was less walking for transportation with age. There was a significant interaction of perceptions of aesthetics and perceived neighborhood social cohesion on utilitarian walking $(\mathrm{b}=.33, \mathrm{OR}=1.39, \mathrm{p}=.07)$, which suggests that the effect of aesthetics on walking for transportation varies by level of social cohesion with neighbors.

The interaction for the association between perceptions of aesthetics and utilitarian walking were plotted for low (one standard deviation below the mean) and high (one standard deviation above the mean) perceived neighborhood social cohesion. These interactions reflect a difference in perceptions of aesthetics at different values of perceived neighborhood social cohesion. At one standard deviation above the mean for perceived neighborhood social cohesion, there was a significant difference in utilitarian walking (b = $.42, \mathrm{OR}=1.52, \mathrm{p}<.05)$. However, at one standard deviation below the mean of perceived 
neighborhood social cohesion, there was not a significant difference in utilitarian walking (b $=-.05, \mathrm{OR}=.95, \mathrm{~ns})($ see Figure 7$)$.

Figure 7. Simple slopes for utilitarian walking on perceptions of aesthetics at values of perceived neighborhood social cohesion

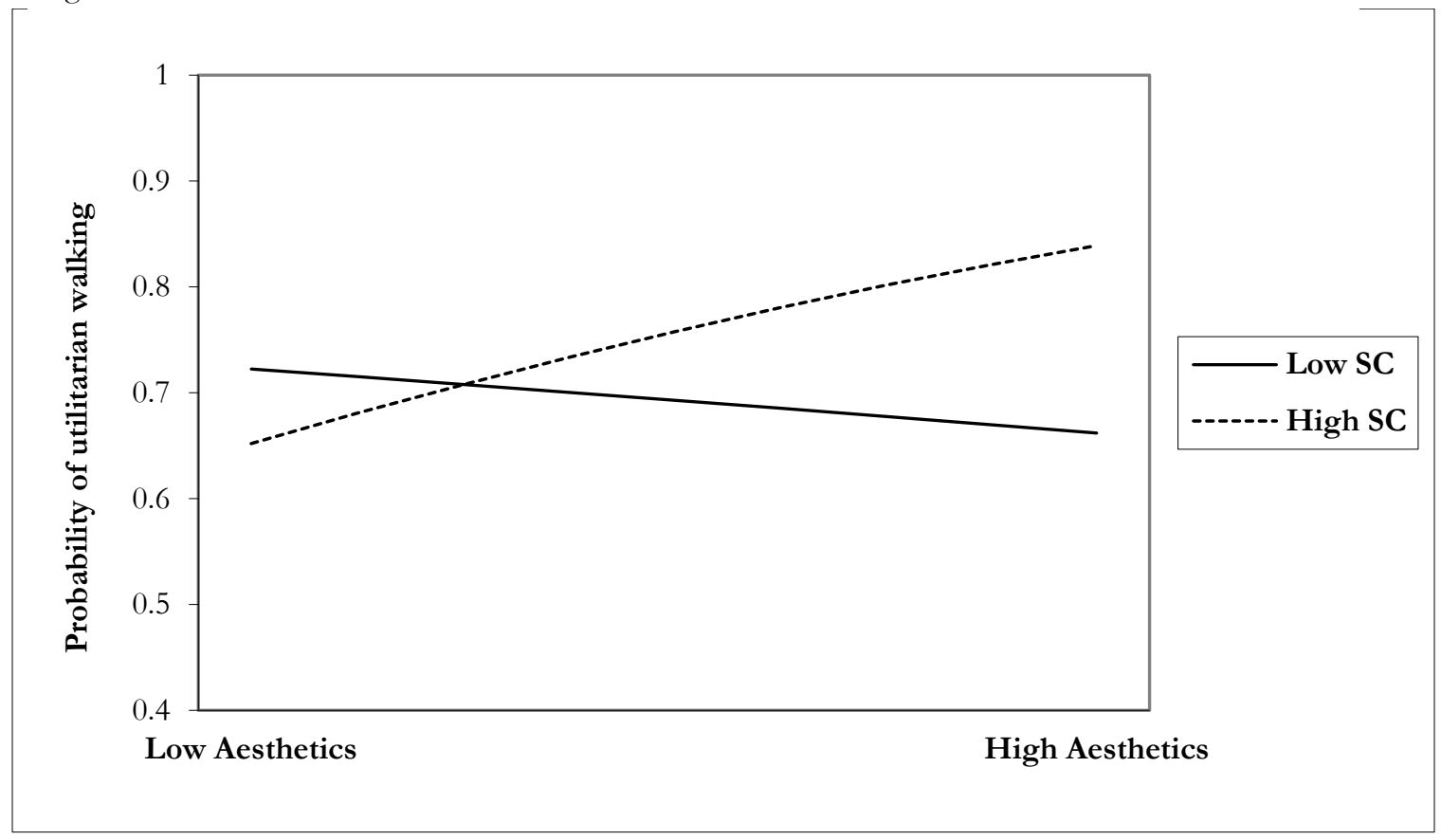

Note: Low = minus 1 SD, High = plus 1 SD; y-axis truncated to provide clear indication of relationship

\section{Perceptions of aesthetics and utilitarian walking - frequency of social}

interaction with neighbors. Perceptions of aesthetics had a marginally significant main effect on utilitarian walking $(\mathrm{b}=.23, \mathrm{OR}=1.26, \mathrm{p}=.07)$, and there was a main effect for frequency of social interaction with neighbors $(\mathrm{b}=.24, \mathrm{OR}=1.27, \mathrm{p}<.01)$. Age also significantly predicted utilitarian walking $(\mathrm{b}=-.03, \mathrm{OR}=.97, \mathrm{p}<.001)$. The moderation hypothesis was supported, as there was an interaction of perceptions of aesthetics and frequency of social interaction with neighbors on utilitarian walking $(\mathrm{b}=.36, \mathrm{OR}=1.44, \mathrm{p}$ $<.01)$. 
The interaction for the association between perceptions of aesthetics and utilitarian walking were plotted for low (one standard deviation below the mean) and high (one standard deviation above the mean) frequency of social interaction with neighbors. These plots depicted a difference in perceptions of aesthetics at different values of frequency of social interaction with neighbors. At one standard deviation above the mean for frequency of social interaction with neighbors, there was a significant difference in utilitarian walking (b $=.61, \mathrm{OR}=1.83, \mathrm{p}<.001)$. However, at one standard deviation below the mean of frequency of social interaction with neighbors, there was not a significant difference in utilitarian walking $(\mathrm{b}=-.15, \mathrm{OR}=.86, \mathrm{~ns})$ (see Figure 8).

Figure 8. Simple slopes for utilitarian walking on perceptions of aesthetics at values of frequency of social interaction with neighbors

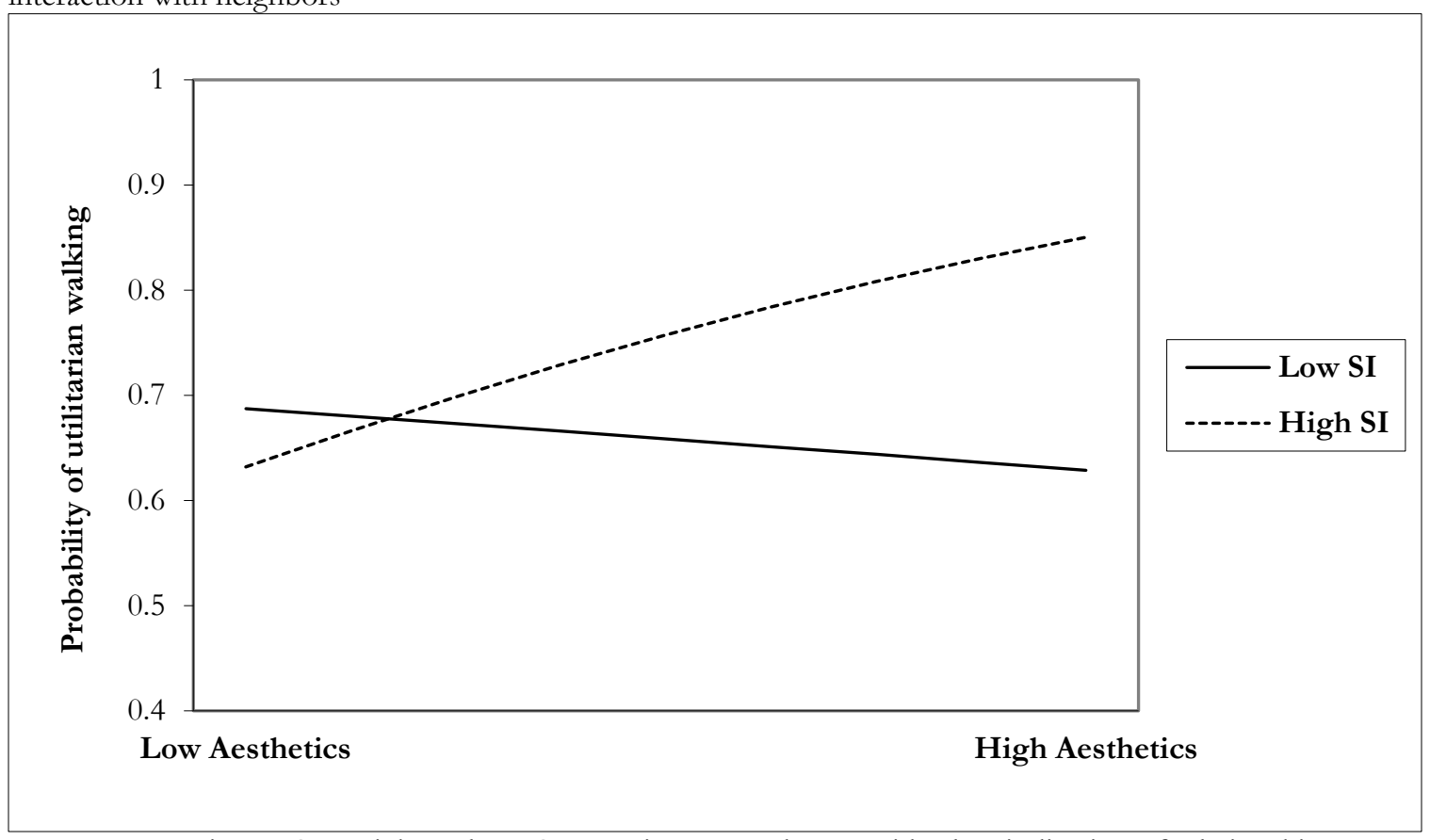

Note: Low $=$ minus $1 \mathrm{SD}$, High $=$ plus $1 \mathrm{SD}$; y-axis truncated to provide clear indication of relationship 
Perceptions of aesthetics and utilitarian walking - age. There was a main effect for age $(\mathrm{b}=-.03, \mathrm{OR}=.97, \mathrm{p}<.001)$ in predicting utilitarian walking but not for perceptions of aesthetics $(\mathrm{b}=.20, \mathrm{OR}=1.22$, ns). The moderation hypothesis was not supported as age did not moderate the effects of perceptions of aesthetics on utilitarian walking $(\mathrm{b}=.01, \mathrm{OR}=1.01, \mathrm{~ns})$.

Perceptions of aesthetics and recreational walking - perceived neighborhood social cohesion. There was a main effect for perceptions of aesthetics on recreational walking $(\mathrm{b}=.31, \mathrm{OR}=1.36, \mathrm{p}<.05)$ but no main effect for perceived neighborhood social cohesion on recreational walking $(\mathrm{b}=.18$, $\mathrm{OR}=1.19$, ns) or interaction effect of the two $(\mathrm{b}$ $=.14, \mathrm{OR}=1.15, \mathrm{~ns})$. Age was also a significant predictor of recreational walking $(\mathrm{b}=-.01$, $\mathrm{OR}=.99, \mathrm{p}<.05)$, such that with increasing age the likelihood of walking for physical or recreational activity decreased.

\section{Perceptions of aesthetics and recreational walking - frequency of social}

interaction with neighbors. Frequency of social interaction with neighbors directly predicted recreational walking $(\mathrm{b}=.32, \mathrm{OR}=1.37, \mathrm{p}<.001)$, as did perceptions of aesthetics $(\mathrm{b}=.33, \mathrm{OR}=1.39, \mathrm{p}<.01)$. Age also had a significant effect on recreational walking $(\mathrm{b}=-.01, \mathrm{OR}=.99, \mathrm{p}<.05)$. There was not an interaction of perceptions of aesthetics and frequency of social interaction with neighbors on recreational walking $(\mathrm{b}=$ $.17, \mathrm{OR}=1.19, \mathrm{~ns})$.

Perceptions of aesthetics and recreational walking - age. Significant main effects for both age $(\mathrm{b}=-.01, \mathrm{OR}=.99, \mathrm{p}<.01)$ and perceptions of aesthetics $(\mathrm{b}=.33$, OR $=1.39, \mathrm{p}<.01)$ were found on recreational walking, meaning that less walking as an activity occurred with increasing age and more attractive environments were associated with more 
walking as a recreational activity. The moderation hypothesis that age would moderate the effects of built environment on walking was not supported in this instance, as there was no evidence of a significant interaction between perceptions of aesthetics and age on recreational walking $(\mathrm{b}=.01, \mathrm{OR}=1.01, \mathrm{~ns})$. 
Table 8. Moderating effects of perceptions of aesthetics and perceived neighborhood social cohesion, frequency of social interaction with neighbors, and age on utilitarian walking and recreational walking

\begin{tabular}{c|c}
\hline Utilitarian Walking & Recreational Walking \\
\hline
\end{tabular}

\begin{tabular}{|ll|lll}
\hline \multicolumn{7}{c}{ Perceived Neighborhood Social Cohesion } \\
\hline $95 \%$ & $95 \%$ & $95 \%$ & $95 \%$
\end{tabular}

$\begin{array}{lllllllllllll}\mathrm{b} & \mathrm{SE} & \mathrm{p} & \mathrm{OR} & \mathrm{CI} & \mathrm{CI} & \mathrm{b} & \mathrm{SE} & \mathrm{p} & \mathrm{OR} & \mathrm{CI} & \mathrm{CI}\end{array}$ LCL UCL

\begin{tabular}{|c|c|c|c|c|c|c|c|c|c|c|c|c|}
\hline & & & & & & & & & & & & \\
\hline Aesthetics & .18 & .14 & .19 & 1.26 & .98 & 1.63 & .31 & .14 & .03 & 1.36 & 1.03 & 1.79 \\
\hline Social cohesion & .16 & .13 & .22 & 1.27 & 1.08 & 1.50 & .18 & .13 & .18 & 1.19 & .92 & 1.54 \\
\hline $\begin{array}{l}\text { Aesthetics } \mathrm{x} \\
\text { Social cohesion }\end{array}$ & .33 & 18 & .05 & 1.44 & 1.13 & 1.83 & .14 & .18 & .43 & 1.15 & .81 & 1.62 \\
\hline Age & -.03 & .01 & .001 & .97 & .96 & .99 & -.01 & .01 & .02 & .99 & .98 & 1.00 \\
\hline Minority & -.63 & .23 & .01 & .53 & .34 & .82 & -.08 & .21 & .71 & .92 & .61 & 1.40 \\
\hline Female & .07 & .18 & .71 & 1.03 & .73 & 1.46 & -.19 & .18 & .27 & .82 & .58 & 1.16 \\
\hline$\leq$ High school & -.20 & .18 & .28 & .84 & .59 & 1.20 & -.18 & .18 & .31 & .83 & .59 & 1.19 \\
\hline $\begin{array}{l}\text { In a } \\
\text { relationship }\end{array}$ & -.30 & .18 & 10 & .72 & .50 & 1.02 & .28 & .18 & .11 & 1.32 & .94 & 1.87 \\
\hline $\begin{array}{l}\text { Physical } \\
\text { functioning }\end{array}$ & .01 & .003 & .05 & 1.01 & 1.00 & 1.01 & .01 & .003 & .01 & 1.01 & 1.00 & 1.02 \\
\hline & & & & Freq & uency of & Social In & ractio & 1 with & Neighb & & & \\
\hline & $\mathrm{b}$ & SE & $\mathrm{p}$ & OR & $\begin{array}{c}95 \% \\
\text { CI } \\
\text { LCL }\end{array}$ & $\begin{array}{c}95 \% \\
\text { CI } \\
\text { UCL }\end{array}$ & $\mathrm{b}$ & SE & $\mathrm{p}$ & OR & $\begin{array}{c}95 \% \\
\text { CI } \\
\text { LCL }\end{array}$ & $\begin{array}{l}95 \% \\
\text { CI } \\
\text { UCL }\end{array}$ \\
\hline Aesthetics & .23 & .13 & .07 & 1.26 & .98 & 1.63 & .33 & .13 & .01 & 1.39 & 1.08 & 1.79 \\
\hline $\begin{array}{l}\text { Social } \\
\text { interaction } \\
\text { Aesthetics x }\end{array}$ & .24 & .09 & .01 & 1.27 & 1.08 & 1.50 & .32 & .08 & .001 & 1.37 & 1.16 & 1.61 \\
\hline $\begin{array}{l}\text { Social } \\
\text { interaction }\end{array}$ & .36 & 12 & .01 & 1.44 & 1.13 & 1.83 & .17 & .12 & .14 & 1.19 & .94 & 1.50 \\
\hline Age & -.03 & .01 & .001 & .97 & .96 & .99 & -.01 & .01 & .02 & .99 & .98 & 1.00 \\
\hline Minority & -.64 & .23 & .01 & .53 & .34 & .82 & -.16 & .21 & .44 & .85 & .56 & 1.29 \\
\hline Female & .03 & .18 & .86 & 1.03 & .73 & 1.46 & -.13 & .17 & .47 & .88 & .63 & 1.24 \\
\hline$\leq$ High school & -.17 & .18 & .34 & .84 & .59 & 1.20 & -.21 & .18 & .23 & .81 & .57 & 1.14 \\
\hline $\begin{array}{l}\text { In a } \\
\text { relationship }\end{array}$ & -.33 & .18 & .07 & .72 & .50 & 1.02 & .19 & .18 & .27 & 1.21 & .86 & 1.71 \\
\hline $\begin{array}{l}\text { Physical } \\
\text { functioning }\end{array}$ & .01 & .003 & .05 & 1.01 & 1.00 & 1.01 & .01 & .003 & .01 & 1.01 & 1.00 & 1.02 \\
\hline & & & & & & & & & & & & \\
\hline & $\mathrm{b}$ & SE & $\mathrm{p}$ & OR & $\begin{array}{c}95 \% \\
\text { CI } \\
\text { LCL }\end{array}$ & $\begin{array}{c}95 \% \\
\text { CI } \\
\text { UCL }\end{array}$ & $\mathrm{b}$ & SE & $\mathrm{p}$ & OR & $\begin{array}{c}95 \% \\
\text { CI } \\
\text { LCL }\end{array}$ & $\begin{array}{l}95 \% \\
\text { CI } \\
\text { UCL }\end{array}$ \\
\hline Aesthetics & .20 & .13 & .12 & 1.22 & .95 & 1.57 & .33 & .13 & .01 & 1.39 & 1.08 & 1.78 \\
\hline Age & -.03 & .01 & .001 & .97 & .96 & .98 & -.01 & .01 & .01 & .99 & .98 & 1.00 \\
\hline $\begin{array}{l}\text { Aesthetics x } \\
\text { Age }\end{array}$ & .01 & .01 & .28 & 1.01 & .99 & 1.02 & .01 & .01 & .49 & 1.01 & .99 & 1.02 \\
\hline Minority & -.55 & .22 & .01 & .58 & .38 & .89 & -.07 & .21 & .73 & .93 & .62 & 1.40 \\
\hline Female & .03 & .17 & .87 & 1.03 & .73 & 1.45 & -.14 & .17 & .40 & .87 & .62 & 1.21 \\
\hline$\leq$ High school & -.15 & .18 & .40 & .86 & .61 & 1.22 & -.17 & .17 & .33 & .84 & .60 & 1.19 \\
\hline $\begin{array}{l}\text { In a } \\
\text { relationship }\end{array}$ & -.31 & .18 & .08 & .73 & .52 & 1.04 & .25 & .17 & .15 & 1.28 & .91 & 1.79 \\
\hline $\begin{array}{l}\text { Physical } \\
\text { functioning }\end{array}$ & .01 & .003 & .03 & 1.01 & 1.00 & 1.01 & .01 & .003 & .001 & 1.01 & 1.00 & 1.02 \\
\hline
\end{tabular}




\section{Perceptions of Crime and Safety}

The following six multiple logistic regression analyses were conducted to test the hypotheses that perceived neighborhood social cohesion, frequency of social interaction with neighbors, and age would moderate the effects of perceptions of crime and safety on walking. The outcomes in these multiple logistic regression analyses were utilitarian walking and recreational walking (see 
Table 9).

\section{Perceptions of crime and safety and utilitarian walking - perceived}

neighborhood social interaction. Perceptions of crime and safety independently predicted utilitarian walking $(\mathrm{b}=-.37, \mathrm{OR}=.69, \mathrm{p}<.01)$, but there was no association for perceived neighborhood social cohesion on utilitarian walking $(\mathrm{b}=.06, \mathrm{OR}=1.07$, ns), and no evidence of statistical interaction of perceptions of crime and safety and perceived neighborhood social cohesion $(b=.05, \mathrm{OR}=1.05, \mathrm{~ns})$. Age had a significant effect on utilitarian walking $(\mathrm{b}=-.03, \mathrm{OR}=.97, \mathrm{p}<.001)$.

\section{Perceptions of crime and safety and utilitarian walking - frequency of social} interaction with neighbors. While there was no statistical interaction of perceptions of crime and safety and frequency of social interaction with neighbors on utilitarian walking (b $=-.10, \mathrm{OR}=.91, \mathrm{~ns})$, there were main effects for both perceptions of crime and safety $(\mathrm{b}=$ $-.42, \mathrm{OR}=.66, \mathrm{p}<.001)$ and frequency of social interaction with neighbors $(\mathrm{b}=.25, \mathrm{OR}=$ $1.29, \mathrm{p}<.01)$ on utilitarian walking. Age also significantly predicted utilitarian walking $(\mathrm{b}=$ $.03, \mathrm{OR}=.97, \mathrm{p}<.001)$. These results suggest that crime and safety crime is an important predictor of walking for transportation, and that crime may operate independently of social interaction in the neighborhood social context when considering walking behavior.

Perceptions of crime and safety and utilitarian walking - age. Both perceptions of crime and safety $(b=-.43, \mathrm{OR}=.65, \mathrm{p}<.001)$ and age $(\mathrm{b}=-.03, \mathrm{OR}=.97, \mathrm{p}<.001)$ had main effects on utilitarian walking, but there was no evidence of a statistical interaction of age and perceptions of crime and safety on utilitarian walking $(\mathrm{b}=-.002$, OR $=1.00, \mathrm{~ns})$.

Perceptions of crime and safety and recreational walking - perceived neighborhood social cohesion. There was a main effect for perceived neighborhood social 
cohesion on recreational walking $(\mathrm{b}=.26, \mathrm{OR}=1.29, \mathrm{p}<.05)$ but no main effect for perceptions of crime and safety on recreational walking $(\mathrm{b}=-.12, \mathrm{OR}=.89$, ns). Age significantly predicted recreational walking $(\mathrm{b}=-.01, \mathrm{OR}=.99, \mathrm{p}<.05)$. Further, there was no interaction of perceptions of crime and safety and perceived neighborhood social cohesion on recreational walking $(\mathrm{b}=-.18, \mathrm{OR}=.84$, ns).

Perceptions of crime and safety and recreational walking - frequency of social interaction with neighbors. There was a marginally significant main effect of perceptions of crime and safety on recreational walking $(\mathrm{b}=-.22, \mathrm{OR}=.80, \mathrm{p}=.06)$, and frequency of social interaction with neighbors significantly predicted recreational walking $(b=.33, \mathrm{OR}=$ $1.39, \mathrm{p}<.001)$. This means that the extent to which individuals engage with their neighbors has an effect on walking as a recreational or leisure activity. Age also significantly predicted recreational walking $(\mathrm{b}=-.01, \mathrm{OR}=.99, \mathrm{p}<.01)$. The moderation hypothesis that social interaction would moderate the effects of the built environment on walking was not supported, as there was no interaction of perceptions of crime and safety and frequency of social interaction with neighbors on recreational walking $(\mathrm{b}=-.04, \mathrm{OR}=.96, \mathrm{~ns})$.

Perceptions of crime and safety and recreational walking - age. Similarly, both perceptions of crime and safety $(b=-.23, \mathrm{OR}=.79, \mathrm{p}<.05)$ and age $(\mathrm{b}=-.01, \mathrm{OR}=.99, \mathrm{p}$ $<$.01) had a significant main effects on recreational walking. However, the moderation hypothesis that age would moderate the effects of the built environment on walking was not supported, as there was not a significant interaction of perceptions of crime and safety and age on recreational walking $(\mathrm{b}=-.01, \mathrm{OR}=.99, \mathrm{~ns})$. 
Table 9. Moderating effects of perceptions of crime and safety and perceived neighborhood social cohesion, frequency of social interaction with neighbors, and age on utilitarian walking and recreational walking

\begin{tabular}{c|ccc}
\hline Utilitarian Walking & \multicolumn{3}{c}{ Recreational Walking } \\
\hline \multicolumn{3}{c|}{ Perceived Neighborhood Social Cohesion } \\
\hline $95 \% \quad 95 \%$ & $95 \%$ & $95 \%$
\end{tabular}

\begin{tabular}{llllll|lllllll}
$\mathrm{b}$ & $\mathrm{SE}$ & $\mathrm{p}$ & $\mathrm{OR}$ & $\mathrm{CI}$ & $\mathrm{CI}$ & $\mathrm{b}$ & $\mathrm{SE}$ & $\mathrm{p}$ & $\mathrm{OR}$ & $\mathrm{CI}$ & $\mathrm{CI}$
\end{tabular}

\begin{tabular}{llll} 
LCL UCL & LCL UCL \\
\hline
\end{tabular}

\begin{tabular}{|c|c|c|c|c|c|c|c|c|c|c|c|c|}
\hline $\begin{array}{l}\text { Crime and } \\
\text { safety }\end{array}$ & -.37 & .13 & .01 & .69 & .54 & .89 & -.12 & .13 & .34 & .89 & .69 & 1.14 \\
\hline Social cohesion & .06 & .13 & .63 & 1.07 & .82 & 1.39 & .26 & .13 & .05 & 1.29 & 1.00 & 1.68 \\
\hline $\begin{array}{l}\text { Land use mix x } \\
\text { Social cohesion }\end{array}$ & .05 & .15 & .74 & 1.05 & .78 & 1.42 & -.18 & .15 & .25 & .84 & .62 & 1.13 \\
\hline Age & -.03 & .01 & .001 & .97 & .96 & .99 & -.01 & .01 & .03 & .99 & .98 & 1.00 \\
\hline Minority & -.61 & .23 & .01 & .55 & .35 & .86 & -.03 & .21 & .90 & .97 & 64 & 1.48 \\
\hline Female & .01 & .18 & .94 & 1.01 & .71 & 1.45 & -.22 & .18 & .22 & .80 & .57 & 1.14 \\
\hline$\leq$ High school & -.15 & .18 & .41 & .86 & .60 & 1.23 & -.18 & .18 & .31 & .84 & .59 & 1.19 \\
\hline $\begin{array}{l}\text { In a } \\
\text { relationship }\end{array}$ & -.34 & .18 & .06 & .71 & .50 & 1.02 & .21 & .18 & .22 & 1.24 & .88 & 1.75 \\
\hline \multirow[t]{3}{*}{$\begin{array}{l}\text { Physical } \\
\text { functioning }\end{array}$} & .01 & .003 & .04 & 1.01 & 1.00 & 1.01 & .01 & .003 & .01 & 1.01 & 1.00 & 1.02 \\
\hline & \multicolumn{12}{|c|}{ Frequency of Social Interaction with Neighbors } \\
\hline & $\mathrm{b}$ & SE & $\mathrm{p}$ & OR & $\begin{array}{c}95 \% \\
\text { CI } \\
\text { LCL }\end{array}$ & $\begin{array}{c}95 \% \\
\text { CI } \\
\text { UCL }\end{array}$ & $\mathrm{b}$ & SE & $\mathrm{p}$ & OR & $\begin{array}{l}95 \% \\
\text { CI } \\
\text { LCL }\end{array}$ & $\begin{array}{c}95 \% \\
\text { CI } \\
\text { UCL }\end{array}$ \\
\hline $\begin{array}{l}\text { Crime and } \\
\text { safety }\end{array}$ & -.42 & .12 & .001 & .66 & .52 & .83 & -.22 & .12 & .06 & .80 & .64 & 1.01 \\
\hline $\begin{array}{l}\text { Social } \\
\text { interaction }\end{array}$ & .25 & .09 & .01 & 1.29 & 1.09 & 1.53 & .33 & .08 & .001 & 1.39 & 1.18 & 1.63 \\
\hline $\begin{array}{l}\text { Land use mix x } \\
\text { Social } \\
\text { interaction }\end{array}$ & -.10 & .11 & .38 & .91 & .72 & 1.13 & -.04 & .11 & .72 & .96 & .77 & 1.19 \\
\hline Age & -.03 & .01 & .001 & .97 & .96 & .99 & -.01 & .01 & .01 & .99 & .98 & 1.00 \\
\hline Minority & -.63 & .23 & .01 & .53 & .34 & .83 & -.11 & .21 & 60 & .89 & .59 & 1.36 \\
\hline Female & -.04 & .18 & .84 & .96 & .68 & 1.37 & -.18 & .17 & .30 & .83 & .59 & 1.17 \\
\hline$\leq$ High school & -.14 & .18 & .45 & .87 & .61 & 1.24 & -.20 & .18 & .26 & .82 & .58 & 1.16 \\
\hline $\begin{array}{l}\text { In a } \\
\text { relationship }\end{array}$ & -.40 & .18 & .03 & .67 & .47 & .96 & .12 & .17 & .49 & 1.13 & .80 & 1.59 \\
\hline \multirow[t]{3}{*}{$\begin{array}{l}\text { Physical } \\
\text { functioning }\end{array}$} & .01 & .003 & .07 & 1.01 & 1.00 & 1.01 & .01 & .003 & .01 & 1.01 & 1.00 & 1.02 \\
\hline & \multicolumn{12}{|c|}{ Age } \\
\hline & $\mathrm{b}$ & SE & $\mathrm{p}$ & OR & $\begin{array}{c}95 \% \\
\text { CI } \\
\text { LCL } \\
\end{array}$ & $\begin{array}{c}95 \% \\
\text { CI } \\
\text { UCL } \\
\end{array}$ & $\mathrm{b}$ & SE & $\mathrm{p}$ & OR & $\begin{array}{c}95 \% \\
\text { CI } \\
\text { LCL } \\
\end{array}$ & $\begin{array}{c}95 \% \\
\text { CI } \\
\text { UCL }\end{array}$ \\
\hline Crime & -.43 & .12 & .001 & .65 & .52 & .83 & -.23 & .12 & .04 & .79 & .63 & .99 \\
\hline Age & -.03 & .01 & .001 & .97 & .96 & .98 & -.01 & .01 & .01 & .99 & .98 & 1.00 \\
\hline Crime x Age & -.002 & .01 & .75 & 1.00 & .98 & 1.01 & -.01 & .01 & .41 & .99 & .98 & 1.01 \\
\hline Minority & -.50 & .22 & .02 & .61 & .39 & .94 & .01 & .21 & .98 & 1.01 & .67 & 1.51 \\
\hline Female & -.02 & .18 & .89 & .98 & .69 & 1.38 & -.20 & .17 & .25 & .82 & .59 & 1.15 \\
\hline$\leq$ High school & -.12 & .18 & .49 & .89 & .62 & 1.26 & -.17 & .17 & .32 & .84 & .60 & 1.18 \\
\hline $\begin{array}{l}\text { In a } \\
\text { relationship }\end{array}$ & -.38 & .18 & .04 & .69 & .48 & .98 & .18 & .17 & .31 & 1.19 & .85 & 1.67 \\
\hline $\begin{array}{l}\text { Physical } \\
\text { functioning }\end{array}$ & .01 & .003 & .06 & 1.01 & 1.00 & 1.01 & .01 & .003 & .01 & 1.01 & 1.00 & 1.02 \\
\hline
\end{tabular}




\section{Perceptions of Pedestrian Infrastructure and Safety}

The following six multiple logistic regression analyses were conducted to test the

hypotheses that perceived neighborhood social cohesion, frequency of social interaction with neighbors, and age would moderate the effects of perceptions of pedestrian infrastructure and safety on walking. The outcomes in these multiple logistic regression analyses were utilitarian walking and recreational walking (see 
Table 10).

\section{Perceptions of pedestrian infrastructure and safety and utilitarian walking -}

perceived neighborhood social cohesion. There was a significant interaction of

perceptions of pedestrian infrastructure and perceived neighborhood social cohesion on utilitarian walking $(\mathrm{b}=.42, \mathrm{OR}=1.53, \mathrm{p}<.05)$. Additionally, there were main effects for both perceptions of pedestrian infrastructure $(\mathrm{b}=-.35, \mathrm{OR}=.70, \mathrm{p}<.05)$ and perceived neighborhood social cohesion $(\mathrm{b}=.25, \mathrm{OR}=1.29, \mathrm{p}<.05)$. Age also had a significant effect on utilitarian walking $(\mathrm{b}=-.02, \mathrm{OR}=.98, \mathrm{p}<.001)$.

The interaction for the association between perceptions of pedestrian infrastructure and safety and utilitarian walking were plotted for low (one standard deviation below the mean) and high (one standard deviation above the mean) perceived neighborhood social cohesion. This plot depicts a difference in perceptions of pedestrian infrastructure and safety at different values of perceived neighborhood social cohesion. At one standard deviation above the mean for perceived neighborhood social cohesion, there was not a significant difference in utilitarian walking $(\mathrm{b}=-.05, \mathrm{OR}=.95$, ns). However, at one standard deviation below the mean of perceived neighborhood social cohesion, there was a significant difference in utilitarian walking $(\mathrm{b}=-.66, \mathrm{OR}=.52, \mathrm{p}<.01)$ (see Figure 9). 
Figure 9. Simple slopes for utilitarian walking on perceptions of pedestrian infrastructure at values of perceived neighborhood social cohesion

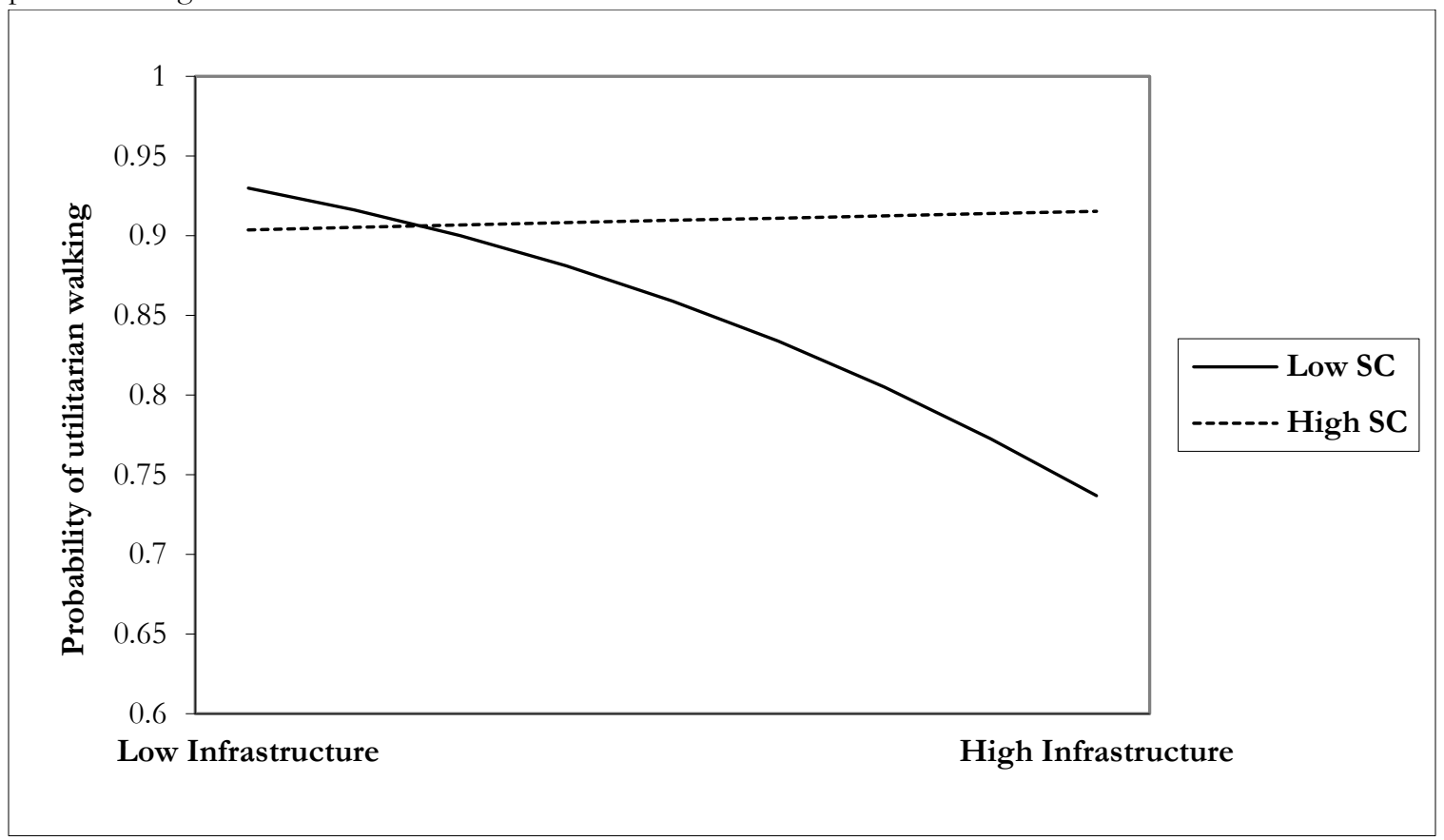

Note: Low $=$ minus $1 \mathrm{SD}$, High = plus $1 \mathrm{SD} ; \mathrm{y}$-axis truncated to provide clear indication of relationship

\section{Perceptions of pedestrian infrastructure and safety and utilitarian walking -}

frequency of social interaction with neighbors. There was a marginally significant

interaction between perceptions of pedestrian infrastructure and frequency of social

interaction with neighbors on utilitarian walking $(\mathrm{b}=.28, \mathrm{OR}=1.32, \mathrm{p}=.08)$, as well as

main effects for both perceptions of pedestrian infrastructure $(b=-.34, \mathrm{OR}=.72, \mathrm{p}<.05)$

and frequency of social interaction with neighbors $(\mathrm{b}=.23, \mathrm{OR}=1.25, \mathrm{p}<.01)$. Age also

significantly predicted utilitarian walking $(\mathrm{b}=-.03, \mathrm{OR}=.98, \mathrm{p}<.001)$.

The interaction for the association between perceptions of pedestrian infrastructure

and safety and utilitarian walking was plotted for low (one standard deviation below the mean) and high (one standard deviation above the mean) frequency of social interaction with neighbors. This plot depicts a difference in perceptions of pedestrian infrastructure and 
safety at different values of frequency of social interaction with neighbors. At one standard deviation above the mean for frequency of social interaction with neighbors, there was not a significant difference in utilitarian walking $(\mathrm{b}=-.05$, OR $=.95$, ns). However, at one standard deviation below the mean of perceived neighborhood social cohesion, there was a significant difference in utilitarian walking $(\mathrm{b}=-.63, \mathrm{OR}=.53, \mathrm{p}<.01)$ (see Figure 10Error!

Figure 10. Simple slopes for utilitarian walking on perceptions of pedestrian infrastructure and safety at values of frequency of social interaction with neighbors

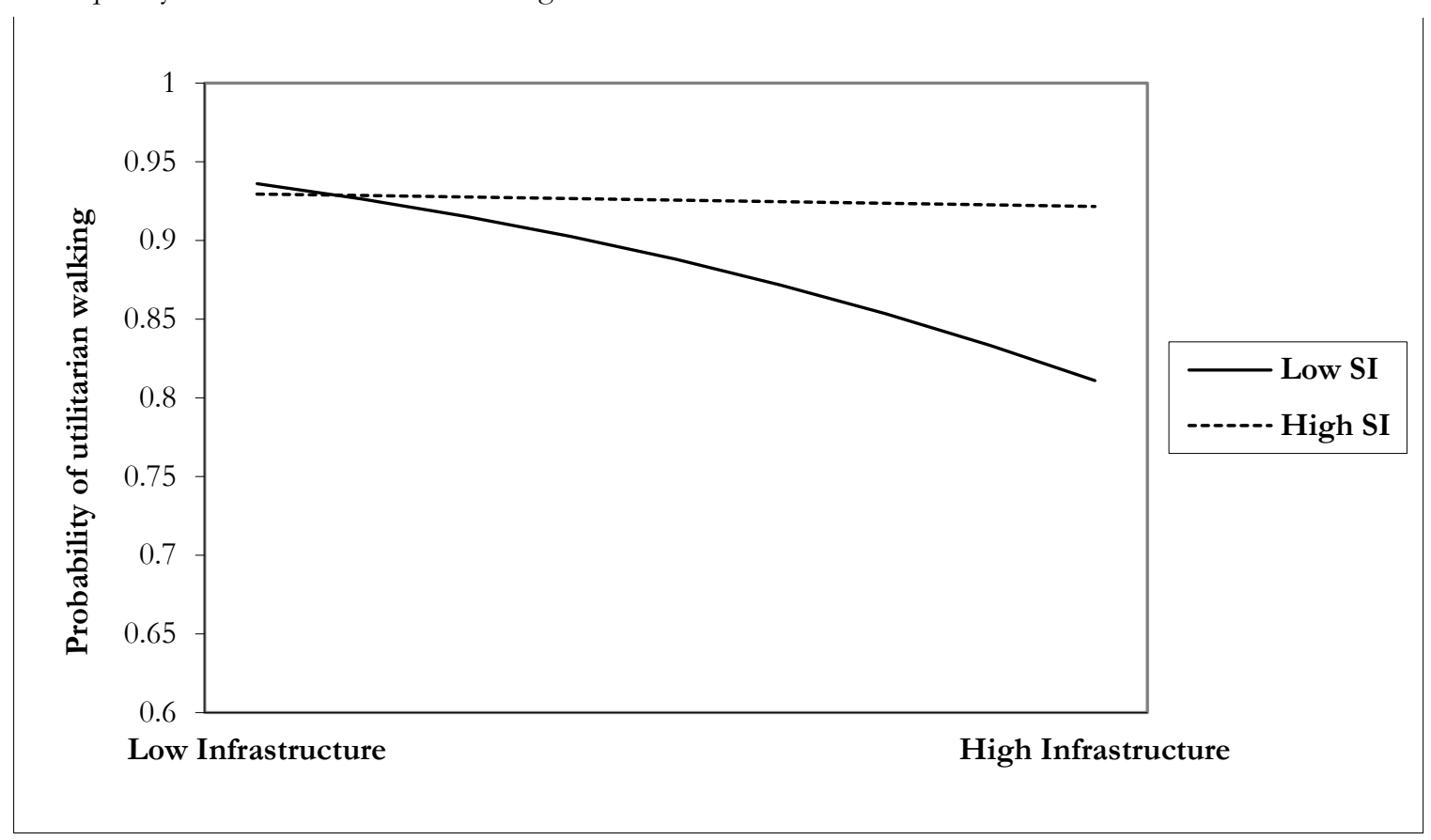

\section{Reference source not found.).}

Note: Low $=$ minus $1 \mathrm{SD}$, High $=$ plus $1 \mathrm{SD} ; \mathrm{y}$-axis truncated to provide clear indication of relationship

\section{Perceptions of pedestrian infrastructure and safety and utilitarian walking -}

age. Perceptions of pedestrian infrastructure $(b=-.29, \mathrm{OR}=.75, \mathrm{p}=.07)$ and age $(\mathrm{b}=$ $.03, \mathrm{OR}=.98, \mathrm{p}<.001)$ had main effects on utilitarian walking, but there was no evidence of a statistical interaction perceptions of pedestrian infrastructure and age on utilitarian walking $(\mathrm{b}=-.01, \mathrm{OR}=1.00, \mathrm{~ns})$. 


\section{Perceptions of pedestrian infrastructure and safety and recreational walking -}

perceived neighborhood social cohesion. In predicting recreational walking, there was a main effect for perceived neighborhood social cohesion $(\mathrm{b}=.28$, OR $=1.32, \mathrm{p}<.05)$ but not for perceptions of pedestrian infrastructure $(\mathrm{b}=-.16, \mathrm{OR}=.86, \mathrm{~ns})$. Age had an indirect effect on recreational walking $(\mathrm{b}=-.02, \mathrm{OR}=.99, \mathrm{p}<.01)$. There was no interaction effect for perceptions of pedestrian infrastructure and perceived neighborhood social cohesion on recreational walking $(\mathrm{b}=.03, \mathrm{OR}=1.03, \mathrm{~ns})$.

Perceptions of pedestrian infrastructure and safety and recreational walking frequency of social interaction with neighbors. Recreational walking was predicted by frequency of social interaction with neighbors $(\mathrm{b}=.40, \mathrm{OR}=1.49, \mathrm{p}<.001)$ but not by perceptions of pedestrian infrastructure $(\mathrm{b}=-.16, \mathrm{OR}=.86, \mathrm{~ns})$. Age significantly predicted recreational walking $(\mathrm{b}=-.02, \mathrm{OR}=.98, \mathrm{p}<.01)$. There was no evidence of an interaction effect of frequency of social interaction with neighbors and perceptions of pedestrian infrastructure on recreational walking $(\mathrm{b}=-.12, \mathrm{OR}=.89$, ns).

Perceptions of pedestrian infrastructure and safety and recreational walking age. While age predicted recreational walking $(b=-.02, \mathrm{OR}=.98, \mathrm{p}<.01)$, there was no significant effect for perceptions of pedestrian infrastructure on recreational walking $(b=-$ $.08, \mathrm{OR}=.93, \mathrm{~ns})$. 
Table 10. Moderating effects of perceptions of pedestrian infrastructure and safety and perceived neighborhood social cohesion, frequency of social interaction with neighbors, and age on utilitarian walking and recreational walking

\begin{tabular}{|c|c|c|c|c|c|c|c|c|c|c|c|c|}
\hline & \multicolumn{6}{|c|}{ Utilitarian Walking } & \multicolumn{6}{|c|}{ Recreational Walking } \\
\hline & \multicolumn{12}{|c|}{ Perceived Neighborhood Social Cohesion } \\
\hline & $\mathrm{b}$ & SE & $\mathrm{p}$ & OR & $\begin{array}{c}95 \% \\
\text { CI } \\
\text { LCL }\end{array}$ & $\begin{array}{c}95 \% \\
\text { CI } \\
\text { UCL }\end{array}$ & $\mathrm{b}$ & SE & $\mathrm{p}$ & OR & $\begin{array}{c}95 \% \\
\text { CI } \\
\text { LCL }\end{array}$ & $\begin{array}{c}95 \% \\
\text { CI } \\
\text { UCL }\end{array}$ \\
\hline Infrastructure & -.35 & .17 & .04 & .70 & .50 & .98 & -.16 & .16 & .34 & .85 & .62 & 1.18 \\
\hline Social cohesion & .25 & .13 & .05 & 1.29 & 1.00 & 1.65 & .28 & .12 & .03 & 1.32 & 1.03 & 1.68 \\
\hline $\begin{array}{l}\text { Infrastructure } \mathrm{x} \\
\text { Social cohesion }\end{array}$ & .42 & .21 & .05 & 1.53 & 1.01 & 2.33 & .03 & .19 & .89 & 1.03 & .70 & 1.50 \\
\hline Age & -.02 & .01 & .001 & .98 & .96 & .99 & -.02 & .01 & .01 & .98 & .97 & 1.00 \\
\hline Minority & -.71 & .24 & .01 & .49 & .31 & .79 & -.06 & .22 & .80 & .95 & .62 & 1.45 \\
\hline Female & -.01 & .19 & .95 & .99 & .69 & 1.43 & -.14 & .18 & .43 & .87 & .61 & 1.24 \\
\hline$\leq$ High school & -.16 & .19 & .41 & .86 & .59 & 1.24 & -.17 & .18 & .35 & .84 & .59 & 1.21 \\
\hline In a relationship & -.35 & .19 & .07 & .70 & .49 & 1.02 & .18 & .18 & .33 & 1.19 & .84 & 1.70 \\
\hline \multirow[t]{3}{*}{$\begin{array}{l}\text { Physical } \\
\text { functioning }\end{array}$} & .01 & .004 & .01 & 1.01 & 1.00 & 1.02 & .01 & .003 & .01 & 1.01 & 1.00 & 1.02 \\
\hline & \multicolumn{12}{|c|}{ Frequency of Social Interaction with Neighbors } \\
\hline & $\mathrm{b}$ & SE & $\mathrm{p}$ & OR & $\begin{array}{c}95 \% \\
\text { CI } \\
\text { LCL }\end{array}$ & $\begin{array}{c}95 \% \\
\text { CI } \\
\text { UCL }\end{array}$ & $\mathrm{b}$ & SE & $\mathrm{p}$ & OR & $\begin{array}{c}95 \% \\
\text { CI } \\
\text { LCL }\end{array}$ & $\begin{array}{c}95 \% \\
\text { CI } \\
\text { UCL }\end{array}$ \\
\hline Infrastructure & -.34 & .16 & .04 & .71 & .52 & .98 & -.16 & .16 & .33 & .86 & .63 & 1.17 \\
\hline $\begin{array}{l}\text { Social } \\
\text { interaction } \\
\text { Infrastructure } \mathrm{x}\end{array}$ & .23 & .09 & .01 & 1.25 & 1.05 & 1.49 & .40 & .09 & .001 & 1.49 & 1.26 & 1.77 \\
\hline $\begin{array}{l}\text { Social } \\
\text { interaction }\end{array}$ & .28 & .16 & .08 & 1.32 & .97 & 1.80 & -.12 & .15 & .42 & .89 & .66 & 1.19 \\
\hline Age & -.02 & .01 & .001 & .98 & .96 & .99 & -.02 & .01 & .01 & .98 & .97 & .99 \\
\hline Minority & -.71 & .24 & .01 & .49 & .31 & .78 & -.12 & .22 & .58 & .89 & .58 & 1.36 \\
\hline Female & -.03 & .18 & .85 & .97 & .67 & 1.38 & -.07 & .18 & .69 & .93 & .66 & 1.32 \\
\hline$\leq$ High school & -.14 & .19 & .46 & .87 & .60 & 1.26 & -.22 & .18 & .24 & .81 & .56 & 1.15 \\
\hline In a relationship & -.38 & .19 & .04 & .68 & .47 & .98 & .07 & .18 & .68 & 1.08 & .76 & 1.53 \\
\hline \multirow[t]{3}{*}{$\begin{array}{l}\text { Physical } \\
\text { functioning }\end{array}$} & .01 & .004 & .01 & 1.01 & 1.00 & 1.02 & .01 & .003 & .01 & 1.01 & 1.00 & 1.02 \\
\hline & \multicolumn{12}{|c|}{ Age } \\
\hline & $\mathrm{b}$ & SE & $\mathrm{p}$ & OR & $\begin{array}{c}95 \% \\
\text { CI } \\
\text { LCL }\end{array}$ & $\begin{array}{c}95 \% \\
\text { CI } \\
\text { UCL }\end{array}$ & $\mathrm{b}$ & SE & $\mathrm{p}$ & OR & $\begin{array}{c}95 \% \\
\text { CI } \\
\mathrm{LCL}\end{array}$ & $\begin{array}{c}95 \% \\
\text { CI } \\
\text { UCL }\end{array}$ \\
\hline Infrastructure & -.29 & .16 & .07 & .75 & .55 & 1.02 & -.08 & .16 & .62 & .93 & .68 & 1.26 \\
\hline Age & -.03 & .01 & .001 & .98 & .96 & .99 & -.02 & .01 & .01 & .98 & .97 & .99 \\
\hline $\begin{array}{l}\text { Infrastructure } x \\
\text { Age }\end{array}$ & -.005 & .01 & .63 & 1.00 & .98 & 1.01 & -.002 & .01 & .85 & 1.00 & .98 & 1.02 \\
\hline Minority & -.62 & .23 & .01 & .54 & .34 & .84 & .01 & .21 & .97 & 1.01 & .67 & 1.52 \\
\hline Female & -.02 & .18 & .92 & .98 & .69 & 1.40 & -.06 & .18 & .73 & .94 & .67 & 1.33 \\
\hline$\leq$ High school & -.11 & .18 & .55 & .90 & .62 & 1.29 & -.18 & .18 & .32 & .84 & .59 & 1.19 \\
\hline In a relationship & -.34 & .18 & .07 & .72 & .50 & 1.03 & .14 & .18 & .42 & 1.15 & .82 & 1.63 \\
\hline $\begin{array}{l}\text { Physical } \\
\text { functioning }\end{array}$ & .01 & .003 & .01 & 1.01 & 1.00 & 1.02 & .01 & .003 & .01 & 1.01 & 1.00 & 1.02 \\
\hline
\end{tabular}




\section{The Effects of the Built Environment on Total Monthly Walking Trips as Mediated by Perceived Neighborhood Social Cohesion and Frequency of Social Interaction with Neighbors}

The following eight regression analyses were conducted to test the hypotheses that perceived neighborhood social cohesion and social interaction with neighbors would mediate the effects of the built environment - perceptions of land use mix, perceptions of aesthetics, perceptions of crime and safety, perceptions of pedestrian infrastructure and safety - on walking. The outcome in these eight analyses was total monthly walking trips. All independent effects were considered statistically significant and worthy of reporting if the pvalue was .10 or less, as p-values greater than .05 and less than .10 are sometimes reported as ‘approaching significance'. Covariates in all of the models included age, functional ability, race/ethnicity, gender, educational attainment, relationship status, and physical functioning.

\section{Perceptions of Land Use Mix and Perceived Neighborhood Social Cohesion as}

\section{Mediator}

A direct effect was found between perceptions of land use mix on total monthly walking trips $(\mathrm{b}=4.83, \beta=.11, \mathrm{p}<.01)$. Perceptions of land use mix significantly predicted perceived neighborhood social cohesion $(\mathrm{b}=.19, \beta=.19, \mathrm{p}<.001)$. The mediator, perceived neighborhood social cohesion, predicted total monthly walking trips $(b=4.27, \beta$ $=.10, \mathrm{p}<.01)$. When both perceptions of land use mix and perceived neighborhood social cohesion were included in the model, the significance of perceptions of land use mix decreased, indicating support for the hypothesis consistent with partial mediation $(b=4.32$, $\beta=.10, \mathrm{p}<.05)$. Age significantly predicted total monthly walking trips $(\mathrm{b}=-.31, \beta=-.17$, $\mathrm{p}<.001)$ 
A test of indirect effects using bootstrap estimation indicated the indirect coefficient was significant $(\mathrm{b}=.73, \mathrm{SE}=.38, \mathrm{CI}=.0900,1.6493)$. Perceptions of land use mix was associated with .73 more total monthly walking trips as mediated by perceived neighborhood social cohesion.

\section{Perceptions of Land Use Mix and Frequency of Social Interaction with Neighbors as}

\section{Mediator}

The mediation hypothesis was not supported in the relationship between perceptions of land use mix and frequency of social interaction with neighbors on total monthly walking trips as perceptions of land use mix did not predict frequency of social interaction with neighbors $(b=.08, \beta=.06, \mathrm{~ns})$.

\section{Perceptions of Aesthetics and Perceived Neighborhood Social Cohesion as Mediator}

A direct effect was found between perceptions of aesthetics on total monthly walking trips $(b=8.29, \beta=.18, p<.001)$. In testing the relationship between the independent variable and the hypothesized mediator, perceptions of aesthetics predicted perceived neighborhood social cohesion $(\mathrm{b}=.40, \beta=.38, \mathrm{p}<.001)$. Perceived neighborhood social cohesion predicted total monthly walking trips $(b=4.27, \beta=.10, p<$ .01). When both perceptions of aesthetics and perceived neighborhood social cohesion were entered into the model predicting total monthly walking trips, perceptions of aesthetics remained significant $(\mathrm{b}=8.39, \beta=.18, \mathrm{p}<.001)$, but the perceived neighborhood social cohesion was no longer significant $(b=1.02, \beta=.02$, ns). Thus, the mediation hypothesis was not supported by these results. 


\section{Perceptions of Aesthetics and Frequency of Social Interaction as Mediator}

A direct effect was found between perceptions of aesthetics on total monthly walking trips $(b=8.29, \beta=.18, \mathrm{p}<.000002)$. When predicting the hypothesized mediator, perceptions of aesthetics significantly predicted frequency of social interaction with neighbors $(b=.14, \beta=.09, \mathrm{p}<.05)$. The relationship between frequency social interaction with neighbors and total monthly walking trips was also significant $(b=4.01, \beta=.13, p<$ .001). With both perceptions of aesthetics and frequency of social interaction with neighbors in the model predicting total monthly walking trips, perceptions of aesthetics remained significant but did decrease $(\mathrm{b}=7.82, \beta=.17, \mathrm{p}<.000007)$, and frequency of social interaction with neighbors significantly predicted total monthly walking trips $(b=3.40, \beta=$ $.11, \mathrm{p}<.01)$. These results were consistent with partial mediation.

A test of indirect effects using bootstrap estimation indicated the indirect coefficient was significant $(\mathrm{b}=.45, \mathrm{SE}=.24, \mathrm{CI}=.0749,1.0304)$. Perceptions of aesthetics was associated with .45 more total monthly walking trips as mediated by frequency of social interaction with neighbors.

\section{Perceptions of Crime and Safety and Perceptions of Pedestrian Infrastructure and}

\section{Safety}

Neither perceptions of crime and safety $(\mathrm{b}=-2.40, \beta=-.06$, ns) nor perceptions of pedestrian infrastructure and safety $(\mathrm{b}=.47, \beta=.01, \mathrm{~ns})$ directly predicted total monthly walking trips. As a result, further tests of the hypotheses that perceived neighborhood social cohesion and frequency of social interaction with neighbors were mediators in the relationship between crime and safety and pedestrian infrastructure and safety, as dimensions of the built environment, and total monthly walking trips were terminated. 


\section{The Effect of the Built Environment on Total Monthly Walking Trips as Moderated by Perceived Neighborhood Social Cohesion, Frequency of Social Interaction with Neighbors, and Age}

The following multiple linear regression models examined the extent to which perceived neighborhood social cohesion, frequency of social interaction, and age moderated the effect of the built environment on the total number of walking trips per month. The dimension of the built environment functioning as independent variables are perceptions of land use mix, perceptions of aesthetics, perceptions of crime and safety, and perceptions of pedestrian infrastructure and safety. Covariates in the model included age, race/ethnicity, gender, educational attainment, relationship status, and physical functioning.

\section{Perceptions of Land Use Mix}

The following three multiple linear regression analyses were conducted to test the hypotheses that perceived neighborhood social cohesion, frequency of social interaction with neighbors, and age would moderate the effects of perceptions of land use mix on walking. The outcome in these multiple linear regression analyses were total monthly walking trips (see Table 11).

\section{Perceptions of land use mix and total monthly walking trips - perceived}

neighborhood social cohesion. In predicting total monthly walking trips, both perceptions of land use mix $(b=4.35, \beta=.10, \mathrm{p}<.01)$ and perceived neighborhood social cohesion $(\mathrm{b}$ $=3.92, \beta=.10, \mathrm{p}<.05)$ independently predicted total monthly walking trips, but there was not a statistical interaction of perceptions of land use mix and perceived neighborhood social cohesion on total monthly walking trips $(\mathrm{b}=1.62, \beta=.03$, ns). These findings suggest that both land use mix and social cohesion are important predictors of walking, but that they function independently of one another. Age significantly predicted total monthly walking 
trips $(\mathrm{b}=-.31, \beta=-.17, \mathrm{p}<.001)$, which indicated that age was associated with less walking over the course of a month.

\section{Perceptions of land use mix and total monthly walking trips - frequency of}

social interaction with neighbors. Both perceptions of land use mix $(b=4.31, \beta=.10, p$ $<.01)$ and frequency of social interaction with neighbors $(b=3.83, \beta=.13, p<.001)$ had significant main effects on total monthly walking trips. Additionally, there was evidence of a significant interaction of the two variables $(b=4.08, \beta=.10, p<.01)$, indicating that the effect of frequency of social interaction with neighbors on total monthly walking trips was not the same for all values of perceptions of land use mix. Age also significantly predicted total monthly walking trips $(\mathrm{b}=-.29, \beta=-.16, \mathrm{p}<.001)$, suggesting that older adults walked less overall as compared to younger adults.

Simple slopes for the association between perceptions of land use mix and total monthly walking trips were tested for low (one standard deviation below the mean), moderate (mean), and high (one standard deviation above the mean) frequency of social interaction with neighbors. The simple slope tests revealed a significant positive association between perceptions of land use mix and total monthly walking trips at medium and high levels of frequency of social interaction with neighbors. Perceptions of land use mix was more strongly related to high levels frequency of social interaction with neighbors $(b=8.47$, $\beta=.20, \mathrm{p}<.001)$ than for moderate levels of frequency of social interaction with neighbors $(b=4.30, \beta=.10, p<.01)($ see Figure 11$)$. 
Figure 11. Simple slopes for total monthly walking trips on perceptions of land use mix at values of frequency of social interaction with neighbors

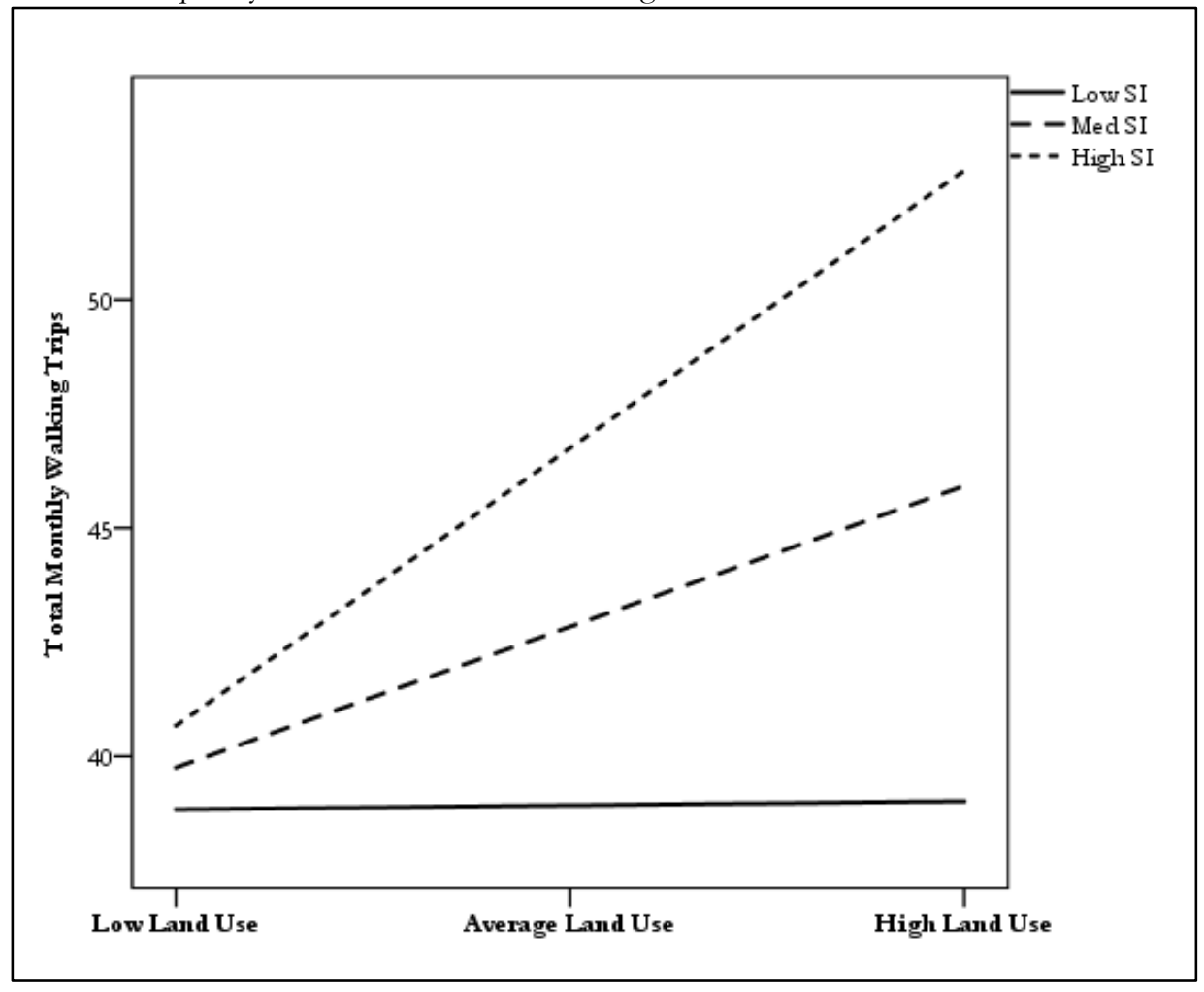

Perceptions of land use mix and total monthly walking trips - age. Both

perceptions of land use mix $(b=4.76, \beta=.11, p<.01)$ and age $(b=-.31, \beta=-.17, p<.001)$ independently predicted total monthly walking trips, but there was no statistical interaction of the two on total monthly walking trips $(b=.06, \beta=.03$, ns). 
Table 11. Moderating effects of perceptions of land use mix and perceived neighborhood social cohesion, frequency of social interaction with neighbors, and age on total monthly walking trips

\begin{tabular}{|c|c|c|c|c|c|}
\hline & \multicolumn{5}{|c|}{ Perceived neighborhood social cohesion } \\
\hline & $\mathrm{b}$ & $\mathrm{SE}$ & $\beta$ & $\mathrm{t}$ & $\mathrm{p}$ \\
\hline Land use mix & 4.35 & 1.77 & .10 & 2.46 & .01 \\
\hline Social cohesion & 3.92 & 1.69 & .09 & 2.32 & .02 \\
\hline Land use mix x Social cohesion & 1.62 & 2.14 & .03 & .76 & .45 \\
\hline Age & -.31 & .08 & -.17 & -3.78 & .001 \\
\hline Minority & -6.62 & 2.98 & -.09 & -2.22 & .03 \\
\hline Female & -.17 & 2.45 & -.003 & -.07 & .94 \\
\hline$\leq$ High school & 3.76 & 2.53 & .06 & 1.49 & .14 \\
\hline In a relationship & -7.27 & 2.46 & -.12 & -2.96 & .01 \\
\hline \multirow[t]{3}{*}{ Physical functioning } & .06 & .05 & .05 & 1.23 & .22 \\
\hline & \multicolumn{5}{|c|}{ Frequency of social interaction with neighbors } \\
\hline & $\mathrm{b}$ & $\mathrm{SE}$ & $\beta$ & $\mathrm{t}$ & $\mathrm{p}$ \\
\hline Land use mix & 4.31 & 1.67 & .10 & 2.58 & .01 \\
\hline Social interaction & 3.83 & 1.14 & .13 & 3.37 & .001 \\
\hline Land use mix x Social interaction & 4.08 & 1.56 & .10 & 2.62 & .01 \\
\hline Age & -.29 & .08 & -.16 & -3.72 & .001 \\
\hline Minority & -7.73 & 2.89 & -.10 & -2.68 & .01 \\
\hline Female & .02 & 2.37 & .0003 & .01 & .99 \\
\hline$\leq$ High school & 3.98 & 2.43 & .06 & 1.64 & .10 \\
\hline In a relationship & -7.95 & 2.39 & -.13 & -3.33 & .001 \\
\hline \multirow[t]{3}{*}{ Physical functioning } & .06 & .05 & .05 & 1.27 & .20 \\
\hline & \multicolumn{5}{|c|}{ Age } \\
\hline & $\mathrm{b}$ & SE & $\beta$ & $\mathrm{t}$ & $\mathrm{p}$ \\
\hline Land use mix & 4.76 & 1.68 & .11 & 2.83 & .01 \\
\hline Age & -.31 & .08 & -.17 & -3.95 & .001 \\
\hline Land use mix x Age & .06 & .09 & .03 & .65 & .52 \\
\hline Minority & -6.16 & 2.88 & -.08 & -2.14 & .03 \\
\hline Female & -.31 & 2.39 & -.005 & -.13 & .90 \\
\hline$\leq$ High school & 4.63 & 2.45 & .07 & 1.89 & .06 \\
\hline In a relationship & -7.55 & 2.40 & -.12 & -3.15 & .01 \\
\hline Physical functioning & .06 & .05 & .05 & 1.19 & .23 \\
\hline
\end{tabular}

\section{Perceptions of Aesthetics}

The following three multiple linear regression analyses were conducted to test the hypotheses that perceived neighborhood social cohesion, frequency of social interaction with neighbors, and age would moderate the effects of perceptions of aesthetics on walking. The outcome in these multiple linear regression analyses was total monthly walking trips (see Table 12). 


\section{Perceptions of aesthetics and total monthly walking trips - perceived}

neighborhood social cohesion. Perceptions of aesthetics significantly predicted total monthly walking trips $(\mathrm{b}=8.37, \beta=.18, \mathrm{p}<.001)$, but there was an absence of a main effect for perceived neighborhood social cohesion on total monthly walking trips $(b=1.59$, $\beta=.04$, ns). Additionally, there was a significant interaction of perceptions of aesthetics and perceived neighborhood social cohesion total monthly walking trips $(b=5.66, \beta=.09, p<$ $.05)$, and thus there was sufficient evidence to examine the moderation hypothesis more closely. Age was a significant predictor of total monthly walking trips $(b=-.31, \beta=-.17, p<$ .001), such that less walking occurred with increasing age.

Simple slopes for the association between perceptions of aesthetics and total monthly walking trips were tested for low (one standard deviation below the mean), average (mean), and high (one standard deviation above the mean) perceived neighborhood social cohesion. The simple slope tests revealed a significant positive association between perceptions of aesthetics and total monthly walking trips at all levels of the moderator. Perceptions of aesthetics was most strongly related to high $(\mathrm{b}=12.45, \beta=.27, \mathrm{p}<.001)$ and moderate levels of perceived neighborhood social cohesion $(b=8.39, \beta=.18, \mathrm{p}<.001)$, and marginally related to low levels of perceived neighborhood social cohesion $(b=4.34$, $\beta$ $=.09, \mathrm{p}=.09)$ (see Figure 12). 
Figure 12. Simple slopes for total monthly walking trips on perceptions of aesthetics at values of perceived neighborhood social cohesion

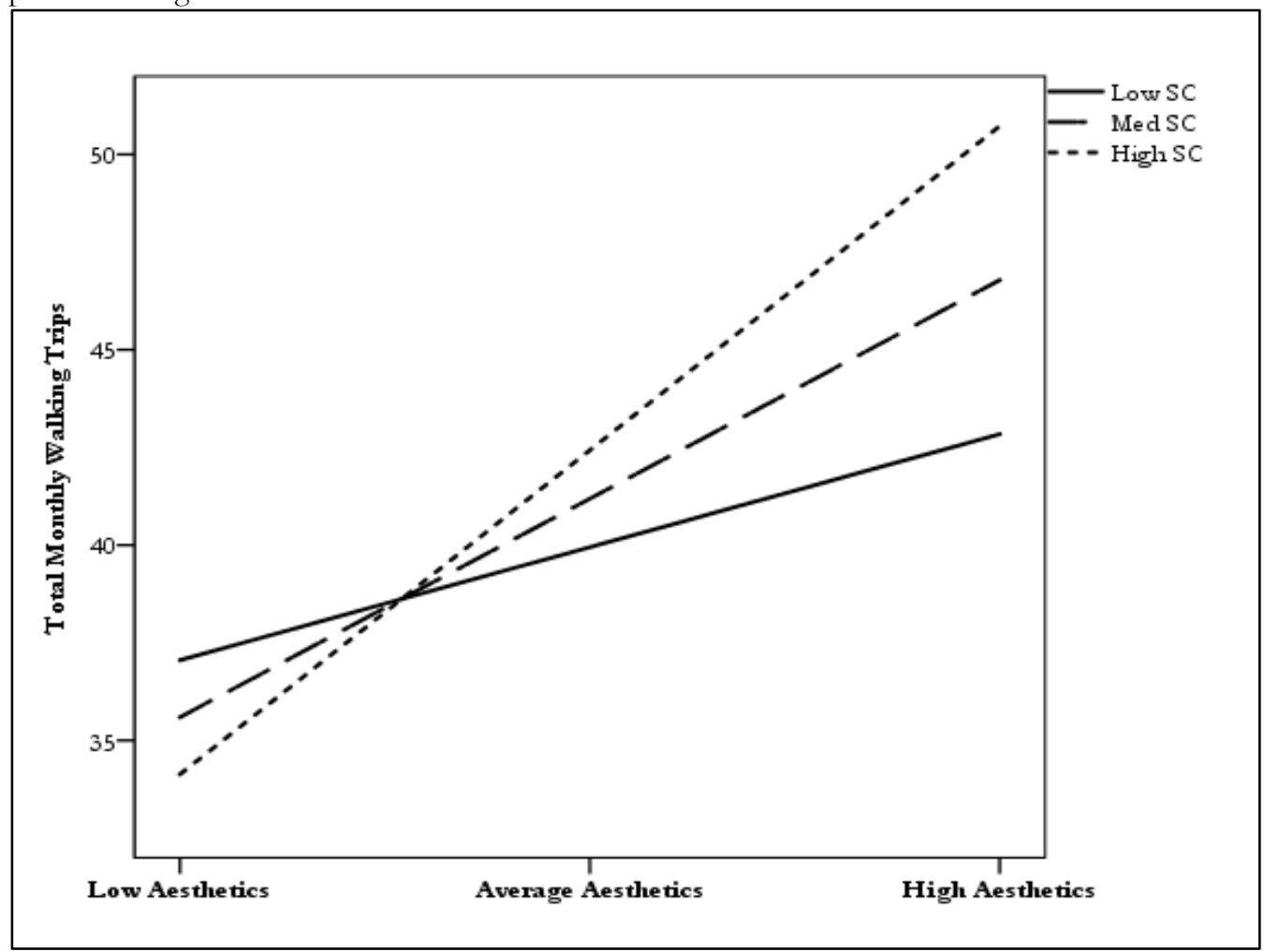

Perceptions of aesthetics and total monthly walking trips - frequency of social interaction with neighbors. While both perceptions of aesthetics $(b=8.02, \beta=.17, p<$ $.001)$ and frequency of social interaction with neighbors $(b=3.46, \beta=.11, p=.003)$ predicted total monthly walking trips, there was no statistical interaction. Age was also a significant predictor of total monthly walking trips $(\mathrm{b}=-.32, \beta=-.17, \mathrm{p}<.001)$.

Perceptions of aesthetics and total monthly walking trips - age. Both increased positive perceptions of aesthetics $(b=8.24, \beta=.18, \mathrm{p}<.001)$ and age $(\mathrm{b}=-.33, \beta=-.18, \mathrm{p}$ $<$.001) predicted the number of times respondents walked per month. However, there was no evidence of a moderation hypothesis, as there was no statistical interaction of perceptions of aesthetics and age on total monthly walking trips $(b=.04, \beta=.01, \mathrm{~ns})$. 
Table 12. Moderating effects of perceptions of aesthetics and perceived neighborhood social cohesion, frequency of social interaction with neighbors, and age on total monthly walking trips

\begin{tabular}{|c|c|c|c|c|c|}
\hline & \multicolumn{5}{|c|}{ Perceived neighborhood social cohesion } \\
\hline & $\mathrm{b}$ & $\mathrm{SE}$ & $\beta$ & $\mathrm{t}$ & $\mathrm{p}$ \\
\hline Aesthetics & 8.37 & 1.91 & .18 & 4.39 & .001 \\
\hline Social cohesion & 1.59 & 1.79 & .04 & .89 & .38 \\
\hline Aesthetics x Social cohesion & 5.66 & 2.33 & .09 & 2.42 & .02 \\
\hline Age & -.31 & .08 & -.17 & -3.89 & .001 \\
\hline Minority & -7.43 & 2.93 & -.10 & -2.53 & .01 \\
\hline Female & -.96 & 2.43 & -.02 & -.39 & .69 \\
\hline$\leq$ High school & 3.52 & 2.49 & .05 & 1.42 & .16 \\
\hline In a relationship & -7.09 & 2.45 & -.11 & -2.90 & .01 \\
\hline \multirow[t]{3}{*}{ Physical functioning } & .09 & .05 & .08 & 1.85 & .07 \\
\hline & \multicolumn{5}{|c|}{ Frequency of social interaction with neighbors } \\
\hline & $\mathrm{b}$ & $\mathrm{SE}$ & $\beta$ & $\mathrm{t}$ & $\mathrm{p}$ \\
\hline Aesthetics & 8.02 & 1.72 & .17 & 4.66 & .001 \\
\hline Social interaction & 3.46 & 1.15 & .11 & 3.02 & .01 \\
\hline Aesthetics x Social interaction & 2.57 & 1.61 & .06 & 1.60 & .11 \\
\hline Age & -.32 & .08 & -.17 & -4.14 & .001 \\
\hline Race/ethnicity & -7.87 & 2.86 & -.11 & -2.75 & .01 \\
\hline Female & -.84 & 2.37 & -.01 & -.35 & .72 \\
\hline$\leq$ High school & 3.85 & 2.42 & .06 & 1.59 & .11 \\
\hline$\overline{\text { In }}$ a relationship & -7.56 & 2.39 & -.12 & -3.17 & .01 \\
\hline \multirow[t]{3}{*}{ Physical functioning } & .08 & .05 & .08 & 1.80 & .07 \\
\hline & \multicolumn{5}{|c|}{ Age } \\
\hline & $\mathrm{b}$ & SE & $\beta$ & $\mathrm{t}$ & $p$ \\
\hline Aesthetics & 8.24 & 1.72 & .18 & 4.79 & .001 \\
\hline Age & -.33 & .08 & -.18 & -4.27 & .001 \\
\hline Aesthetics x Age & .04 & .10 & .01 & .36 & .72 \\
\hline Race/ethnicity & -6.91 & 2.85 & -.09 & -2.43 & .02 \\
\hline Female & -.94 & 2.38 & -.02 & -.40 & .69 \\
\hline$\leq$ High school & 4.20 & 2.44 & .07 & 1.72 & .09 \\
\hline In a relationship & -6.87 & 2.39 & -.11 & -2.88 & .01 \\
\hline Physical functioning & .09 & .05 & .08 & 2.01 & .05 \\
\hline
\end{tabular}

\section{Perceptions of Crime and Safety}

The following three multiple linear regression analyses were conducted to test the hypotheses that perceived neighborhood social cohesion, frequency of social interaction with neighbors, and age would moderate the effects of perceptions of crime and safety on walking. The outcome in these multiple linear regression analyses was total monthly walking trips (see Table 13). 


\section{Perceptions of aesthetics and total monthly walking trips - perceived}

neighborhood social cohesion. Perceived neighborhood social cohesion predicted total monthly walking trips $(\mathrm{b}=4.46, \beta=.10, \mathrm{p}<.05)$, but there was not a main effect for perceptions of crime and safety and no evidence of moderation. Age significantly predicted total monthly walking trips $(\mathrm{b}=-.34, \beta=-.18, \mathrm{p}<.001)$.

Perceptions of aesthetics and total monthly walking trips - frequency of social interaction with neighbors. Perceptions of crime and safety did not have a significant main effect on total monthly walking trips $(\mathrm{b}=-2.11, \beta=-.05$, ns), but there was a significant main effect for frequency of social interaction with neighbors $(b=4.05, \beta=.13, p<.001)$. There was no evidence of an interaction of the two on total monthly walking trips. Age significantly predicted total monthly walking trips $(b=-.33, \beta=-.18, \mathrm{p}<.001)$.

Perceptions of aesthetics and total monthly walking trips - age. Only age had a significant main effect on total monthly walking trips $(b=-.35, \beta=-.19, \mathrm{p}<.001)$, not perceptions of crime and safety $(b=-2.46, \beta=-.06, \mathrm{~ns})$. There was no evidence to support the hypothesis that age would moderate the effects of crime and safety on walking, as there was no significant interaction of perceptions of crime and safety and age in predicting total monthly walking trips $(\mathrm{b}=-.08, \beta=-.03$, ns). 
Table 13. Moderating effects of perceptions of crime and safety and perceived neighborhood social cohesion, frequency of social interaction with neighbors, and age on total monthly walking trips

\begin{tabular}{|c|c|c|c|c|c|}
\hline & \multicolumn{5}{|c|}{ Perceived neighborhood social cohesion } \\
\hline & $\mathrm{b}$ & $\mathrm{SE}$ & $\beta$ & $\mathrm{t}$ & $\mathrm{p}$ \\
\hline Crime and safety & -.33 & 1.78 & -.01 & -.19 & .85 \\
\hline Social cohesion & 4.46 & 1.85 & .10 & 2.41 & .02 \\
\hline Crime x Social cohesion & -2.07 & 2.12 & -.04 & -.98 & .33 \\
\hline Age & -.34 & .08 & -.18 & -4.13 & .001 \\
\hline Minority & -7.12 & 3.00 & -.09 & -2.38 & .02 \\
\hline Female & -1.03 & 2.48 & -.02 & -.41 & .68 \\
\hline$\leq$ High school & 4.57 & 2.54 & .07 & 1.80 & .07 \\
\hline In a relationship & -7.56 & 2.48 & -.12 & -3.05 & .01 \\
\hline \multirow[t]{3}{*}{ Physical functioning } & .08 & .05 & .07 & 1.68 & .09 \\
\hline & \multicolumn{5}{|c|}{ Frequency of social interaction with neighbors } \\
\hline & $\mathrm{b}$ & $\mathrm{SE}$ & $\beta$ & $\mathrm{t}$ & $\mathrm{p}$ \\
\hline Crime and safety & -2.11 & 1.61 & -.05 & -1.31 & .19 \\
\hline Social interaction & 4.05 & 1.16 & .13 & 3.50 & .001 \\
\hline Crime x Social interaction & -2.39 & 1.54 & -.06 & -1.55 & .12 \\
\hline Age & -.33 & .08 & -.18 & -4.18 & .001 \\
\hline Minority & -7.88 & 2.91 & -.11 & -2.71 & .01 \\
\hline Female & -1.18 & 2.40 & -.02 & -.49 & .62 \\
\hline$\leq$ High school & 5.12 & 2.44 & .08 & 2.10 & .04 \\
\hline In a relationship & -8.27 & 2.41 & -.13 & -3.43 & .001 \\
\hline \multirow[t]{3}{*}{ Physical functioning } & .07 & .05 & .07 & 1.54 & .12 \\
\hline & \multicolumn{5}{|c|}{ Age } \\
\hline & $\mathrm{b}$ & $\mathrm{SE}$ & $\beta$ & $\mathrm{t}$ & $\mathrm{p}$ \\
\hline Crime and safety & -2.46 & 1.62 & -.06 & -1.52 & .13 \\
\hline Age & -.35 & .08 & -.19 & -4.47 & .001 \\
\hline Crime x Age & -.08 & .09 & -.03 & -.89 & .37 \\
\hline Minority & -6.30 & 2.89 & -.09 & -2.18 & .03 \\
\hline Female & -1.40 & 2.42 & -.02 & -.58 & .56 \\
\hline$\leq$ High school & 5.45 & 2.45 & .09 & 2.22 & .03 \\
\hline In a relationship & -7.57 & 2.41 & -.12 & -3.13 & .01 \\
\hline Physical functioning & .08 & .05 & .07 & 1.62 & .11 \\
\hline
\end{tabular}

\section{Perceptions of Pedestrian Infrastructure and Safety}

The following three multiple linear regression analyses were conducted to test the hypotheses that perceived neighborhood social cohesion, frequency of social interaction with neighbors, and age would moderate the effects of perceptions of pedestrian infrastructure and safety on walking. The outcome in these multiple linear regression analyses was total monthly walking trips (see Table 14). 


\section{Perceptions of pedestrian infrastructure and safety and total monthly walking}

trips - perceived neighborhood social cohesion. While there was no main effect for perceptions of pedestrian infrastructure and safety in predicting total monthly walking trips $(\mathrm{b}=-.65, \beta=-.01, \mathrm{~ns})$, there was a statistical interaction between perceived pedestrian infrastructure and safety and perceived neighborhood social cohesion $(b=10.07, \beta=.15, p$ $<$.001). There was a main effect for perceived neighborhood social cohesion in predicting total monthly walking trips $(\mathrm{b}=4.46, \beta=.10, \mathrm{p}<.01)$. Additionally, age significantly predicted total monthly walking trips $(b=-.34, \beta=-.18, \mathrm{p}<.001)$.

Simple slopes for the association between perceptions of pedestrian infrastructure and safety and total monthly walking trips were tested for low (one standard deviation below the mean), moderate (mean), and high (one standard deviation above the mean) perceived neighborhood social cohesion. The simple slope tests revealed a significant positive association between perceptions of pedestrian infrastructure and safety and total monthly walking trips at low and high levels of perceived neighborhood social cohesion. Perceptions of pedestrian infrastructure and safety was more strongly related to low levels perceived neighborhood social cohesion $(b=-7.96, \beta=-.14, \mathrm{p}<.01)$ than for high levels of perceived neighborhood social cohesion $(b=6.66, \beta=.12, \mathrm{p}<.05)$ (see Figure 13). 
Figure 13. Simple slopes for total monthly walking trips on perceptions of pedestrian infrastructure and safety at values of perceived neighborhood social cohesion

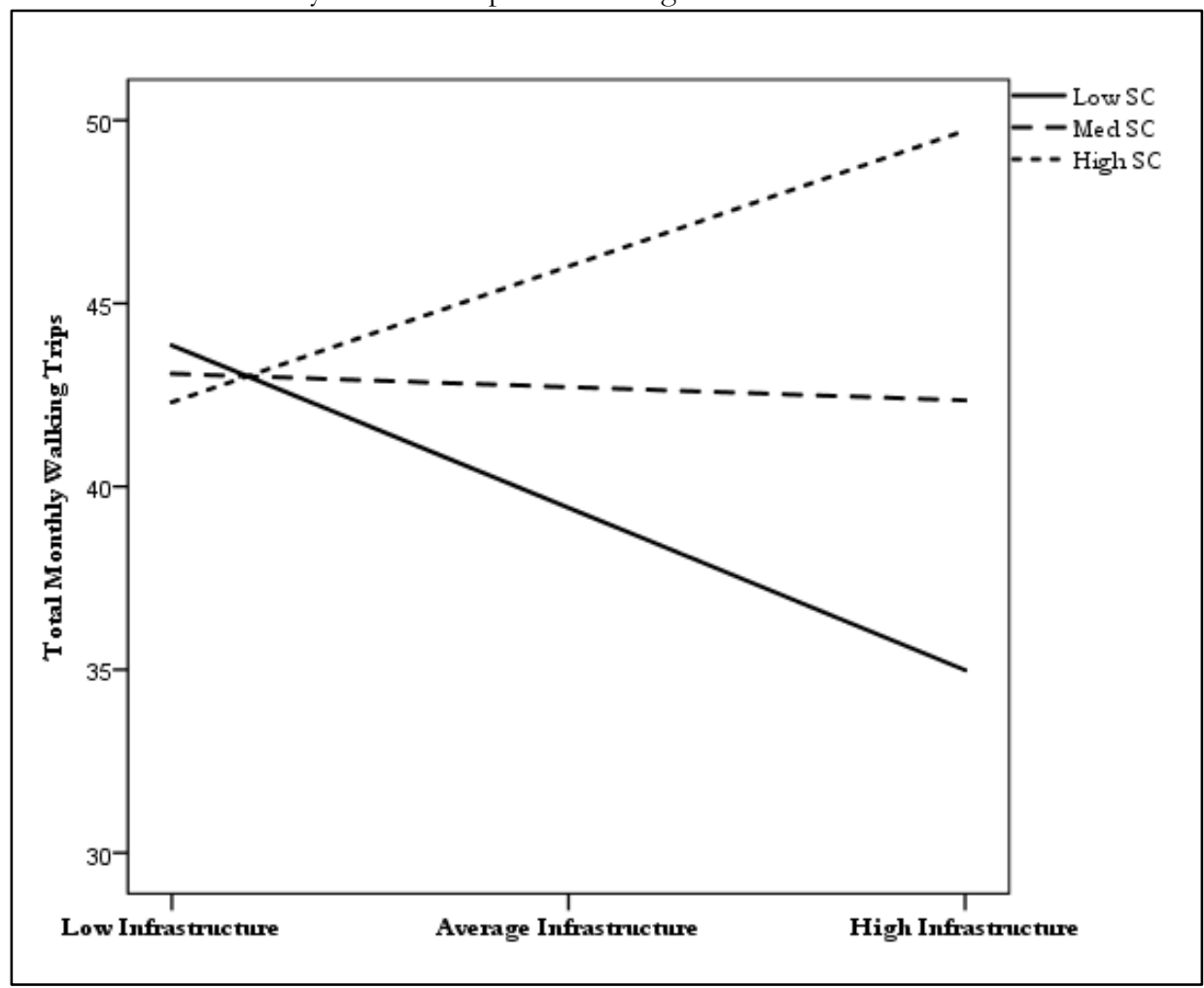

Perceptions of pedestrian infrastructure and safety and total monthly walking trips - frequency of social interaction with neighbors. There was no main effect for perceptions of pedestrian infrastructure and safety on total monthly walking trips $(\mathrm{b}=-.07$, $\beta=-.001$, ns), but there was a significant main effect for frequency of social interaction with neighbors $(\mathrm{b}=3.95, \beta=.13, \mathrm{p}<.001)$. The moderation hypothesis was supported, as there was an interaction effect of perceptions of pedestrian infrastructure and safety and frequency of social interaction with neighbors on total monthly walking trips $(b=4.86, \beta=.09, p<$ $.05)$. Age was also a significant predictor of total monthly walking trips $(b=-.34, \beta=-.18, p$ $<$.001) (see Table 20). 
Simple slopes for the association between perceptions of pedestrian infrastructure and safety and total monthly walking trips were tested for low (one standard deviation below the mean), moderate (mean), and high (one standard deviation above the mean) frequency of social interaction with neighbors. The simple slope tests revealed a marginally significant positive association between perceptions of pedestrian infrastructure and safety and total monthly walking trips at low and high levels of frequency of social interaction with neighbors. Perceptions of pedestrian infrastructure and safety was more strongly related to satisfaction for low levels frequency of social interaction with neighbors $(b=-.4 .80, \beta=-.08$, $\mathrm{p}=.11)$ than for high $(\mathrm{b}=4.92, \beta=.09, \mathrm{p}=.11)$ of frequency of social interaction with neighbors (see Figure 14).

Figure 14. Simple slopes for total monthly walking trips on perceptions of pedestrian infrastructure and safety at values of perceived neighborhood social cohesion

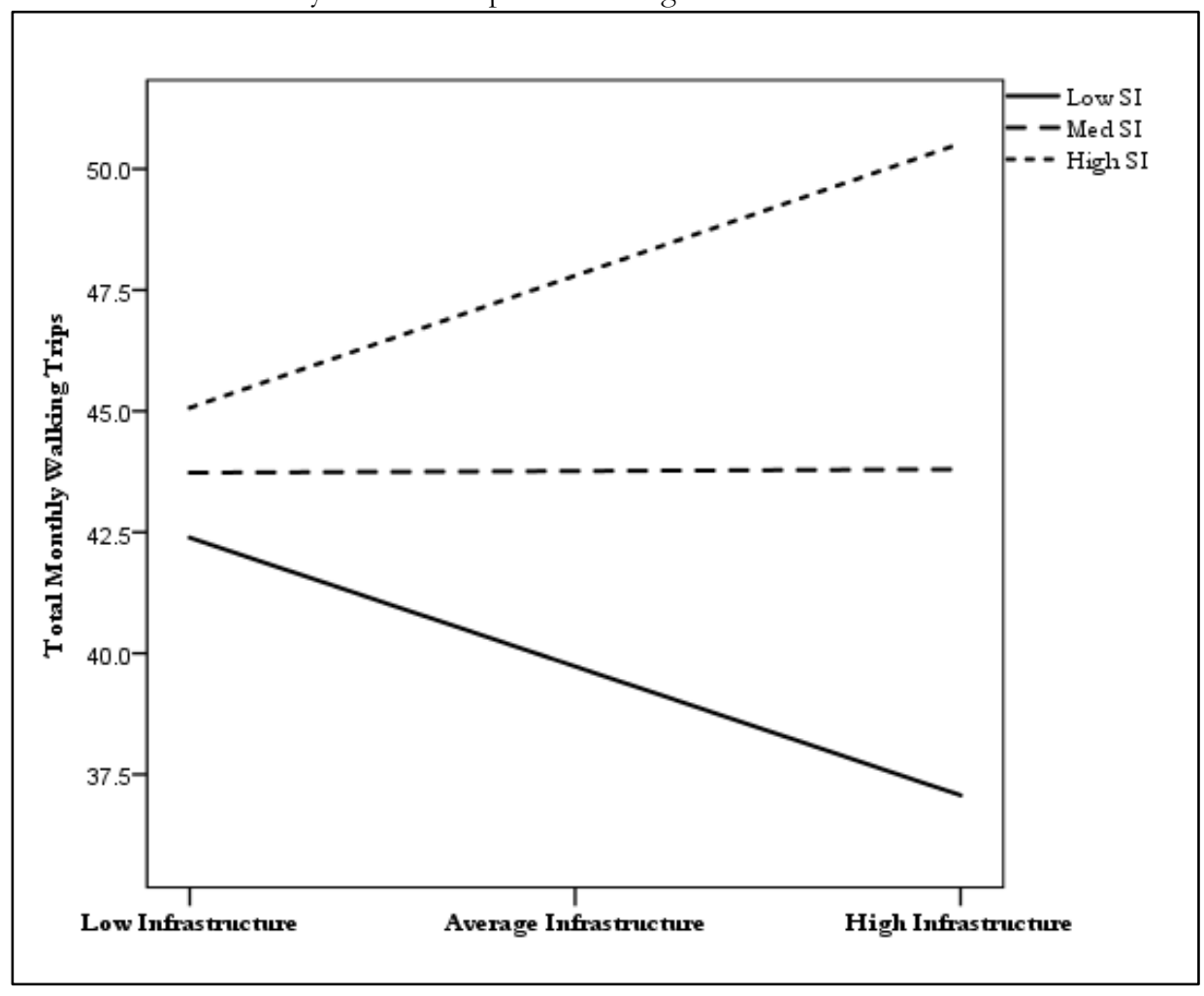




\section{Perceptions of pedestrian infrastructure and safety and total monthly walking}

trips - age. In examining the possible multiplicative effect of perceptions of pedestrian

infrastructure and safety and age on total monthly walking trips, there was no significant

main effect for pedestrian infrastructure and safety on total monthly walking trips $(b=.48, \beta$

$=.01, \mathrm{~ns})$. Age, however, did have a significant independent effect on total monthly walking

trips $(b=-.35, \beta=-.19, \mathrm{p}<.001)$. The moderation hypothesis was not supported as there

was not a significant interaction of perceptions of pedestrian infrastructure and safety and

age on total monthly walking trips $(\mathrm{b}=.003, \beta=.001$, ns).

Table 14. Moderating effects of perceptions of pedestrian infrastructure and safety and perceived neighborhood social cohesion, frequency of social interaction with neighbors, and age on total monthly walking trips

\begin{tabular}{|c|c|c|c|c|c|}
\hline & \multicolumn{5}{|c|}{ Perceived neighborhood social cohesion } \\
\hline & $\mathrm{b}$ & $\mathrm{SE}$ & $\beta$ & $\mathrm{t}$ & $\mathrm{p}$ \\
\hline Infrastructure & -.65 & 2.29 & -.01 & -.29 & .77 \\
\hline Social cohesion & 4.46 & 1.76 & .10 & 2.54 & .01 \\
\hline Infrastructure x Social cohesion & 10.07 & 2.72 & .15 & 3.71 & .001 \\
\hline Age & -.34 & .08 & -.18 & -4.09 & .001 \\
\hline Minority & -7.65 & 3.09 & -.10 & -2.48 & .01 \\
\hline Female & -1.01 & 2.56 & -.02 & -.39 & .69 \\
\hline$\leq$ High school & 5.02 & 2.63 & .08 & 1.91 & .06 \\
\hline In a relationship & -8.68 & 2.58 & -.14 & -3.37 & .001 \\
\hline \multirow[t]{3}{*}{ Physical functioning } & .10 & .05 & .09 & 2.02 & .04 \\
\hline & \multicolumn{5}{|c|}{ Frequency of social interaction with neighbors } \\
\hline & $\mathrm{b}$ & $\mathrm{SE}$ & $\beta$ & $\mathrm{t}$ & $\mathrm{p}$ \\
\hline Infrastructure & -.07 & 2.20 & .001 & -.03 & .97 \\
\hline Social interaction & 3.95 & 1.23 & .12 & 3.21 & .001 \\
\hline Infrastructure x Social interaction & 4.86 & 2.10 & .09 & 2.32 & .02 \\
\hline Age & -.34 & .08 & -.18 & -4.18 & .001 \\
\hline Minority & -7.92 & 3.03 & -.10 & -2.62 & .01 \\
\hline Female & -.52 & 2.50 & -.01 & -.21 & .83 \\
\hline$\leq$ High school & 5.33 & 2.56 & .08 & 2.08 & .04 \\
\hline$\overline{\text { In }}$ a relationship & -8.86 & 2.53 & -.14 & -3.51 & .001 \\
\hline \multirow[t]{3}{*}{ Physical functioning } & .09 & .05 & .08 & 1.87 & .06 \\
\hline & \multicolumn{5}{|c|}{ Age } \\
\hline & $\mathrm{b}$ & SE & $\beta$ & $\mathrm{t}$ & $\mathrm{p}$ \\
\hline Infrastructure & .48 & 2.22 & .01 & .21 & .83 \\
\hline Age & -.35 & .08 & -.19 & -4.34 & .001 \\
\hline Infrastructure x Age & .003 & .13 & .001 & .02 & .98 \\
\hline Minority & -7.21 & 3.04 & -.09 & -2.37 & .02 \\
\hline Female & -.44 & 2.52 & -.01 & -.17 & .86 \\
\hline$\leq$ High school & 5.75 & 2.59 & .09 & 2.22 & .03 \\
\hline In a relationship & -7.94 & 2.54 & -.12 & -3.13 & .01 \\
\hline Physical functioning & .10 & .05 & .09 & 2.03 & .04 \\
\hline
\end{tabular}




\section{Chapter 5 - Discussion and Conclusion}

\section{Recap of Dissertation Objectives}

The purpose of this dissertation research was to examine how features in the built environment - as perceived by neighborhood residents - were associated health-related behaviors, with a focus on the potential influence of social relationships on walking within a defined neighborhood. In this case, the neighborhood was an area encompassed by the Lents neighborhood in Portland, Oregon. This research integrated key theories and methods from two disciplines - urban planning and public health. Although not new, the intersection of the two disciplinary areas has received a resurgence of attention over the last several years as more focus has been placed on developing multilevel and systemic interventions to target population and individual health around physical activity in its different forms, with a focus on active living (Sallis, Cervero, Ascher, Henderson, Kraft, \& Kerr, 2006). As reflected in a comprehensive review by Sallis and colleagues, multidisciplinary efforts at multilevel policies and interventions are appropriate for the promotion of active living, which includes walking as both a form of transportation and of physical activity (Sallis, Cervero, Ascher, Henderson, Kraft, \& Kerr, 2006). While the analyses did not test an intervention, they support causal claims about the relationship between the built environment and health outcomes like walking. Future research could build upon this examine interventions to promote community and increase walking activity.

Attractive built environments - which often include attractive buildings and homes, interesting sights, and trees - and features such as sidewalks that promote walking are a public health concern because walking, as a type of physical activity, may improve health through reducing the risk of falls as an individual ages, lowering the risk of premature death, 
and enhancing cognitive function (U.S. Department of Health and Human Services [US DHHS], 2015). Features of the built environment such as attractive sights, trees, and sidewalks are believed to promote walking, as these infrastructural and design features are thought to increase the walkability of the built environment (Southworth, 2008). Walking, in sum, is an appropriate target outcome as it is widely accepted as both a form of physical activity and transportation accessible to many across the life course

Additionally, the current study considered the built environment context of a residential neighborhood. The reason for this focus on the neighborhood is that the places where people live shape health behaviors and outcomes. Further, neighborhoods also influence and are influenced by social relationship factors such as social cohesion and social interaction, as perceptions about community and engagement with social network members are known social determinants of health. The overall goal of this study was to contribute to the literature on the built environment of residential neighborhoods as a place for walking as a form of health promotion among adults aged 18 years of age and older; and more importantly, to examine how more distal social network members such as neighbors are associated with walking.

While the independent effects of the built environment and neighborhood social context on physical activity and health in general have been examined extensively as reported in a review by Diez Roux \& Mair (2010), the current research sought to examine how they work together in a theoretical model testing possible mediating and moderating roles that social relationship factors (e.g., perceived social cohesion and frequency of neighboring behaviors) may play in the association between the built environment and walking behavior. The social ecological framework, as it recognizes that a multitude of factors at varying levels 
of societal organization influence health and health behaviors (Glass \& Balfour, 2003), was an important underpinning of this research. The specific research aims included investigating:

1. whether frequency of neighboring behaviors and perceived social cohesion moderate the relationship between built environment and walking behavior;

2. whether frequency of neighboring behaviors and perceived social cohesion mediate the relationship between built environment and walking behavior; and

3. whether the resident's age moderates the relationship between built environment and walking behavior and frequency of neighboring behaviors and perceived social cohesion.

The remainder of this chapter will discuss the findings in relation to the theoretical frameworks and analytic aims and their respective hypotheses and will propose some health promotion and policy recommendations to increase walking across the life course and provide considerations for creating walkable and age-friendly environments that are safe, accessible, and amenable to individuals of all ages (Neal, DeLaTorre, \& Carder, 2014; World Health Organization [WHO], 2007).

\section{Key Findings in Relation to Theoretical Frameworks and Specific Research Aims}

The findings presented here both reify and elucidate the understanding of the connections between the built environment and health. The results are consistent with previously reported relationships between the built environment and physical activity and walking. Features and qualities of the built environment that are perceived to exist by area residents - such as crosswalks and attractive landscapes - affect the kind of walking they engage in (e.g., recreational or utilitarian), and the amount of walking (e.g., total monthly walking trips). It is still useful to understand how perceptions of the built environment vary 
among members of a residential community, because individuals within a targeted geographic area, such as a neighborhood, will evaluate the importance of features and qualities in different ways, in turn, potentially impacting variation in walking both as a form of transportation (i.e., utilitarian walking) and physical activity (i.e., recreational walking). As there is likely to be variation in what built environment and neighborhood social context factors predict walking in a small and socioeconomically diverse geographic area, this variation has implications for future research. These current findings reveal and underscore the functional importance of social context in influencing the effects of the built environment on walking, and this knowledge has programmatic and policy implications. Below the aims are restated and the results corresponding with these aims are briefly discussed.

\section{Neighborhood social context as moderator or mediator of the effect of built}

environment on walking. The analyses of Aim 1 investigated whether perceived neighborhood social cohesion and frequency of social interaction with neighbors would moderate the effect of built environment perceptions on walking, in which the perceptions of the built environment would be associated with more walking only when there were greater perceptions of social cohesion or greater social interaction. Aim 2 analyses sought to examine the mediating role of social cohesion and social interaction in the path between the built environment and physical activity, as it was hypothesized that perceptions of the built environment would enhance perceptions about the neighborhood community and the amount of social interaction with neighbors. The mediational hypothesis assumes that the neighborhood social context (i.e., perceived neighborhood social cohesion and frequency of social interaction with neighbors) would be associated with increased walking. 
Related to the theses briefly described above is the idea that walking begets more socially connected communities. A recent review (Boniface, Scantlebury, Watkins, \& Mindell, 2015) provides evidence that transportation, including walking as active transportation, does influence both social capital and social cohesion. The authors refer to the various social relationship measures as 'social interactions', which parallels the current study's consideration of social cohesion and social interaction in the neighborhood environment as 'neighborhood social context'. Future research should expand both on the idea that the built environment may influence the neighborhood social context and, in turn, walking as well as the possibility that walking influences the neighborhood social context.

Neighborhood social cohesion. Social cohesion is important because it is known to be associated with a variety of health outcomes such as reduced stress through increased feelings of safety, and, like social capital, social cohesion can be used as an indicator of the social health of a community. The more that individuals evaluate others in their surrounding residential community or neighborhood as similar in some way, such as holding similar values about political or community activism, the more likely it will be that these perceptions will translate into a healthier and more socially vibrant community. The survey respondents from this study were asked to indicate the extent to which their neighborhood community was close-knit and neighbors were willing to help others, held shared values, and could be trusted. As the social cohesion measure is intended, it does not necessarily require that respondents know their neighbors well or even at all; rather, the survey items tap into judgments about the general social milieu of an area. As such, these general or global judgments about the neighborhood social milieu may simply be part of the general positive 
or negative perceptions about the neighborhood, including perceptions about the built environment.

A related body of literature on risk taking and decision making indicates that people will behave in accordance with the level of risk that they perceive in a certain setting. This relates to the notions of the theory of planned behavior and theory of reasoned action. Similarly, it could be argued that people will behave walk for either physical activity or recreation within their neighborhood based on the extent to which they feel some affinity or connectedness to their community. If only the bivariate correlations (see Tables $2-4$ ) are examined, there is evidence reflecting a positive relationship between the two measures of the neighborhood social context and walking - essentially, those who engage more with and feel a stronger sense of connection to their neighbors walk more than those who do not.

In this current study, perceived neighborhood social cohesion tended to be associated with the effects of the built environment on walking after controlling for both physical and design characteristics of the built environment, but did not appear to consistently moderate the effect of the built environment on walking. There was, however, some evidence supporting mediation. For example, the finding that aesthetics leads to a sense of social cohesion, which in turn positively influences walking, was consistent with the mediational pathway.

It is also plausible and worth consideration in future studies, that social cohesion may shape or alter individual perceptions of aesthetic attractiveness. Further, it may also be that people will choose to walk more as active transportation if they perceive their neighborhood as sharing similar values and social connection, and that these community 
assessments enhance the aesthetic judgments made about the "look and feel" or appearance of the neighborhood.

This alternative model is specified differently than this study's hypothesized model that the built environment has a relationship with walking through the neighborhood social context. This proposed model and related research, in order have enough statistical power to glean meaningful results, would require several geographically similar neighborhoods as well as some that are dissimilar in terms of sociodemographic characteristics in order to explicate the function of the neighborhood social context in determining walking behavior writ large and specifically as a means of physical activity and of transportation.

Land use mix. While there was no evidence of moderation by social cohesion on the effect of land use mix on either utilitarian or recreational walking, neighborhood social cohesion was directly associated with recreational walking after controlling for land use mix. The findings suggest that those who evaluate their neighborhood as more socially cohesive are more likely to engage in recreational walking than their neighbors who assess their neighborhood as less socially cohesive. This connection between the neighborhood social context of the neighborhood residential environment and recreational walking is important in light of the known connections between social relationships and health promoting behaviors. Social relationships with members of one's social network, such as with family or friends, are known to be predictors of health behaviors and various health outcomes (see Chapter 1). Neighborhood social cohesion was only marginally significant for predicting utilitarian walking, so will not be considered further here. That said, it could be the case that as far as walking for transportation will occur regardless of whether or not an individual 
perceives their neighborhood as socially cohesive. Walking for transportation, in that regard, is a necessity regardless of sense of connection to a community.

In terms of examining the occurrence or frequency with which one walks over the course of the month, a greater sense of social cohesion was associated with more walking after controlling for land use mix. The moderation hypothesis that the effect of land use mix on walking would vary at different levels of social cohesion, was not supported in this instance, but as both land use mix and social cohesion were predictive of the number of walking trips - that they both had main effects on walking, this could suggest that land use mix and social cohesion function concurrently and independently on walking behavior. In other words, though the interactive effect of land use mix and social cohesion may not be determining factor in walking, the presence of one factor is a necessary condition for the effect of the other factor on walking. Social cohesion and land use mix ought to not be separated in future analyses examining both the neighborhood social context and built environment effects on walking, not to mention other health behaviors and outcomes that are sensitive to environmental influence.

Aesthetics. While neither aesthetics nor social cohesion appeared to be independently associated with utilitarian walking, the two measures did multiplicatively influence walking. Specifically, respondents who reported greater levels of neighborhood social cohesion were also more likely to report more neighborhood attractiveness and, in turn, they were more likely to walk as a means of transportation. This result suggests that efforts to increase walking ought to consider a focus on community engagement in addition to investments to maintain and beautify the built environment. 
The findings with respect to utilitarian walking (transportation) were echoed in the relationship of the built environment attractiveness and neighborhood social cohesion on the number of monthly walking trips. Overall, with increased perceived attractiveness of the built environment walked for transportation, regardless of how socially cohesive the neighborhood was perceived. The simple slopes test revealed what appeared to be a gradient, with those evaluating the neighborhood as more socially cohesive taking more walking trips than those who viewed the neighborhood as less socially cohesive.

Pedestrian infrastructure. Whereas the presence or recognition of the built environment as having pedestrian infrastructure such as crosswalks was associated with less walking, those who reported less social cohesion and who felt that pedestrian infrastructure was lacking tended to walk for transportation more than those who viewed their neighbors similarly but observed more pedestrian infrastructure. These results might seem counterintuitive, but could possibly explain that the social context is not particularly important when attempting to explain utilitarian forms of walking. This does not negate the importance of the neighborhood social context, but rather suggests that there are more salient factors that could explain the relationship between pedestrian infrastructure and walking as a form of transportation. The relationship between pedestrian infrastructure and utilitarian walking was not present for individuals reporting higher levels of social cohesion. In fact, those who reported higher levels social cohesion engaged in more utilitarian walking regardless of their perceptions of the existence of pedestrian infrastructure.

It is challenging to assess what these findings might mean in context. Perhaps for those who believe their neighborhood to be more cohesive walk more for transportation because they feel a greater sense of connection to their community and safer regardless of 
the presence or absence of pedestrian infrastructure. In the case of those who feel the neighborhood is not as cohesive, the presence of pedestrian infrastructure actually decreases the sense of safety and that could translate into less walking. It could also be that the respondents evaluating the neighborhood as less cohesive also walk less in general, and a longitudinal study would help clarify even further the role of both the built environment and the neighborhood social context as determinants of walking.

The relationship between pedestrian infrastructure and the number of walking trips was similar to the association between infrastructure and utilitarian walking. In this instance, however, there appeared to be clear differences in the total number of trips taken between those who viewed their neighborhood as less socially cohesive compared to those who saw their neighborhood as more socially cohesive. Specifically, those who saw the neighborhood as more socially cohesive walked more with more awareness of pedestrian infrastructure, but the inverse was the case for those perceiving the neighborhood as less socially cohesive. The implications here are to continue emphasis on the development of community at the neighborhood level. The evidence supports the benefit of social connection to and familiarity with neighbors as a boon to walking.

Social interaction with neighbors. Prior research has indicated that social engagement and physical activity, in general, go hand in hand. Individuals who are more socially connected tend in engage in more physical activity than those who are less socially connected. Additionally, walking about the neighborhood is thought to be one way of promoting social engagement and a sense of community (CDC, 2015). Social interaction with neighbors, as analyzed in this current study, was one way which the neighborhood social context is associated with health. Where frequency of social interaction 
with neighbors did moderate the effects of the built environment on walking, the results indicated that individuals who interacted with their neighbors more frequently were also more likely to perceive the built environment more positively, and positive perceptions of the environment were, in turn, associated with more walking behavior. These findings indicate that social engagement or interaction with neighbors increases the odds of and the frequency of walking.

Land use mix. Social interaction with neighbors was associated with both utilitarian and recreational walking when controlling for land use mix. These findings could suggest that social interaction with neighbors and land use mix may function independently in influencing walking. Given that land use mix was not a significant predictor of recreational walking when controlling for social interaction, it could be that, similar to neighborhood social cohesion, social interaction with neighbors may be a more important determinant of physical activity regardless of the features of land use mix. For utilitarian walking - that is walking as a means of transportation - both land use mix and social interaction with neighbors were important factors. In fact, respondents who perceived greater land use mix were 43 percent more likely to engage in utilitarian walking, and respondents reporting more social interaction with neighbors were 30 percent more likely to engage in utilitarian walking. Though it cannot be said for certain that land use mix (or other variation in access to different services), leads to more walking, it is clear that engagement with neighbors in the relationship between access to services and the frequency with which an individual walks.

Aesthetics. As hypothesized, there was evidence of a relationship between social contact with neighbors and built environment aesthetics in predicting utilitarian and recreational walking. With increasing engagement with neighbors, individuals were far more 
likely to walk for transportation and physical activity if they considered their neighborhood to be attractive. This could indicate that attention to aesthetic concerns in urban development is important for bringing individuals outside and fostering a sense of community. However, this relationship was not evident when examining the interactive effects of social cohesion and aesthetics.

Pedestrian infrastructure. As was the case with perceived social cohesion, social interaction with neighbors was associated with more utilitarian walking when coupled with pedestrian infrastructure. Specifically, greater perception of pedestrian infrastructure paired with less social interaction was associated with less walking for transportation. Individuals reporting the most social interaction appeared to engage utilitarian walking regardless of pedestrian infrastructure. Individuals who interacted the most with their neighbors walked far more than neighbors who interacted with their neighbors less, regardless of pedestrian infrastructure. Perceptions regarding the presence of pedestrian infrastructure could be a deterrent to walking for those who are less socially engaged.

Van Holle and colleagues (2015) did not find evidence of a moderating effect of psychosocial factors in the relationship between built environment walkability and walking behavior among older adults in the Netherlands. However, similar to this current study, they did find direct effects between psychosocial factors with the exception of social support on recreational walking. The current study and the Dutch study both highlight the need for a variety of psychosocial and social contextual measures in understanding the function of social relationships in the association between the residential environment and walking. 
Crime. Perceptions of crime and safety as a measure of the built environment's walkability was inconsistently related to walking and the neighborhood social context measures. The lack of a relationship of crime and safety with social context measures was surprising, given that both a perceived lack of safety and the occurrence of crime are often deterrents to walking (Foster, Giles-Corti, \& Knuiman, 2014). It could be that the measure of crime used in this study would be more useful as a potential moderator of the effects of the built environment on walking behavior rather than as an independent predictor. For example, in future research crime and safety could be specified as a moderator or mediator in a model examining built environment effects on walking.

\section{Age as a Moderator of the Effect of the Built Environment on Walking}

Although there was variation in walking by age across all analyses, whereby with increasing age there was less walking, albeit the results were of modest magnitude, age did not appear to moderate the effects of the built environment on walking as hypothesized (see Aim 3). The hypothetical assumption would be that older adults would walk more in environments considered more walkable; or rather, there would be no differences in walking by age when the built environment was amenable to walking in considering pedestrian infrastructure, land use mix, aesthetics, and the like. The main effects of age on walking merely suggest that, even after controlling for the built environment walkability measures, demographic characteristics, and functional ability, those who are older walk less than their younger counterparts.

This failure to find an interaction effect between the built environment and chronological age is potentially informative about the built environment and individual perceptions. Due to the consistent findings with age in the models as an independent 
variable, it appears that older adults are evaluating the built environment in similar ways to their younger counterparts. These null findings are at odds with previous research that has suggested, that older adults perceive and use the built environment in different ways than their younger adults (Shigematsu, Sallis, Conway, Saelens, Frank, Cain, et al., 2009). The current study's conflicting findings may have implications for future research and practice, or on the other hand, they may be an artifact of the current study.

As for the theoretical and practical implications of age relative to the built environment, it could be time to consider other variables traditionally associated with age, such as physical ability (Milanovic, Pantelic, Trajkovic, Sporis, Kostic, \& James, 2013), as a principal factor rather than age. It makes sense to consider the ecological model of aging presented earlier and the notion of environmental press in this vein. The built environment can hinder an individual's capacity to be physically active through environmental press (Lawton, 1986) not because a person is old per se, but rather a multitude of factors including physical and cognitive functioning - alter or limit physical activity. This is environmental press and how individual differences in functional capacity either enable or limit the ability for activity is a function of the tension or fit between a person and their environment (Lawton, 1986) and warrants further investigation in the research of the built environment and health. In essence, it is less an issue of age difference in physical activity in the built environment context and more a concern about physical and cognitive capacity at any age across the life course.

Given the diversity that occurs within the population as people age - shaped not only by psychological and genetic factors but also environmental and social factors - it is important to consider how variation in the aging experience is influenced by different 
contexts. The WHO recommends a focus on intrinsic capacity, which is a combination of both physical and cognitive abilities (WHO, 2015). A more useful way to frame studies of older adults and aging in the growing science of health and place would be through the further understanding of the connections between functional ability within different environments.

Further research could examine with more sophistication and a larger age- and geographically-stratified sample how perceptions of the built environment vary within and between age groups, as well as by functional ability, across different geographic areas. With respect to functional ability, future research must further examine motivations in desire to walk, reasons for walking, and the frequency of walking by physical capacity as well as age. It is possible that rather than the built environment being the primary predictor of walking, it is functional ability that either constrains or enables walking through either a mediating or moderating pathway of the built environment.

\section{Research Limitations}

A strength of this study was that it helped to clarify the relationship between the built environment and residential neighborhood social context on walking. In accordance with a social ecological model, the analyses supported the notion that different facets of social relationships may alter or modify the effects of the built environment on walking behavior. This is important because it demonstrates that the built environment is not solely predictive of walking behavior, but rather it suggests that walking is a product of or influenced by both the built environment and neighborhood social context. Because of these environmental influences walking, and health more generally, the built environment and the 
neighborhood social context should be isolated to look at their relative effects on health and also their joint effects when conducting studies of place effects on health.

However, while these analyses yielded interesting and useful findings, future study design and methods could be improved in several ways that could potentially enhance the findings and increase the generalizability of the results. These analyses do not clarify the relative importance of features and qualities of the built environment to area residents. For example, this means that the study does not clarify what is important to individuals in motivating them to walk. The available data are not conducive to evaluating the extent to which specific features of the built environment determine respondents' walking behavior and how the different features and qualities of the built environment might be instrumental in determining the decision to walk. The NEWS-A measure provides only an indication as to what area residents do and do not observe in their surrounding residential environment.

Geographic Extent. The first way in which future work could improve upon the current study would be to collect data on a larger geographic area or extent in the same city or across different cities of similar size. These intra- and inter-urban comparisons would provide a more accurate assessment of sociodemographic variations in walking behavior, including some of the complex associations that may exist among these variables. Another limitation related to the geographic extent at which the data were collected is generalizability to other areas both within Portland and beyond. While the data do provide some necessary insight as to walking behavior in an urban context, the resultant narrative is more descriptive than inferential, meaning that causal claims cannot be made about the effect of the built environment and neighborhood social context on walking. 
In 2010, older adults comprised approximately 11 percent of the Lents neighborhood population, 60 percent were White, and approximately 54 percent of all housing units were owner occupied (https://www.portlandoregon.gov/oni/article/375977). Lents neighborhood is a largely residential neighborhood crossed north and south and east and west by major road arterials and bisected by a major interstate highway, and is largely platted in a grid configuration. The neighborhood's transportation infrastructure - which does include sidewalks for walking, as well as the absence of sidewalks - may influence walking differently compared to other types of neighborhoods, such as neighborhoods absent freeway bisection or neighborhoods that are characteristically suburban (i.e., non-grid configurations). Land use and mix of amenities may also differentially influence walking in other types of neighborhoods with different transportation features. Further, other areas will vary sociodemographically such as by racial composition and income. Results from this study may not generalize to other neighborhoods within Portland or neighborhoods within other cities.

In addition to greater geographic coverage, a larger sample would allow for not only more generalizability but also testing of different types of predictive models, such as hierarchical linear models. Hierarchical or nested models would permit more specific examination of built environment effects on walking behavior and would have the ability to distinguish the effects of individual and environmental or psychosocial attributes on behavior - a more nuanced examination of micro and macro effects on walking. Though it would be ambitious in scale, a multilevel study allowing for individual, neighborhood, and cross-level interactions, that is the interaction of the macro and micro levels, would require at least 100 neighborhoods with a minimum of five cases per neighborhood (Hox, 2010). 
The current analyses, given that they were cross-sectional, merely established that there was a connection between the built environment, social relationships, and walking.

\section{Other Methodological Concerns}

Missing data. The regression analyses presented in this study were based on listwise deletion, which is commonly used in the behavioral and social sciences literature but may not be the optimal choice as compared to other modern methods of handing missing data, such as multiple imputation. It is possible that the results would have been different had responses to the survey items been more complete. Listwise deletion of cases within each analysis in this study resulted in the deletion of less than 20 percent to around 23 percent of cases. There may not be an advantage to multiple imputation when missing data is less than 20 percent, according to some simulation studies (Arbuckle, 1996). Should missing cases begin to exceed that 20 percent threshold, there is the risk of biased estimates. There is a chance that the given the extent to which data were missing, multiple imputation might have increased statistical power, and some results that did not attain statistical significance might have done so. In sum, future work with these data could address these concerns either through the use of multiple imputation or other missing data methods.

False discovery. Another potential concern is that some of the significant effects may be a consequence of a false discovery rate (FDR). An FDR is a potential problem when conducting multiple significance tests, resulting in the increased likelihood of a Type I error, which is falsely rejecting the null hypotheses. The risk of one or more Type 1 errors is especially a problem when examining a family or series of related hypotheses (Benjamini \& Yekutieli, 2001). Adjustments for familywise error or FDR are rare in this literature for regression models, and it is difficult to determine what constitutes a "family" of tests. To 
explore this issue, syntax was run that sorted the p-values and computed an adjustment for significance on one regression model from the current study. The results were no different than the original test (not included).

\section{Recommendations for Policy, Programmatic, and Individually-Targeted Efforts to Increase Walking}

In addition to providing direction for future research, the findings regarding neighborhood social context have practical implications for practitioners and policymakers at the intersection of public health and urban planning, and are important for targeting both individual and population health in the context of the built environment. A recent initiative of the Office of the Surgeon General (US DHHS, 2015) has instituted a call to action to increase walking and create more walkable communities in the US. Walking is a fairly inclusive and inexpensive form of physical activity, but people across the life course are walking in sufficient numbers to see appreciable improvements in health. The CDC has also indicated that older adults, specifically, are not walking sufficiently to meet basic physical activity requirements. While walking is a beneficial form of activity for all, walking among older adults (assuming physical capacity to do so) is important for slowing down and staving off physical decline. Increasing the likelihood that someone will walk and the duration and frequency of walking requires increased programmatic and policy attention. The remainder of this section will offer some suggestions to these ends.

Social Relationships. The findings reported here expand on the government messaging. Through increasing the motivation to walk and creating environments that are considered more walkable, it would be logical that people would become more familiar with others in their surrounding residential and other life environments, and this would, in turn, increase 
walking. And as also found in this dissertation, those who know their neighbors or feel some sort of affinity with their neighbors will typically walk more. Evidence cited in the CDC's report also underscores the importance of social connection with neighbors for making areas safer, thus encouraging more walking. Knowing that social interaction influences walking ought to be sufficient impetus to design community-based interventions to promote social engagement through walking activities. In communities where outdoor walking may be limited by the elements and perceptions of the surrounding residential built environment, organized walking programs such as walking groups in public places might be an effective solution to increasing walking among adults. As an example, organized walking groups in malls is one way to increase socialization while promoting physical activity (Belza, Allen, Brown, Farren, Janicek, Jones, et al., 2015). In smaller towns, such as Albert Lea, Minnesota, public messaging around the benefits of walking has been demonstrated to be associated with overall improvements along a number of health outcomes (Walljasper, 2015)

A summative report brief by the American Planning Association [APA] (2015) emphasizes the need for continued efforts at street scale development. This type of development reduces the focus on automobiles and increases the focus on and safety for pedestrians and cyclists by including features such as traffic calming interventions, crossing aids, aesthetic improvement efforts, and street furniture (e.g., benches). Through this focal shift in transportation design and infrastructure, it is theorized that the fostering of community and bonding of social ties will naturally occur. Street scale development is age friendly development and does benefit the community in other ways as well. For example, though not within the scope of this dissertation, other research might investigate the economic benefits to the community that extend beyond the social and physical health 
benefits to the community. As examples of economic impacts, street scale development is thought to increase property values and both pedestrian and bicyclists will spend more time in an area than automobile driver (APA, 2015), which could translate into more spending in addition to increased social engagement.

\section{Walkable and Age-Friendly Environments}

Land use mix and aesthetics are important components of walkability, as presented in the greater active living body of research (Cerin, Saelens, Sallis, \& Frank, 2006). The reasons for their importance can be distilled to the fact that areas with a mix of land uses largely residential mixed with commercial - and that are attractive tend to be considered more "walkable" as compared to areas with fewer amenities. Individuals will walk more, and use motorized transportation less, in theory, in environments where there are destinations within a walking distance of home.

Although in this study age did not modify the effects of the built environment on walking, the findings did reveal that older adults walked less than younger adults. This variation in walking behavior by age can be used to inform development and policy solutions. With increased attention focused on age-friendly development to promote lifelong health and social inclusion, and given known demographic shifts in population aging, attention to dense, varied, and walkable built environments will increase in importance.

\section{Conclusion}

This chapter summarized the findings in the relationship between neighborhood social context and dimensions of the built environment on walking. Specifically, that the neighborhood social context is an important determinant of walking when controlling for the built environment. In some instances, there is a relationship between the two in that at 
different levels of social interaction (namely, higher levels of social interaction with neighbors) there is more walking when assessments are made about the presence of certain qualities and features of the built environment. As an example, when individuals acknowledge that features of the surrounding built environment are aesthetically attractive and they engage with their neighbors more frequently, they will walk more than those individuals who engage less frequently with their neighbors. This finding is important for at least a couple of reasons. First, people factor into aesthetic judgments regarding places; and second, one cannot assess the built environment without considering social context. Failure to consider the neighborhood or residential social context when examining the built environment and health behaviors and outcomes would be antithetical or counter to the social ecological model that seeks to explain so much of the environmental complexity of influence on health.

The results from this study revealed that social relationships or social context are instrumental in influencing engagement in and levels of physical activity such as walking. To ignore social relationship factors or the social context in research on built environment and health would overlook a vital determinant of behavior, as identified in a social ecological framework. Considering the effects of the built environment on walking without accounting for the mediating and moderating effects of social relationships and social context could lead to an overreliance on built environment interventions that are solely physical in nature and provide results that are more descriptive as opposed to inferential. This research builds upon and supports prior research findings that social cues and social interaction behaviors are influential in ways that the built environment fails to be (Clark \& Scott, 2013). Engagement with neighbors and the extent to which individuals perceive their neighborhood as socially 
cohesive is important for health outcomes and are important covariates to consider when examining how the built environment influences health and walking. 


\section{References}

Adams, M. A., Ryan, S., Kerr, J., Sallis, J. F., Patrick, K., Frank, L. D., et al. (2009).

Validation of the Neighborhood Environment Walkability Scale (NEWS) Items

Using Geographic Information Systems. Journal of Physical Activity \& Health, 6, S113S123.

Administration of Community Living (2011). A Profile of Older Americans: 2011. Retrieved from http://www.aoa.gov/aoaroot/aging_statistics/Profile/2011/docs/2011profile.pdf.

Aiken, L. S., \& West, S. G. (1991). Multiple regression: Testing and interpreting interactions. Newbury Park, CA: Sage.

Altman, I. (1975). The Environment and Social Behavior. Monterey, CA: Brooks/Cole Publishing Company.

American Planning Association. (2015). The benefits of street-scale features for walking and biking.

Arbuckle, J. L. (1996). Full information estimation in the presence of incomplete data. In G. A. Marcoulides and R. E. Schumaker (Eds.) Advanced structural equation modeling: Issues and techniques. Mawwah, NJ: Lawrence Erlbaum Associates.

Auchincloss, A. H., \& Diez Roux, A. V. (2008). A new tool for epidemiology: the usefulness of dynamic-agent models in understanding place effects on health. American Journal of Epidemiology, 168(1), 1-8.

Augustin, T., Glass, T. A., James, B. D., \& Schwartz, B. S. (2008). Neighborhood psychosocial hazards and cardiovascular disease: The Baltimore Memory Study. American Journal of Public Health, 98(9), 1664-167. 
Baron, R. M., \& Kenny, D. A. (1986). The moderator-mediator variable distinction in social psychological research: Conceptual, strategic and statistical considerations. Journal of Personality and Social Psychology, 51, 1173-1182.

Barrera, M. (1986). Distinctions between social support concepts, measures, and models. American Journal of Community Psychology, 14(4), 413-445.

Bassett, D. R., Jr., Pucher, J., Buehler, R., Thompson, D. L., \& Crouter, S. E. (2008). Walking, cycling, and obesity rates in Europe, North America, and Australia. Journal of Physical Activity \& Health, 5(6), 795-814.

Belza, B., Allen, P., Brown, D. R., Farren, L., Janicek, S., Jones, D. L., et al. (2015). Mall walking: A program resource guide. Seattle, WA: University of Washington Health Promotion Research Center. Retrieved from http://www.cdc.gov/physicalactivity/downloads/mallwalking-guide.pdf

Benjamini, Y., \& Yekutieli, D. (2001). The control of the false discovery rate in multiple testing under dependency. The Annals of Statistics, 29, 1165-1188.

Beaudoin, C. E. (2009). Bonding and bridging neighborliness: An individual-level study in the context of health. Social Science \& Medicine, 68(12), 2129-2136.

Berkman, L. F., \& Glass, T. A. (2000). Social integration, social networks, social support and health. In L. F. Berkman \& I. Kawachi (Eds.), Social Epidemiology. New York, New York: Oxford University Press.

Berkman, L. F., \& Syme, S. L. (1979). Social networks, host resistance, and mortality: A nineyear follow-up study of Alameda County residents. American Journal of Epidemiology, 109, 186-204. 
Boniface, S., Scantlebury, R., Watkins, S. J., \& Mindell, J. S. (2015). Health implications of transport: Evidence of effects of transport on social interactions. Journal of Transport \& Health, 2, 441-446.

Borst, H. C., de Vries, S. I., Graham, J. M. A., van Dongen, J. E. F., Bakker, I., \& Miedema, H. M. E. (2009). Influence of environmental street characteristics on walking route choice of elderly people. Journal of Environmental Psychology, 29(4), 477-484.

Bourdieu, P. (2001). The forms of capital. In M. Granovetter \& R. Swedberg (Eds.), The Sociology of Economic Life (pp. 96-111). Boulder, Colorado: Westview Press.

Browning, C. R., \& Cagney, K. A. (2002). Neighborhood structural disadvantage, collective efficacy, and self-rated physical health in an urban setting. Journal of Health and Social Behavior, 43(4), 383-399.

Broyles, S. T., Mowen, A. J., Theall, K. P., Gustat, J., \& Rung, A. L. (2011). Integrating social capital into a park-use and active-living framework. American Journal of Preventive Medicine, 40(5), 522-529.

Cagney, K. A., Browning, C. R., \& Wen, M. (2005). Racial disparities in self-rated health at older ages: what difference does the neighborhood make? The Journals of Gerontology, Series B Psychological Science and Social Sciences, 60(4), S181-19.

Centers for Disease Control and Prevention and The Merck Company Foundation. (2007). The State of Aging and Health in America 2007. Whitehouse Station, NJ: The Merck Company Foundation. Retrieved from https://www.cdc.gov/aging/pdf/saha_2007.pdf 
Cerin, E., Saelens, B. E., Sallis, J. F., \& Frank, L. D. (2006). Neighborhood Environment Walkability Scale: Validity and development of a short form. Medicine and Science in Sports and Exercise, 38(9), 1682-1691.

Chaix, B. (2009). Geographic life environments and coronary heart disease: a literature review, theoretical contributions, methodological updates, and a research agenda. Annual Review of Public Health, 30, 81-105.

Chaix, B., Billaudeau, N., Thomas, F., Havard, S., Evans, D., Kestens, Y., et al. (2011). Neighborhood effects on health correcting bias from neighborhood effects on participation. Epidemiology, 22(1), 18-26.

Clark, A. F., \& Scott, D. M. (2013). Does the social environment influence active travel? A investigation of walking in Hamilton, Canada. Journal of Transport Geography, 31, 278285.

Cohen, S., \& Wills, T. A. (1985). Stress, social support, and the buffering hypothesis. Psychological Bulletin, 98, 310-357.

Coutts, A., \& Kawachi, I. (2006). The urban social environment and its effects on health. In N. Freudenberg, S. Galea \& D. Vlahov (Eds.), Cities and the Health of the Public (pp. 49-60). Nashville, Tennessee: Vanderbilt University Press.

Cummins, S., Curtis, S., Diez-Roux, A. V., \& Macintyre, S. (2007). Understanding and representing 'place' in health research: A relational approach. Social Science \& Medicine, 65(9), 1825-1838.

Cunningham, G. O., \& Michael, Y. L. (2004). Concepts guiding the study of the impact of the built environment on physical activity for older adults: A review of the literature. American Journal of Health Promotion, 18(6), 435-443. 
Dannenberg, A. L., Jackson, R. J., Frumkin, H., Schieber, R. A., Pratt, M., Kochtitzky, C., et al. (2003). The impact of community design and land-use choices on public health: A scientific research agenda. American Journal of Public Health, 93(9), 1500-1508.

Dassopoulos, A., \& Monnat, S. M. (2011). Do Perceptions of Social Cohesion, Social Support, and Social Control Mediate the Effects of Local Community Participation on Neighborhood Satisfaction? Environment and Behavior, 43(4), 546-565.

Diez-Roux, A. V. (1998). Bringing context back into epidemiology: Variables and fallacies in multilevel analysis. American Journal of Public Health, 88(2), 216-222.

Diez Roux, A. V., \& Mair, C. (2010). Neighborhoods and health. Annals of the New York Academy of Sciences, 1186, 125-145.

Dill, J., Neal, M., Shandas, V., Luhr, G., Adkins, A., \& Lund, D. (2010). Demonstrating the benefits of green streets for active aging: Final report to EPA.

du Toit, L., Cerin, E., Leslie, E., \& Owen, N. (2007). Does walking in the neighbourhood enhance local sociability? Urban Studies, 44(9), 1677-1695.

Echeverria, S., Diez-Roux, A. V., Shea, S., Borrell, L. N., \& Jackson, S. (2008). Associations of neighborhood problems and neighborhood social cohesion with mental health and health behaviors: The Multi-Ethnic Study of Atherosclerosis. Health \& Place, 14(4), 853-865.

Feng, J., Glass, T. A., Curriero, F. C., Stewart, W. F., \& Schwartz, B. S. (2010). The built environment and obesity: A systematic review of the epidemiologic evidence. Health \& Place, 16(2), 175-19.

Fleming, C. B., White, H. R., \& Catalano, R. F. (2010). Romantic relationships and substance abuse in early adulthood: An examination of the influences of relationship type, 
partner substance use, and relationship quality. Journal of Health and Social Behavior, $51(2), 153-167$.

Forsyth, A., Hearst, M., Oakes, J. M., \& Schmitz, K. H. (2008). Design and destinations: Factors influencing walking and total physical activity. Urban Studies, 45(9), 19731996.

Foster, S., Giles-Corti, B., \& Knuiman, M. (2011). Creating safe walkable streetscapes: Does house design and upkeep discourage incivilities in suburban neighbourhoods? Journal of Environmental Psychology, 31(1), 79-88.

Frank, L. D., Saelens, B., Powell, K., \& Chapman, J. (2007a). Disentangling urban form effects on physical activity, driving, and obesity from individual predisposition for neighborhood type and travel choice. Annals of Behavioral Medicine, 33, S143-S143.

Frank, L. D., Saelens, B. E., Powell, K. E., \& Chapman, J. E. (2007b). Stepping towards causation: Do built environments or neighborhood and travel preferences explain physical activity, driving, and obesity? Social Science \&o Medicine, 65(9), 1898-1914.

Fried, L., \& Barron, J. (2005). Older adults: Guardians of our cities. In S. Galea \& D. Vlahov (Eds.), Handbook of Urban Health: Populations, Methods, and Practice (pp. 177199). New York, New York: Springer.

Frumkin, H. (2002). Urban sprawl and public health. Public Health Reports, 117, 201-217.

Gallagher, N. A., Gretebeck, K. A., Robinson, J. C., Torres, E. R., Murphy, S. L., \& Martyn, K. K. (2010). Neighborhood Factors Relevant for Walking in Older, Urban, African American Adults. Journal of Aging and Physical Activity, 18(1), 99-115. 
Gidlof-Gunnarsson, A., \& Ohrstrom, E. (2007). Noise and well-being in urban residential environments: The potential role of perceived availability to nearby green areas. Landscape and Urban Planning, 83(2-3), 115-126.

Glass, T. A., \& Balfour, J. L. (2003). Neighborhoods, aging, and functional limitations. In I. Kawachi \& L. F. Berkman (Eds.), Neighborhoods and Health (pp. 303-334). New York, New York: Oxford University Press.

Godley, J., Haines, V. A., Hawe, P., \& Shiell, A. (2010). Small area contextual effects on selfreported health: Evidence from Riverside, Calgary. BMC Public Health, 10.

Gordon-Larsen, P., Nelson, M. C., Page, P., \& Popkin, B. M. (2006). Inequality in the built environment underlies key health disparities in physical activity and obesity. Pediatrics, 117(2), 417-424.

Green, C. G., \& Klein, E. G. (2011). Promoting active transportation as a partnership between urban planning and public health: The Columbus Healthy Places Program. Public Health Reports, 126(S1), 41-49.

Greiner, K. A., Li, C. Y., Kawachi, I., Hunt, D. C., \& Ahluwalia, J. S. (2004). The relationships of social participation and community ratings to health and health behaviors in areas with high and low population density. Social Science \& Medicine, 59(11), 2303-2312.

Handy, S. L., Boarnet, M. G., Ewing, R., \& Killingsworth, R. E. (2002). How the built environment affects physical activity: views from urban planning. American Journal of Preventive Medicine, 23(2 Suppl), 64-73. 
Healthy People 2020 (2012). Older Adults. Retrieved from

http://www.healthypeople.gov/2020/topicsobjectives2020/overview.aspx?topicId= $\underline{31}$

Heath, G. W., Brownson, R. C., Kruger, J., Miles, R., Powell, K. E., Ramsey, L. T., et al. (2006). The effectiveness of urban design and land use and transport policies and practices to increase physical activity: A systematic review. Journal of Physical Activity and Health, 3(Suppl 1), S55-S76.

Hirvensalo, M., Rantanen, T., \& Heikkinen, E. (2000). Mobility difficulties and physical activity as predictors of mortality and loss of independence in the communitydwelling older population. Journal of the American Geriatrics Society, 48(5), 493-498.

Hooker, S. P., Cirill, L., \& Wicks, L. (2007). Walkable neighborhoods for seniors: The Alameda County experience. Journal of Applied Gerontology, 26(2), 157-181.

House, J. S., Landis, K. R., \& Umberson, D. (1988). Social relationships and health. Science, 241.

Hox, J. J., Moerbeek, M., Schoot, R. (2010). Multilevel Analysis. Routledge.

Hu, F. B., Stampfer, M. J., Solomon, C., Liu, S., Colditz, G. A., Speizer, F. E., et al. (2001). Physical activity and risk for cardiovascular events in diabetic women. Annals of Internal Medicine, 134, 96-105.

Jackson, C. H., Richardson, S., \& Best, N. G. (2008). Studying place effects on health by synthesising individual and area-level outcomes. Social Science \& Medicine, 67(12), 1995-2006.

Jackson, R. J., \& Sinclair, S. (2012). Designing Healthy Communities. San Francisco, CA: Jossey-Bass. 
Jones, D. K., Evenson, K. R., Rodriguez, D. A., \& Aytur, S. A. (2010). Addressing pedestrian safety: A content analysis of pedestrian master plans in North Carolina. Traffic Injury Prevention, 11(1), 57-65.

Kaczynski, A. T. (2010). Neighborhood walkability perceptions: Associations with amount of neighborhood-based physical activity by intensity and purpose. Journal of Physical Activity \& Health, 7(1), 3-1.

Kaczynski, A. T., \& Sharratt, M. T. (2010). Deconstructing Williamsburg: Using focus groups to examine residents' perceptions of the building of a walkable community. International Journal of Behavioral Nutrition and Physical Activity, 7.

Kawachi, I., \& Berkman, L. (2000). Social cohesion, social capital, and health. In L. F. Berkman \& I. Kawachi (Eds.), Social Epidemiology. New York, NY: Oxford University Press.

Kim, D. (2008). Blues from the Neighborhood? Neighborhood characteristics and depression. Epidemiologic Reviews, 30(1), 101-117.

King, A. C., Sallis, J. F., Frank, L. D., Saelens, B. E., Cain, K., Conway, T. L., et al. (2011). Aging in neighborhoods differing in walkability and income: Associations with physical activity and obesity in older adults. Social Science \& Medicine, 73(10), 15251533.

Krause, N., Shaw, B., \& Liang, J. (2011). Social relationships in religious institutions and healthy lifestyles. Health Education \& Behavior, 38(1), 25-38.

Kubzansky, L. D., Subramanian, S. V., Kawachi, I., Fay, M. E., Soobader, M. J., \& Berkman, L. F. (2005). Neighborhood contextual influences on depressive symptoms in the elderly. American Journal of Epidemiology, 162(3), 253-26. 
Kuo, F. E., Bacaicoa, M., \& Sullivan, W. C. (1998). Transforming inner-city landscapes Trees, sense of safety, and preference. Environment and Behavior, 30(1), 28-59.

Kuo, F. E., \& Sullivan, W. C. (2001). Aggression and violence in the inner city - Effects of environment via mental fatigue. Environment and Behavior, 33(4), 543-571.

Langlois, J. A., Keyl, P. M., Guralnik, J. M., Foley, D. J., Marottoli, R. A., \& Wallace, R. B. (1997). Characteristics of older pedestrians who have difficulty crossing the street. American Journal of Public Health, 87(3), 393-397.

Lawton, M. P. (1986). Environment and Aging (pp. 1-20). Albany, New York: Center for the Study of Aging.

Leal, C., \& Chaix, B. (2011). The influence of geographic life environments on cardiometabolic risk factors: a systematic review, a methodological assessment and a research agenda. Obesity Reviews, 12(3), 217-23.

Lee, C., \& Vernez Moudon, A. (2001). Physical activity and environment research in the health field: Implications for urban and transportation planning practice and research. Journal of Planning Literature, 19, 147-181.

Leonard, K. E., \& Eiden, R. D. (2007). Marital and family processes in the context of alcohol use and alcohol disorders. Annual Review of Clinical Psychology, 3, 285-31.

Leslie, E., Cerin, E., \& Kremer, P. (2010). Perceived neighborhood environment and park use as mediators of the effect of Area socio-economic status on walking behaviors. Journal of Physical Activity \& Health, 7(6), 802-81.

Li, F. Z., Harmer, P., Cardinal, B. J., \& Vongjaturapat, N. (2009). Built environment and changes in blood pressure in middle aged and older adults. Preventive Medicine, 48(3), 237-241. 
Lovasi, G. S., Hutson, M. A., Guerra, M., \& Neckerman, K. M. (2009). Built Environments and Obesity in Disadvantaged Populations. Epidemiologic Reviews, 31(1), 7-2.

Lund, H. (2003). Testing the claims of new urbanism - Local access, pedestrian travel, and neighboring behaviors. Journal of the American Planning Association, 69(4), 414-429.

Macintyre, S., Ellaway, A., \& Cummins, S. (2002). Place effects on health: how can we conceptualise, operationalise and measure them? Social Science \& Medicine, 55(1), 125 139.

MacKinnon, D. P. (2008). Introduction to statistical mediation analysis. Mawah, NJ: Erlbaum.

Mair, C., Diez Roux, A. V., \& Galea, S. (2008). Are neighbourhood characteristics associated with depressive symptoms? A review of evidence. Journal of Epidemiology and Community Health, 62(940-946).

Manson, J. E., Hu, F. B., Rich-Edwards, J. W., Colditz, G. A., \& Stampfer, M. J. (1999). A prospective study of walking as compared with vigorous exercise in the prevention of coronary heart disease in women. New England Journal of Medicine, 341, 650-658.

Matthews, S. A., \& Yang, T. C. (2010). Exploring the Role of the Built and Social Neighborhood Environment in Moderating Stress and Health. Annals of Behavioral Medicine, 39(2), 170-183.

McCormack, G., Giles-Corti, B., Lange, A., Smith, T., Martin, K., \& Pikora, T. J. (2004). An update of recent evidence of the relationship between objective and self-report measures of the physical environment and physical activity behaviours. Journal of Science and Medicine in Sport, 7(1, Supplement 1), 81-92. 
McNeill, L. H., Kreuter, M. W., \& Subramanian, S. V. (2006). Social Environment and Physical activity: A review of concepts and evidence. Social Science \& Medicine, 63(4), 1011-1022.

Michael, Y. L., Green, M. K., \& Farquhar, S. A. (2006). Neighborhood design and active aging. Health \& Place, 12(4), 734-74.

Michael, Y. L., \& Yen, I. H. (2009). Invited commentary: Built environment and obesity among older adults--Can neighborhood-level policy interventions make a difference? American Journal of Epidemiology, 169(4), 409-412.

Milanovic, Z., Pantelic, S., Trajkovic, N., Sporis, G., Kostic, R., \& James, N. (2013). Agerelated decrease in physical activity and functional fitness among elderly men and women. Clinical Interventions in Aging, 9.

Morenoff, J. D., Sampson, R. J., \& Raudenbush, S. W. (2001). Neighborhood inequality, collective efficacy, and the spatial dynamics of urban violence. Criminology, 39(3), 517 559.

Moudon, A. V., Lee, C., Cheadle, A. D., Garvin, C., Johnson, D., Schmid, T. L., et al. (2006). Operational definitions of walkable neighborhoods: Theoretical and empirical insights. Journal of Physical Activity and Health, 3(Suppl 1), S99-S117.

Nagel, C. L., Carlson, N. E., Bosworth, M., \& Michael, Y. L. (2008). The relation between the neighborhood built environment and walking activity among older adults. American Journal of Epidemiology, 168(4), 461-468.

Neal, M. B., DeLaTorre, A. K., \& Carder, P. C. (2014). Age-Friendly Portland: A universitycity-community partnership. Journal of Aging \& Social Policy, 26, 88-101. 
Newsom, J., Mahan, T. L., Rook, K. S., \& Krause, N. (2008). Stable negative exchanges and health. Health Psychology, 27(1), 78-86.

Omariba, D. W. R. (2010). Neighbourhood characteristics, individual attributes and selfrated health among older Canadians. Health \& Place, 16(5), 986-995.

Owen, N., Humpel, N., Leslie, E., Bauman, A., \& Sallis, J. F. (2004). Understanding environmental influences on walking - Review and research agenda. American Journal of Preventive Medicine, 27(1), 67-76.

Papas, M. A., Alberg, A. J., Ewing, R., Helzlsouer, K. J., Gary, T. L., \& Klassen, A. C. (2007). The built environment and obesity. Epidemiologic Reviews, 29, 129-143.

Paterson, D. H., Jones, G. R., \& Rice, C. L. (2007). Ageing and physical activity: Evidence to develop exercise recommendations for older adults. Applied Physiology, Nutrition, and Metabolism, 32(S2E).

Patterson, P. K., \& Chapman, N. J. (2004). Urban form and older residents' service use, walking, driving, quality of life, and neighborhood satisfaction. American Journal of Health Promotion, 19(1), 45-52.

Putnam, R. D. (2000). Bowling Alone. New York, New York: Simon \& Schuster.

Rodriguez, D. A., Aytur, S., Forsyth, A., Oakes, J. M., \& Clifton, K. J. (2008). Relation of modifiable neighborhood attributes to walking. Preventive Medicine, 47(3), 260-264.

Rook, K. S. (1992). Detrimental aspects of social relationships: Taking stock of an emerging literature. In Veiel, Hans O. F. (Ed); Baumann, Urs (Ed). The meaning and measurement of social support., (pp. 157-169). Washington, DC, US: Hemisphere Publishing Corp. 
Rook, K. S. (1984). The negative side of social interaction: Impact on psychological wellbeing. Journal of Personality and Social Psychology, 46, 1097-1108.

Rook, K. S., \& Pietromonaco, P. (1987). Close relationships: Ties that heal or ties that bind. Advances in Personal Relationships, 1, 1-35.

Ross, C. E., \& Jang, S. J. (2000). Neighborhood disorder, fear, and mistrust: The buffering role of social ties with neighbors. American Journal of Community Psychology, 28(4), 40142.

Saelens, B. E., \& Handy, S. L. (2008). Built environment correlates of walking: A review. Medicine and Science in Sports and Exercise, 40(7), S550-S566.

Saelens, B. E., Sallis, J. F., \& Frank, L. D. (2003). Environmental correlates of walking and cycling: Findings from the transportation, urban design, and planning literatures. Annals of Behavioral Medicine, 25(2), 80-91.

Sallis, J. F., Frank, L. D., Saelens, B. E., \& Kraft, M. K. (2004). Active transportation and physical activity: opportunities for collaboration on transportation and public opportunities health research. Transportation Research Part A-Policy and Practice, 38(4), 249-268.

Sallis, J. F., Owen, N., \& Fisher, E. B. (2008). Ecological models of health behavior. In K. Glanz, B. K. Rimer \& K. Viswanath (Eds.), Health behavior and health education: Theory, research, and practice (pp. 465-485). San Francisco: John Wiley \& Sons.

Sampson, R. J. (2003). The neighborhood context of well-being. Perspectives in Biology and Medicine, 46, S53-S64.

Sampson, R. J., Raudenbush, S. W., \& Earls, F. (1997). Neighborhoods and violent crime: A multilevel study of collective efficacy. Science, 277(5328), 918-924. 
Seeman, T. E. (2000). Health promoting effects of friends and family on health outcomes in older adults. American Journal of Health Promotion, 14(6), 362-37.

Seeman, T. E., \& Crimmins, E. (2001). Social environment effects on health and aging: integrating epidemiologic and demographic approaches and perspectives. Annals of the New York Academy of Sciences, 954, 88-117.

Shigematsu. R., Sallis, J. F., Conway, T. L., Saelens, B. E., Frank, L. D., Cain, K. L., Chapman, J. E., \& King, A. C. (2009). Age differences in the relation of perceived neighborhood environment to walking. Medicine \& Science in Sports \& Exercise, 41, 314-321.

Shrout, P. E., \& Bolger, N. (2002). Mediation in experimental and nonexperimental studies: New procedures and recommendations

Southworth, M. (2005). Designing the walkable city. Journal of Urban Planning and Development, 131(4), 246-257.

Stafford, M., \& McCarthy, M. (2006). Neighbourhoods, housing, and health. In M. Marmot \& R. G. Wilkinson (Eds.), Social Determinants of Health (2nd ed., pp. 297-317). New York: Oxford University Press.

Stahl, A., Carlsson, G., Hovbrandt, P., \& Iwarsson, S. (2008). "Let's go for a walk!": Identification and prioritisation of accessibility and safety measures involving elderly people in a residential area. European Journal of Ageing, 5(3), 265-273.

Stokols, D. (1996). Translating social ecological theory into guidelines for community health promotion. American Journal of Health Promotion, 10(282-298). 
Strath, S., Isaacs, R., \& Greenwald, M. J. (2007). Operationalizing environmental indicators for physical activity in older adults. Journal of Aging and Physical Activity, 15(4), $412-424$.

Sullivan, W. C., Kuo, F. E., \& DePooter, S. F. (2004). The fruit of urban nature - Vital neighborhood spaces. Environment and Behavior, 36(5), 678-70.

Takano, T., Nakamura, K., \& Watanabe, M. (2002). Urban residential environments and senior citizens' longevity in megacity areas: the importance of walkable green spaces. Journal of Epidemiology and Community Health, 56(12), 913-918.

Talbot, J. F., \& Kaplan, R. (1984). Needs and fears: The response to trees and nature in the inner city. Journal of Arboriculture, 10(8), 222-228.

Thompson, C. W., Roe, J., Aspinall, P., Mitchell, R., Clow, A., \& Miller, D. (2012). More green spaces is linked to stress in deprived communities: Evidence from salivary cortisol patterns. Landscape and Urban Planning, 105(3), 221-229.

Transportation Research Board, \& Institute of Medicine (2005). Does the built environment influence physical activity? Examing the evidence. Washington, D.C.: Transportation Research Board.

Uchino, B. (2004). Social Support and Physical Health. New Haven: Yale University Press. U.S. Department of Health and Human Services. (2015). Step It Up! The Surgeon General's Call to Action to Promote Walking and Walkable Communities. Washington, DC: U.S. Department of Health and Human Services, Office of the Surgeon General. Van Holle, V., Van Cauwenberg, J., Deforche, B., Van de Weghe, N., De Bourdeaudhuij, I., \& Van Dyck, D. (2015). Do psychosocial factors moderate the association between 
objective neighborhood walkability and older adults' physical activity? Health \& Place, $34,118-125$.

Walljasper, J. (2015, May 23). Blue Zones project helped Albert Lea, Minn., find the benefits of walking. Star Tribune. Retrieved from http://www.startribune.com/blue-zonesproject-helped-albert-lea-minn-find-the-benefits-of-walking/304823171/

Wang, Z., \& Lee, C. (2010). Site and neighborhood environments for walking among older adults. Health \& Place, 16(6), 1268-1279.

Wen, M., Cagney, K. A., \& Christakis, N. A. (2005). Effect of specific aspects of community social environment on the mortality of individuals diagnosed with serious illness. Social Science \& Medicine, 61(6), 1119-1134.

Wen, M., \& Christakis, N. A. (2005). Neighborhood effects on posthospitalization mortality: a population-based cohort study of the elderly in Chicago. Health Serv Res, 40(4), $1108-1127$.

Wood, L., \& Giles-Corti, B. (2008). Is there a place for social capital in the psychology of health and place? Journal of Environmental Psychology, 28(2), 154-163.

World Health Organization. (2007). Global Age-friendly Cities: A Guide. Geneva, Switzerland: World Health Organization. Retrieved from http://www.who.int/ageing/publications/Global_age_friendly_cities_Guide_Englis h.pdf?ua $=1$

World Health Organization. (2015). Summary - World Report on Ageing and Health. Geneva, Switzerland: World Health Organization. 
Yen, I. H., Michael, Y. L., \& Perdue, L. (2009). Neighborhood Environment in Studies of Health of Older Adults A Systematic Review. American Journal of Preventive Medicine, 37(5), 455-463. 


\section{Appendix A - Study Area Selection}

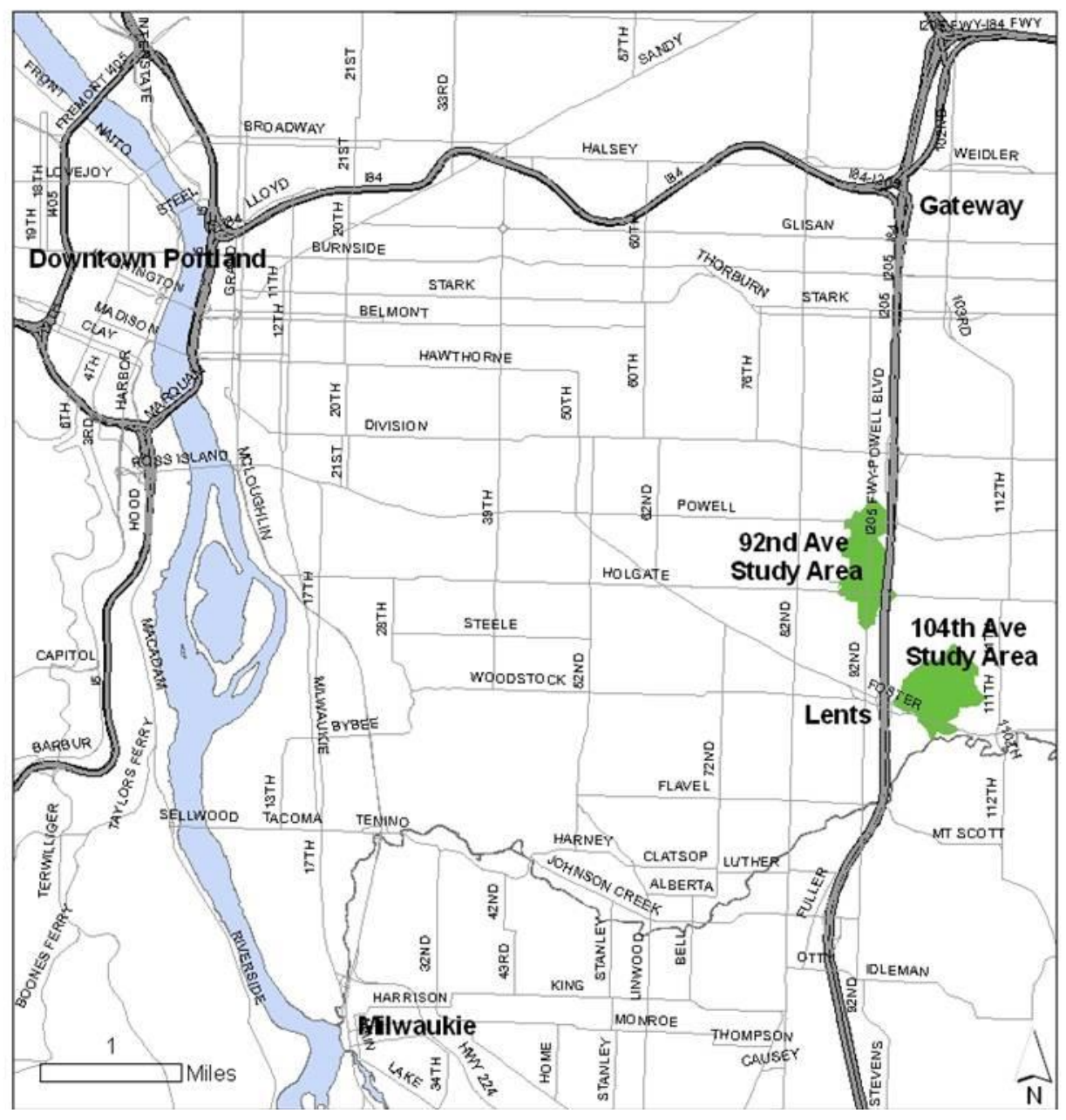

Two areas met the following criteria:

At least 10 green street treatments over a 5-block area

Primarily residential land use

In an existing neighborhood 


\section{Appendix B - Adjusted Significance Tests}

Forty multiple logistic regression models were tested to determine the predictors of both utilitarian and recreational walking in the Lents neighborhood in outer southeast Portland, Oregon. Each model consisted of nine variables. The primary independent variable in each model was a perceived measurement of the built environment - either perceptions of land use mix, aesthetics, crime, or pedestrian infrastructure. Each logistic regression model consisted of one of three hypothesized moderators of the relationship of independent variables on the dependent variables - specifically, perceived neighborhood social cohesion, frequency of social interaction with neighbors, and age. All models had the same covariates: age, minority race versus white, male versus female, high school education or less versus more education, in a relationship versus not in a relationship, and physical functioning.

Because multiple models were tested and each variable comprised one hypothesis test, it was necessary to adjust for multiple comparisons. The false discovery rate (FDR) adjustment method initially developed by Benjamini \& Hochberg (2000) for independent tests, and extended by Benjamini \& Yekutieli for dependent tests (2001) was used to calculate adjusted p-values or 'q-values'. The control of the FDR is generally more statistically powerful than family-wise error rate methods such as the Bonferroni adjustment (Dunn, 1954) or the Holm or Holm-Šidák methods (Holm, 1979) because it is both scalable in that it does not rely on an undefined concept of 'family,' (Benjamini \& Hochberg, 1995; Benjamini \& Hochberg, 2000) and 'adaptive' in the "sense that when some of the tested hypotheses are not true... the FDR is smaller, and more so when more of the hypotheses are not true.” (Benjamini \& Hochberg, 2000) An FDR of .10 was used, and and both 
unadjusted p-values and adjusted q-values were reported. Note that because the FDR method rejects hypotheses based on both q-values and ordering of test statistics, it is not possible to simply compare q-values to .10 to make rejection decisions.

Of the forty logistic regression models, 18 of these models presented significant hypothesis tests of at least one variable's effect on either recreational or utilitarian walking. See Table 15 for the significant predictors of both utilitarian and recreational walking. Of the four built environment measures, only crime predicted walking, specifically, feeling less safe walking either during the day, night, or in general, was associated with less utilitarian walking. While perceived neighborhood social cohesion was not a predictor of either utilitarian or recreational walking, frequency of social interaction with neighbors was associated with recreational walking. This means that the extent to which individuals engage with their neighbors - ranging from merely saying hello to asking neighbors for assistance - has an effect on the propensity for walk for leisure or recreation in the neighborhood. Age, uniformly, was a consistent predictor of utilitarian but not recreational walking. These findings suggest that with increasing age, individuals walk less as a means of transportation. This could also mean that these adults have other means of transportation both independently or with the assistance of others.

Table 16 reports the FDR adjusted q-values for hypothesis tests predicting total monthly walking trips. Built environment aesthetics appear to have a relationship with the overall frequency with which individuals walk when controlling for neighborhood social cohesion and age. Pedestrian infrastructure and safety significantly predicted total monthly walking trips when controlling for social interaction and vice versa, and with FDR adjustment there was a significant statistical interaction of pedestrian infrastructure and 
social interaction on total monthly walking trips. This finding suggests that the effect of

infrastructure on walking varies by level of social interaction with neighbors.

Table 15. Adjusted q-values for multiple hypothesis tests for predicting utilitarian and recreational walking

\begin{tabular}{|c|c|c|c|c|}
\hline $\begin{array}{l}\text { Independent Variable (IV) and } \\
\text { Hypothesized Moderator (M) }\end{array}$ & $\begin{array}{l}\text { Dependent } \\
\text { Variable }\end{array}$ & Predictor & $p$ & $q$ \\
\hline $\begin{array}{l}\text { Aesthetics (IV) and Social } \\
\text { Interaction (M) }\end{array}$ & $\begin{array}{l}\text { Recreational } \\
\text { walking }\end{array}$ & $\begin{array}{l}\text { Social } \\
\text { interaction }\end{array}$ & 0.000147 & 0.02 \\
\hline $\begin{array}{l}\text { Crime (IV) and Social } \\
\text { Interaction }(\mathrm{M})\end{array}$ & $\begin{array}{l}\text { Recreational } \\
\text { walking }\end{array}$ & $\begin{array}{l}\text { Social } \\
\text { interaction }\end{array}$ & 0.000069 & 0.011 \\
\hline $\begin{array}{l}\text { Infrastructure (IV) and Social } \\
\text { Interaction }(\mathrm{M})\end{array}$ & $\begin{array}{l}\text { Recreational } \\
\text { walking }\end{array}$ & $\begin{array}{l}\text { Social } \\
\text { interaction }\end{array}$ & 0.000005 & 0.004 \\
\hline $\begin{array}{l}\text { Land Use (IV) and Social } \\
\text { Interaction }(\mathrm{M})\end{array}$ & $\begin{array}{l}\text { Recreational } \\
\text { walking }\end{array}$ & $\begin{array}{l}\text { Social } \\
\text { interaction }\end{array}$ & 0.000098 & 0.014 \\
\hline Aesthetics (IV) and Age (M) & $\begin{array}{l}\text { Utilitarian } \\
\text { walking }\end{array}$ & Age & 0.000002 & 0.004 \\
\hline $\begin{array}{l}\text { Aesthetics (IV) and Social } \\
\text { Cohesion (M) }\end{array}$ & $\begin{array}{l}\text { Utilitarian } \\
\text { walking }\end{array}$ & Age & 0.000018 & 0.005 \\
\hline $\begin{array}{l}\text { Aesthetics (IV) and Social } \\
\text { Interaction (M) }\end{array}$ & $\begin{array}{l}\text { Utilitarian } \\
\text { walking }\end{array}$ & Age & 0.000005 & 0.003 \\
\hline Crime (IV) and Age (M) & $\begin{array}{l}\text { Utilitarian } \\
\text { walking }\end{array}$ & Age & 0.000002 & 0.006 \\
\hline Crime (IV) and Age (M) & $\begin{array}{l}\text { Utilitarian } \\
\text { walking }\end{array}$ & Crime & 0.000393 & 0.047 \\
\hline $\begin{array}{l}\text { Crime (IV) and Social } \\
\text { Cohesion (M) }\end{array}$ & $\begin{array}{l}\text { Utilitarian } \\
\text { walking }\end{array}$ & Age & 0.000011 & 0.004 \\
\hline $\begin{array}{l}\text { Crime (IV) and Social } \\
\text { Interaction }(\mathrm{M})\end{array}$ & $\begin{array}{l}\text { Utilitarian } \\
\text { walking }\end{array}$ & Age & 0.000007 & 0.003 \\
\hline $\begin{array}{l}\text { Crime (IV) and Social } \\
\text { Interaction }(\mathrm{M})\end{array}$ & $\begin{array}{l}\text { Utilitarian } \\
\text { walking }\end{array}$ & Crime & 0.000491 & 0.055 \\
\hline $\begin{array}{l}\text { Infrastructure (IV) and Age } \\
(\mathrm{M})\end{array}$ & $\begin{array}{l}\text { Utilitarian } \\
\text { walking }\end{array}$ & Age & 0.000017 & 0.005 \\
\hline $\begin{array}{l}\text { Infrastructure (IV) and Social } \\
\text { Cohesion (M) }\end{array}$ & $\begin{array}{l}\text { Utilitarian } \\
\text { walking }\end{array}$ & Age & 0.000083 & 0.013 \\
\hline $\begin{array}{l}\text { Infrastructure (IV) and Social } \\
\text { Interaction }(\mathrm{M})\end{array}$ & $\begin{array}{l}\text { Utilitarian } \\
\text { walking }\end{array}$ & Age & 0.000041 & 0.008 \\
\hline Land Use (IV) and Age (M) & $\begin{array}{l}\text { Utilitarian } \\
\text { walking }\end{array}$ & Age & 0.000006 & 0.004 \\
\hline $\begin{array}{l}\text { Land Use (IV) and Social } \\
\text { Cohesion (M) }\end{array}$ & $\begin{array}{l}\text { Utilitarian } \\
\text { walking }\end{array}$ & Age & 0.000026 & 0.006 \\
\hline $\begin{array}{l}\text { Land Use (IV) and Social } \\
\text { Interaction (M) }\end{array}$ & $\begin{array}{l}\text { Utilitarian } \\
\text { walking }\end{array}$ & Age & 0.000017 & 0.005 \\
\hline
\end{tabular}


Table 16. Adjusted q-values for multiple hypothesis tests for predicting total monthly walking trips

\begin{tabular}{|c|c|c|c|c|}
\hline Test & $\begin{array}{l}\text { Dependent } \\
\text { Variable }\end{array}$ & $\begin{array}{l}\text { Independent } \\
\text { variable }\end{array}$ & $p$ & $q$ \\
\hline Aesthetics (IV) and Age (M) & $\begin{array}{l}\text { Total monthly } \\
\text { walking trips }\end{array}$ & Aesthetics & 0.000002 & 0.003 \\
\hline Aesthetics (IV) and Age (M) & $\begin{array}{l}\text { Total monthly } \\
\text { walking trips }\end{array}$ & Age & 0.000022 & 0.006 \\
\hline $\begin{array}{l}\text { Aesthetics (IV) and Social } \\
\text { Cohesion (M) }\end{array}$ & $\begin{array}{l}\text { Total monthly } \\
\text { walking trips }\end{array}$ & Aesthetics & 0.000013 & 0.005 \\
\hline $\begin{array}{l}\text { Aesthetics (IV) and Social } \\
\text { Cohesion (M) }\end{array}$ & $\begin{array}{l}\text { Total monthly } \\
\text { walking trips }\end{array}$ & Age & 0.000111 & 0.016 \\
\hline $\begin{array}{l}\text { Aesthetics (IV) and Social } \\
\text { Interaction (M) }\end{array}$ & $\begin{array}{l}\text { Total monthly } \\
\text { walking trips }\end{array}$ & Aesthetics & 0.000004 & 0.004 \\
\hline $\begin{array}{l}\text { Aesthetics (IV) and Social } \\
\text { Interaction (M) }\end{array}$ & $\begin{array}{l}\text { Total monthly } \\
\text { walking trips }\end{array}$ & Age & 0.00004 & 0.008 \\
\hline Crime (IV) and Age (M) & $\begin{array}{l}\text { Total monthly } \\
\text { walking trips }\end{array}$ & Age & 0.000009 & 0.004 \\
\hline $\begin{array}{l}\text { Crime (IV) and Social } \\
\text { Cohesion (M) }\end{array}$ & $\begin{array}{l}\text { Total monthly } \\
\text { walking trips }\end{array}$ & Age & 0.000041 & 0.007 \\
\hline $\begin{array}{l}\text { Crime (IV) and Social } \\
\text { Interaction }(\mathrm{M})\end{array}$ & $\begin{array}{l}\text { Total monthly } \\
\text { walking trips }\end{array}$ & Age & 0.000032 & 0.007 \\
\hline $\begin{array}{l}\text { Crime (IV) and Social } \\
\text { Interaction }(\mathrm{M})\end{array}$ & $\begin{array}{l}\text { Total monthly } \\
\text { walking trips }\end{array}$ & In a relationship & 0.000645 & 0.069 \\
\hline $\begin{array}{l}\text { Crime (IV) and Social } \\
\text { Interaction }(\mathrm{M})\end{array}$ & $\begin{array}{l}\text { Total monthly } \\
\text { walking trips }\end{array}$ & $\begin{array}{l}\text { Social } \\
\text { interaction }\end{array}$ & 0.000495 & 0.054 \\
\hline $\begin{array}{l}\text { Infrastructure (IV) and Age } \\
(\mathrm{M})\end{array}$ & $\begin{array}{l}\text { Total monthly } \\
\text { walking trips }\end{array}$ & Age & 0.000017 & 0.006 \\
\hline $\begin{array}{l}\text { Infrastructure (IV) and Social } \\
\text { Cohesion (M) }\end{array}$ & $\begin{array}{l}\text { Total monthly } \\
\text { walking trips }\end{array}$ & Age & 0.00005 & 0.009 \\
\hline $\begin{array}{l}\text { Infrastructure (IV) and Social } \\
\text { Cohesion (M) }\end{array}$ & $\begin{array}{l}\text { Total monthly } \\
\text { walking trips }\end{array}$ & $\begin{array}{l}\text { Infrastructure } x \\
\text { Social cohesion }\end{array}$ & 0.000231 & 0.029 \\
\hline $\begin{array}{l}\text { Infrastructure (IV) and Social } \\
\text { Cohesion (M) }\end{array}$ & $\begin{array}{l}\text { Total monthly } \\
\text { walking trips }\end{array}$ & In a relationship & 0.000796 & 0.083 \\
\hline $\begin{array}{l}\text { Infrastructure (IV) and Social } \\
\text { Interaction }(\mathrm{M})\end{array}$ & $\begin{array}{l}\text { Total monthly } \\
\text { walking trips }\end{array}$ & Age & 0.000033 & 0.007 \\
\hline $\begin{array}{l}\text { Infrastructure (IV) and Social } \\
\text { Interaction }(\mathrm{M})\end{array}$ & $\begin{array}{l}\text { Total monthly } \\
\text { walking trips }\end{array}$ & In a relationship & 0.000486 & 0.056 \\
\hline Land Use (IV) and Age (M) & $\begin{array}{l}\text { Total monthly } \\
\text { walking trips }\end{array}$ & Age & 0.000087 & 0.013 \\
\hline $\begin{array}{l}\text { Land Use (IV) and Social } \\
\text { Cohesion (M) }\end{array}$ & $\begin{array}{l}\text { Total monthly } \\
\text { walking trips }\end{array}$ & Age & 0.000172 & 0.023 \\
\hline $\begin{array}{l}\text { Land Use (IV) and Social } \\
\text { Interaction (M) }\end{array}$ & $\begin{array}{l}\text { Total monthly } \\
\text { walking trips }\end{array}$ & Age & 0.000213 & 0.027 \\
\hline $\begin{array}{l}\text { Land Use (IV) and Social } \\
\text { Interaction (M) }\end{array}$ & $\begin{array}{l}\text { Total monthly } \\
\text { walking trips }\end{array}$ & In a relationship & 0.00091 & 0.09 \\
\hline $\begin{array}{l}\text { Land Use (IV) and Social } \\
\text { Interaction (M) }\end{array}$ & $\begin{array}{l}\text { Total monthly } \\
\text { walking trips }\end{array}$ & $\begin{array}{l}\text { Social } \\
\text { interaction }\end{array}$ & 0.000804 & 0.081 \\
\hline
\end{tabular}

